GRASSYARA PINHO TOLENTINO

\title{
AVALIAÇÃO DA COMPOSIÇÃO CORPORAL, QUALIDADE DE VIDA E TOXICIDADE DO TRATAMENTO QUIMIOTERÁPICO EM MULHERES COM CÂNCER DE MAMA
}




\author{
UNIVERSIDADE DE BRASÍLIA \\ FACULDADE DE CIÊNCIAS DA SAÚDE \\ PROGRAMA DE PÓS-GRADUAÇÃO EM CIÊNCIAS DA SAÚDE
}

\author{
GRASSYARA PINHO TOLENTINO
}

Avaliação da composição corporal, qualidade de vida e toxicidade do tratamento quimioterápico em mulheres com câncer de mama

Tese apresentada como requisito parcial a obtenção do Título de Doutor em Ciências da Saúde pelo Programa de Pós-Graduação em Ciências da Saúde da Universidade de Brasília.

Orientador: Dr. Ricardo Jacó de Oliveira 
Avaliação da composição corporal, qualidade de vida e toxicidade do tratamento quimioterápico em mulheres com câncer de mama

Tese apresentada como requisito parcial a obtenção do Título de Doutor em Ciências da Saúde pelo Programa de Pós-Graduação em Ciências da Saúde da Universidade de Brasília.

Aprovado em 29 de junho de 2016

\section{BANCA EXAMINADORA}

Dr. Ricardo Jacó de Oliveira - presidente Universidade de Brasília

Dr. Martim Francisco Bottaro Marques

Universidade de Brasília

Dr. Otávio Toledo de Nóbrega

Universidade de Brasília

Dr. Gislane Ferreira de Melo

Universidade Católica de Brasília

Dr. Patrícia Espindola Mota Venâncio

Centro Universitário de Anápolis 


\section{AGRADECIMENTOS}

Agradeço a cada pessoa que Deus colocou no meu caminho ao longo desta jornada. 


\section{RESUMO}

O presente estudo teve como objetivo analisar a composição corporal e estabelecer associações e correlações com a qualidade de vida relacionada à saúde, as variáveis clínicas, histopatológicas e os efeitos adversos em mulheres com câncer de mama durante o período de quimioterapia. Tratou-se de uma pesquisa analítica prospectiva que mensurou 11 mulheres com diagnósticos de câncer de mama com indicação para o tratamento quimioterápico. As avaliações iniciais foram composição corporal a partir daabsorciometria de dupla energia de raios-X(DEXA), a saúde subjetiva a partir doSF-36, além do monitoramento dos eventos adversos e das características clínicas da doença. Os dados relativos à composição corporal indicaram que a amostra foi classificada como sobrepesada (IMC $=28,08 \pm 4,48 \mathrm{Kg} / \mathrm{m}^{2}$ ). Sobre o percentual de massa gorda (\%MG) somente $27,3 \%$ apresentaram níveis de gordura considerados adequados, em 9,1\% o \%MG classificava-as com sobrepeso e 63,3\% com obesidade. A partir dos valores de referência 18,2\% das mulheres apresentavam quantidades insuficientes de massa livre de gordura (MLG), 45,4\% possuíam valores adequados e $36,36 \%$ estariam acima dos valores médios populacionais. Observou-se que os eventos motores apresentaram uma correlação negativa com o \%MLG ( $r=-$ $0.845, p=0,039)$ e positiva a $M G(r=0.845, p=0,008)$ e o \%MG $(r=0.845, p=0,008)$. Não foram identificadas associações entre a classificação tumoral, o estádio da doença o tipo de quimioterapia, os marcadores tumorais, os subtipos histológicos e as variáveis da composição corporal ou qualidade de vida. A capacidade funcional foi o aspecto com maior escore referido $(72 \pm 18,13)$. Por outro lado, as limitações por aspectos físicos $(37,5 \pm 48,94)$, a dor $(39 \pm 23,31)$ e a saúde mental $(32 \pm 7,54)$ apresentaram os menores valores. Foi observado que na auto avaliação da dor aqueles que relataram quadros negativos apresentaram maior massa corporal, IMC, MG, \%MG, e ainda menor MLG. Com relação ao grupo de limitações por aspectos físicos aqueles que percebiam maiores limitações possuíam menor quantidade de MLG maior quantidade de MG e \%MG.

PALAVRAS-CHAVES: composição corporal, câncer de mama, quimioterapia, qualidade de vida relacionada à saúde. 


\begin{abstract}
This study aimed to analyze the body composition and to establish associations and correlations with quality of life related to health, the clinical and histopathological variables and side effects in women with breast cancer undergoing chemotherapy. The research was a prospective analytical study that has measured 11 women diagnosed with breast cancer with indication for chemotherapy treatment. Initial assessments were body composition using Dual-energy X-ray absorptiometry (DEXA), Subjective Health according to Medical Outcomes Study 36_Item Short-Form Health Survey (SF-36), and monitoring side-effects and clinical characteristics of the disease. Data related to body composition had shown that the sample was classified as over-weighted $(\mathrm{BMI}=28,08 \pm 4,48 \mathrm{Kg} / \mathrm{m} 2)$. According to the percent of fat mass (\%FM), following classification of Flegal et al.(2009), only $27,3 \%$ had showed satisfactory levels of fat, 9,1\% were classified as over-weighted and $63.3 \%$ with obesity. Based on the reference data proposed by Souza et al.(2003) 18,2\% of women had showed poor amounts of fat-free mass (FFM), 45,4\% had adequate scores and $36,36 \%$ were higher than the value of population mean. The motor side effects has showed negative correlation with \%FFM ( $r=-0.845, p=0.039)$ and positive with FM $(r=.845, p=0.008)$ and \%FM(r=0.845, $p=0.008)$. There were not identified associations among the tumor classification, the stage of disease, type of chemotherapy, the tumor markers, histologic subtypes and the variables for the body composition and quality of life. The functional capability was the aspect with greater score $(72 \pm 18,13)$. On the other hand, physical aspects limitations $(37,5 \pm 48,94)$, pain $(39 \pm 23,31)$ and mental health $(32 \pm 7,54)$ has showed the lowest scores. It was observed that in self-assessment of pain, those who has reported negative outcome showed greater body mass, BFP, FM, \%FM and lower FFM. Among the group of physical aspects limitations, those with perception of greater physical limitations has had lower FFM and grater FM and \%FM as well.
\end{abstract}

Keywords: body composition, breast cancer, chemotherapy, quality of life related to health. 


\section{LISTAS DE ILUSTRAÇÕES}

Figura 1: Grupamento por estadios do câncer de mama propostos pela UICC......18

Figura 2: Incisão e ferida suturada para tratamento do câncer de mama do início do século $X X$ 23

FIGURA 3: Vias de associação direta entre obesidade e câncer de mama proposta por Sinicropeet al. (2001) e adaptada pelo autor 35

Figura 4: Fluxograma de seleção da amostra .42

Figura 5: Classificação do Índice de Massa Corporal segundo a WHO. .46

Figura 6: Procedimentos de identificação da amostra e coletas de dados...... .51

Figura 7: Descrição da Qualidade de vida relacionada à saúde .63

Figura 8: Proposta teórica sobre a interação entre a massa livre de gordura o tecido adiposo e a saúde auto relatada em mulheres submetidas à quimioterapia 77 


\section{LISTAS DE TABELAS}

Tabela 1: Frequência (f) e percentual (\%) dos motivos de recusa à participação no estudo.

Tabela 2: Prevalência ponderada do percentual de gordura categorizada por idade e correspondentes percentis do IMC adaptado de Flegalet al., (2009) 48

Tabela 3: Características demográficas das mulheres avaliadas 53

Tabela 4: Frequência (f) e percentual (\%) dos hábitos de vida das mulheres avaliadas .54

Tabela 5: Frequência (f) e percentual (\%) das características clínico patológicas da amostra .55

Tabela 6: Frequência (f) e percentual (\%) dos marcadores tumorais da amostra.....56

Tabela 7: Caracterização do tratamento clínico recebido pelas voluntárias .57

Tabela 8: Eventos adversos registrados durante o período de quimioterapia 57

Tabela 9: Classe de eventos registrados durante o período de acompanhamento 59

Tabela 10: Valores médios das variáveis relacionadas à composição corporal 60

Tabela 11Valores médios da composição corporal associados aos eventos adversos da quimioterapia. 61

Tabela 12: Correlações e níveis de significância entre eventos indesejados e a composição corporal. 62 
Tabela 13: Percepção da transição subjetiva sobre a saúde.

Tabela 14: Comparação dos valores médios da composição corporal entre os grupos com maior ou menor dor .64

Tabela 15: Comparação dos valores médios da composição corporal entre os grupos com maior ou menor dor. .65 


\section{LISTAS DE ABREVIATURAS E SIGLAS}

$17 q 12$ localização do gene c-erbB2 no braço esquerdo do cromossomo 17

5-HT 5-Hidroxitriptamina

A Adriamicina ou doxorrubicina

AAC American Cancer Society

ABCTCG Adjuvant Breast Cancer Trials Collaborative Group

AC Adriamicina e Ciclofosfamida

ACT Adriamicina; Ciclofosfamida e Taxol

AIDS Síndrome de Imunodeficiência Adquirida

ASC Área de Superfície Corporal

C Ciclofosfamida

CD340 Receptor da proteína tirosina quinaseerbB-2 (sinônimo)

c-erbB2 Proto-oncogene da família dos receptores de tirosina quinase

CID Classificação Internacional das Doenças

DEXA Absorciometria de dupla energia de raio- $x$

DF Distrito Federal

DNA Ácido Desoxirribonucleico

DP Desvio Padrão

E Epirrubicina

EGF Fator de crescimento epidermal

ERBB2 Proto-oncogene da família dos receptores de tirosina quinase

ErbB-2 Receptor da proteína tirosina quinase erbB-2 (sinônimo)

F 5- Fluorouracil

f Frequência

FISH Hibridização In Situ com fluorescência

HER 2Fator de crescimento epidermalhumano tipo 2

HER2+ Fator de crescimento epidermalhumano tipo 2 negativo

HER2+ Fator de crescimento epidermalhumano tipo 2 positivo

HGF Fator de crescimento do hepatócito

HR Hazard ratio

IAEA International Atomic Energy Agency

IARC Internacional Agency For Research On Cancer 

IC
Índice de Confiança
IGF Fator de crescimento relacionado à insulina
IGF-1 Fator de crescimento similar à insulina tipo 1
IL-1 $\beta$ Interleucina do tipo 1 beta
IL-6 Interleucine -6

IL6-LM Interleucine -6 liberada pelo músculo

IMC Índice de Massa Corporal

INCA Instituto Nacional do Câncer

Ki67 Antígeno codificado pelo gene MKI67

M Ausência ou presença de Metástase à distância - TNM

MG Massa Gorda

MLG Massa livre de Gordura

MRM Mastectomia Radical Modificada

$\mathbf{N}$

Ausência ou presença e a extensão de metástase em linfonodos regionais - TNM

n

Amostra

neu Proto-oncogene da família dos receptores de tirosina quinase

OR Oddsratio

QT Quimioterapia

QVRS Qualidade de Vida Relacionada à Saúde

RE Receptores de estrogênio

RE- Receptor de estrogênio negativo

RE+ $\quad$ Receptor de estrogênio positivo

RP- Receptor de progesterona negativo

RP Receptores de progesterona

RP+ Receptor de progesterona positivo

RSMI Índice Musculo Esquelético Relativo

SF-36 Medical OutcomesStudy 36. Item Short-Form Health Survey

SHBG Globulina liberadora de hormônios sexuais

SUS Sistema Único de Saúde

T Taxotere

T Extensão do tumor primário (tamanho) - TNM

TGF- $\beta$ Fator de transformação de crescimento tipo beta

TNF 1 Fator de necrose tumoral 1 
TNFs 2 Fator de necrose tumoral 2

TNFa Fator de necrose tumoral do tipo alfa

TNM Classificação tumoral

UICC Union InternationaleContreleCancer

VEGF Fator de crescimento endotelial vascular

WHO World Health Organization 


\section{LISTAS DE SÍMBOLOS}

$\begin{array}{ll}\% & \text { Percentual } \\ (\mathbf{~} & \text { Parênteses } \\ \bar{x} & \text { Média } \\ {[\mathbf{]}} & \text { Colchete } \\ < & \text { Menor que } \\ = & \text { Igual a } \\ > & \text { Maior que } \\ \mathbf{\pm} & \text { Mais ou menos } \\ \cong & \text { Aproximadamente } \\ \leq & \text { Menor ou igual a } \\ \geq & \text { Maior ou igual a } \\ \mathbb{8} & \text { Marca registrada } \\ \circ & \text { Graus Célsius } \\ \mathbf{c m} & \text { Centímetros cúbicos } \\ \mathbf{K g} & \text { Quilogramas } \\ \mathbf{k g} / \mathbf{m}^{2} & \text { Quilogramas por metro ao quadrado } \\ \mathbf{m} / \mathbf{k g} & \text { Metros por quilogramas ao quadrado } \\ \mathbf{m} \mathbf{m}^{3} & \text { Milímetros cúbicos } \\ \mathbf{p} & \text { Nível de significância } \\ \mathbf{\alpha} & \text { Alfa } \\ \boldsymbol{\beta} & \text { Beta } \\ \boldsymbol{\Delta} & \text { Delta }\end{array}$




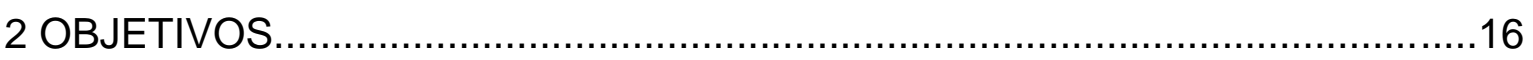

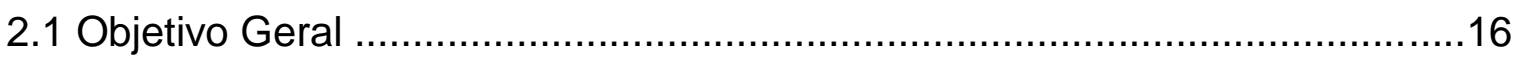

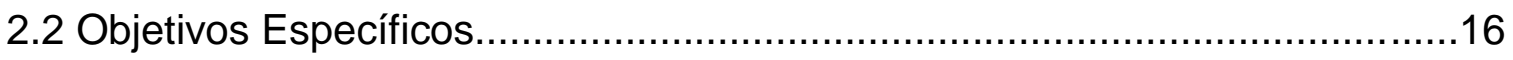

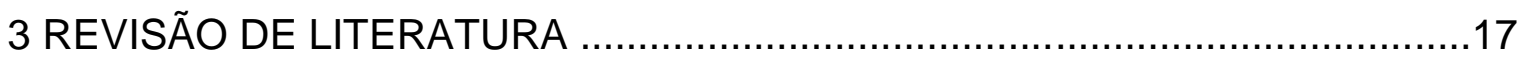

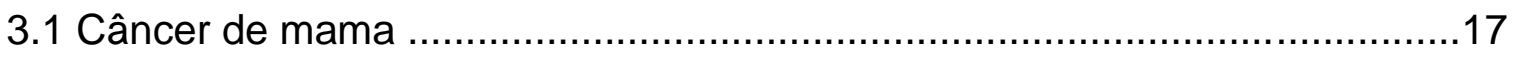

3.2 Classificação do Câncer de Mama..........................................................17

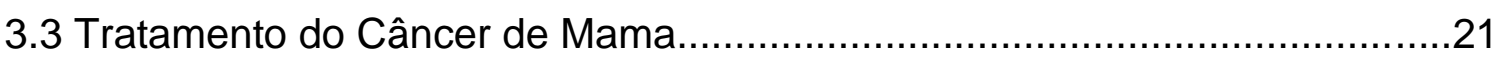

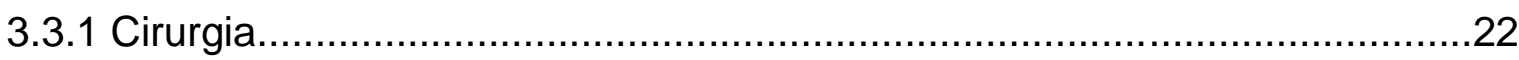

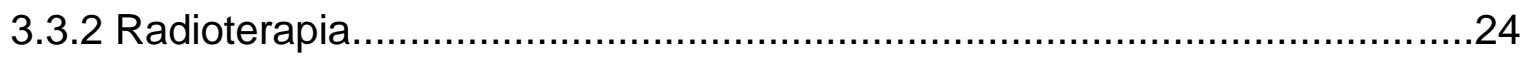

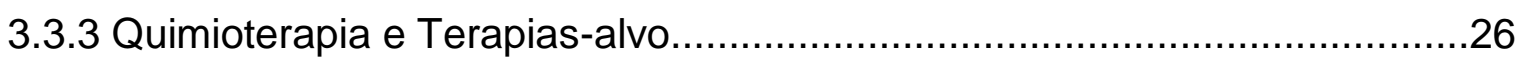

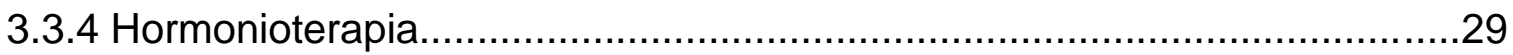

3.4 Composição Corporal e o Câncer de Mama....................................................30

3.4.1 Composição Corporal, prognóstico, recorrência e sobrevida em câncerde

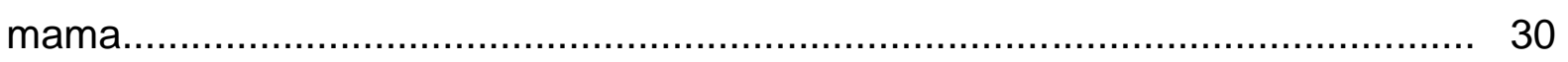

3.4.2 Alterações na composição corporal induzidas pelo tratamento antineoplásico 35

3.4.3 Massa livre de gordura, massa gorda e o tratamento antineoplásico .38

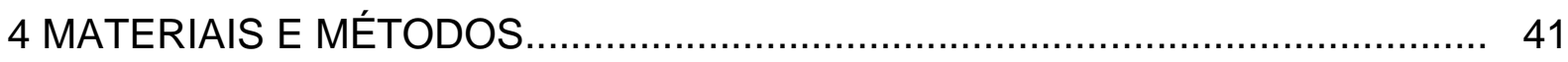

4.1 Delineamento do estudo......................................................................... 41

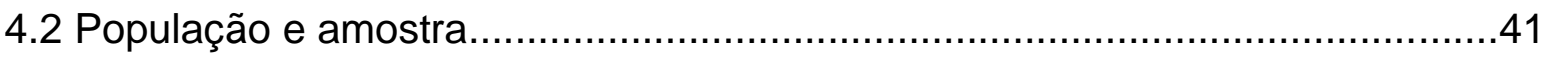

4.3 Protocolo de Avaliação........................................................................ 45

4.4 Procedimentos .............................................................................. 49

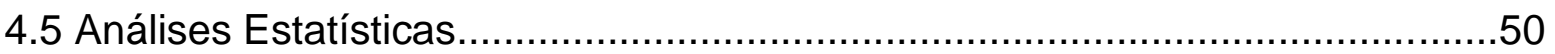

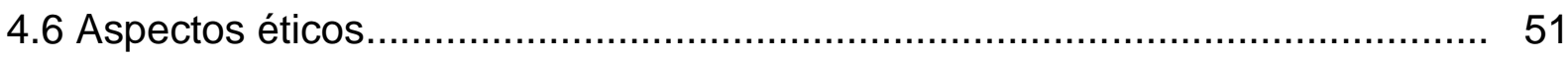

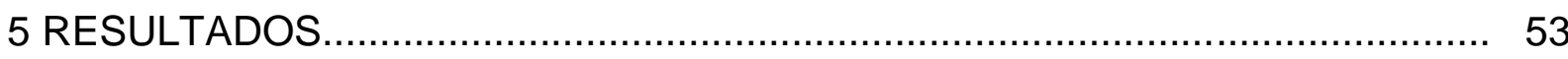

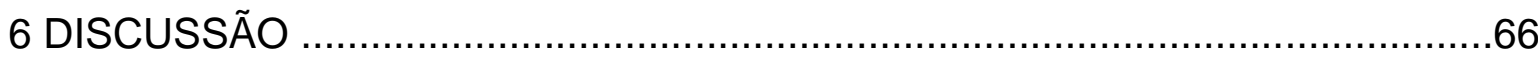


6.1 Associação e correlação entre as variáveis clínicas, histopatológicas com a qualidade de vida relacionada à saúde e com as variáveis da composição

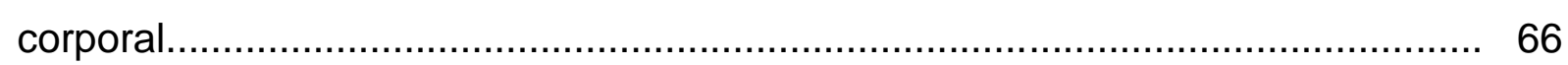

6.2 Associação da qualidade de vida relacionada à saúde com as variáveis da composição corporal e os eventos adversos.................................................. $\quad 70$

7 LIMITAÇÕES DO ESTUDO E DIRECIONAMENTOS FUTUROS.......................70

8 CONSIDERAÇÕES FINAIS................................................................ 80

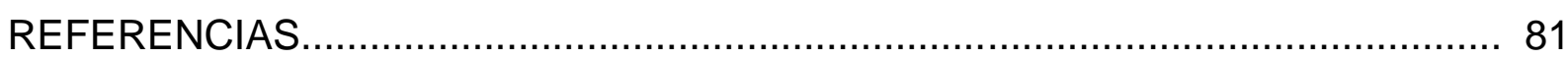

APÊNDICE A - Perfil Socioeconômico e cultural................................................... 111

APËNDICE B - Termo de Consentimento Livre e Esclarecido.............................. 113

ANEXO- A Medical OutcomesStudy 36 -Item Short-Form Health Survey (SF-

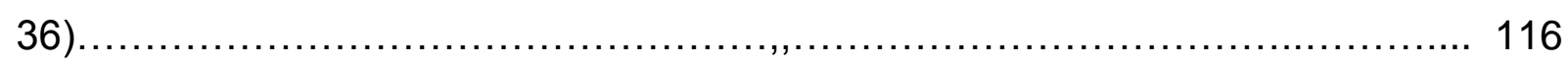

ANEXO B - Carta de Aprovação doComitêÉtica da UnB......................................119

ANEXO C - Carta de Aprovação doComitêÉtica da UnB...................................120 


\section{INTRODUÇÃO}

O câncer de mama continua sendo a forma neoplásica mais incidente entre mulheres (INTERNACIONAL AGENCY FOR RESEARCH ON CANCER, 2012). Em contrapartida, os avanços tecnológicos utilizados no diagnostico precoce e no tratamento, dos últimos 20 anos, conduziram a um prognóstico muito favorável em cinco anos (SIEGEL, MILLER, JEMAL, 2016), estes aspectos qualificaram o câncer de mama como o mais prevalente do mundo na atualidade (PARKINet al., 2012).

Apesar da enorme atenção dada ao diagnóstico precoce e os avanços no tratamento clínico do câncer, os hábitos de vida modificáveis exercem uma influência considerável sobre o risco, o prognóstico, a recorrência e a mortalidade da maioria das formas de câncer (SONG; GIOVANUCCI, 2016; MAAS et al., 2016; SIEGEL et al., 2015; KUSHI et al., 2012; WOLIN; CARSON; COLDITZ, 2010; CAANet al., 2008; SEDJO et al., 2007). Assim, as alterações na massa corporal, por exemplo, podem representar um impacto negativo na saúde e na sobrevida de mulheres diagnosticadas com câncer de mama (IWASE et al., 2016; BABAEl et al., 2015; SUN et al., 2015; PAXTON et al., 2012). A elevação do índice de massa corporal (IMC) está associada não somente ao risco de diversas formas de câncer, como também, à mortalidade prematura naqueles acometidos por esta condição (FLEGAL et al., 2013; CHENet al., 2010; PARR et al., 2010; REEVESet al., 2007).

Há indícios de que mulheres acometidas pelo câncer de mama, tanto na pré quanto pós-menopausa, com massa corporal elevada em um período pré-diagnóstico e aquelas que ganham peso durante toda a vida podem ter a sobrevida reduzida (PLAYDON et al., 2015; CLEVELANDet al., 2007). Naquelas com câncer de mama metastático, o IMC $>30 \mathrm{Kg} / \mathrm{m}^{2}$ estaria associado a uma redução na sobrevida livre da progressão da doença e na sobrevida global (COPSON et al., 2015; AZRAD; DEMARK-WAHNEFRIED, 2014; DRYGALSKI et al., 2011). E mesmo em mulheres diagnosticadas nos estágios iniciais da doença, a obesidade foi considerada um fator prognóstico independente para o desenvolvimento de metástase à distância e morte. Entretanto, ainda há resultados contraditórios (ADEMUYIWA et al., 2011; CAAN et al., 2008).

Contudo, a proposta da composição corporal em oncologia, não se esgota nas questões de fatores de risco e incidência da doença. Além de interferir a sobrevida e 
mortalidade, o excesso de gordura corporal estaria associado, ainda, a dificuldades na terapêutica do câncer de mama (TORO et al., 2016; DEGLISEet al., 2010). Estudos relatam que mulheres com excesso de peso e obesidade podem ser submetidas a um tratamento quimioterápico com doses inferiores as preconizadas, 0 que reduziria a eficiência do tratamento e comprometeria a sobrevida (POTRANI; COORI; MARTIN, 2010; GREENMAN; JAGIELSKI; GRIGGS, 2008), não sendo, contudo, estes achados unânimes (BREWSTERet al., 2011). Outros relatos apontam efeitos colaterais severos em mulheres submetidas à quimioterapia que apresentavam redução na massa livre de gordura e IMC acima de $25 \mathrm{~kg} / \mathrm{m}^{2}$ (PRADOet al., 2011; PRADOet al., 2009; PRADO et al., 2008). Mesmo em doses terapêuticas padrão, o excesso de tecido adiposo pode interferir na farmacocinética das drogas quimioterápicas, sejam pelas características do medicamento (ex: lipossolúveis, hidrossolúveis), ou pelas alterações metabólicas e fisiológicas associadas ao excesso de massa corporal e obesidade (BARPE, 2009).

A composição corporal é uma variável que pode sofrer influência da própria condição crônica, da idade, do estado menopausal e das terapias antineoplásicas (EWERTZet al., 2011; YAWet al., 2011; AZAMBUJA et al., 2010). Além disso, um balanço energético inadequado, alterações hormonais, redução das atividades laborais, atividade física e recreacionais podem ser aspectos alterados com o tratamento do câncer e refletir diretamente na massa corporal, independência física e possivelmente em um pior prognóstico, e qualidade de vida em mulheres com câncer de mama (PAXTONet al., 2012; GADÉAet al., 2011; FOULADIUN et al., 2005).

Apesar das medidas objetivas parecerem unânimes no que diz respeito ao risco de extremos da massa corporal para a saúde de mulheres com câncer, ainda não está claro quais os reflexos da alteração da massa corporal nas avaliações subjetivas de saúde. Numa doença onde a sobrevida é medida em períodos de cinco anos devido à baixa eficácia dos tratamentos, e que as taxas mais positivas de sobrevivência, neste período, giram em torno de $78 \%$ a $87 \%$ (BRASIL, 2015), avaliar o estado de saúde a partir da percepção do próprio indivíduo tornou-se uma prática desejável e valorosa (KOOL et al., 2016). A qualidade de vida relacionada à saúde mensura como as pessoas julgam suas vidas na presença da condição crônica. $E$, num quadro de saúde-doença permanente como elas avaliam seu bem-estar (POST, 2014). Há indícios de que o aumento da massa corporal pode estar associado, também, a uma qualidade de vida reduzida em mulheres sobreviventes ao câncer de 
mama (PAXTON et al., 2012; VOSKUILet al., 2010; MOSCHERet al., 2009). Ainda não se sabe quais as avaliações das mulheres sobre sua condição física na presença da obesidade ou na ausência da massa magra adequada em condições crônicas.

Deste modo, buscando compreender as repercussões do tratamento quimioterápico, sobre a composição corporal e a qualidade de vida de mulheres diagnosticadas com câncer de mama, justifica-se a realização do presente estudo. 


\section{OBJETIVOS}

\subsection{Objetivo Geral}

O objetivo do presente estudo foi analisar a composição corporal e estabelecer associações e correlações com a qualidade de vida relacionada à saúde, as variáveis clínicas e os efeitos adversos em mulheres com câncer de mama submetidas à quimioterapia.

\subsection{Objetivos Específicos}

$\rightarrow$ Verificar associações e correlações entre a massa corporal, o índice de massa corporal, massa livre de gordura, a massa gorda e o índice músculo esquelético relativono início do tratamento à ocorrência de eventos adversos ao longo do período quimioterápico;

$\rightarrow$ Verificar associações e correlações entre a massa corporal, o índice de massa corporal, massa livre de gordura, a massa gorda e o índice músculo esquelético relativo às variáveis clínicas de mulheres diagnosticadas com câncer de mama submetidas ao tratamento quimioterápico;

$\rightarrow$ Verificar associações e correlações entre a massa corporal, o índice de massa corporal, massa livre de gordura, a massa gorda e o índice músculo esquelético relativo e à qualidade de vida relacionada à saúde em mulheres diagnosticadas com câncer de mama submetidas ao tratamento quimioterápico;

$\rightarrow$ Verificar associações e correlações das variáveis clínicas e dos eventos adversos à qualidade de vida relacionada à saúde em mulheres diagnosticadas com câncer de mama ao longo do tratamento quimioterápico. 


\section{REVISÃO DE LITERATURA}

\subsection{Câncer de mama}

Sob um ponto de vista biológico o câncer pode ser entendido como o crescimento de células livres do controle regulatório exercido pelo corpo (BUERNET, 1975). Numa perspectiva da saúde coletiva o câncer é compreendido por um grupo de doenças onde a principal característica é o crescimento celular desordenado e incontrolável que pode invadir outros tecidos e conduzir à morte (AMERICAN CANCER SOCIETY, 2016).

Dados mundiais revelam que no ano de 2012 houve 14,1 milhões de novos casos de câncer no mundo, sendo que, ocorreram 8,2 milhões de morte e 32,6 milhões de pessoas viviam com a condição dentro do período de 5 anos após o diagnóstico. O câncer de mama é o segundo câncer que mais acomete pessoas no mundo inteiro, sendo o primeiro entre as mulheres (INTERNACIONAL AGENCY FOR RESEARCH ON CANCER, 2012).

No Brasil para o biênio 2016/2017 estima-se 600 mil novos casos de câncer, destes, são esperados 57.960 mil novos casos de câncer de mama, sendo 1020 casos no Distrito Federal (BRASIL, 2015). Apesar de ser considerado uma das formas de câncer de melhor prognóstico, quando diagnosticado precocemente e tratado de forma adequada, as taxas de mortalidade ainda são muito elevadas no Brasil, cerca de 14 óbitos a cada 100 mil mulheres em 2013. Sendo a sobrevida estimada para 5 anos em torno de $78 \%$ para $87 \%$.

O câncer de mama é uma condição multifatorial que está ligada a causas genéticas, endócrinas, perfil reprodutivo, histórico familiar, idade, raça, hábitos de vida, infecções e exposição às agentes mutagênicos externos (ANAND et al., 2008).

\subsection{Classificação do Câncer de Mama}

Atualmente foram identificados aproximadamente 50 tipos e subtipos histológicos de câncer da mama (WHO, 2012). Os carcinomas invasivos são os mais comuns, sendo aqueles do tipo ductal infiltrante, os que ocorrem em $90 \%$ dos casos diagnosticados (BRASIL, 2014). 
O estágio tumoral, ou avanço da doença é dado pela Classificação de Tumores Malignos chamada simplificadamente de TNM, proposta pela União Internacional Contra o Câncer (UICC); onde são avaliados as categorias tumorais (T), - acometimento linfonodal (N) e características metásticas (M) (SOBIN; GOSPODAROWICZ; WITTEKIND, 2009). De forma simplificada, TX indica que o tumor primário não pode ser avaliado, T0 sem evidências de tumor primário, Tis são tumores in situ; o T1 refere-se a tumores com tamanho inferior a $2 \mathrm{~cm}$, T2 tumores com diâmetros maiores que $2 \mathrm{~cm}$ e inferiores a $5 \mathrm{~cm}$, T3 tumores com tamanho maior ou igual a $5 \mathrm{~cm}$, T4 são tumores de qualquer tamanho com extensão direta à parede torácica ou à pele. $\mathrm{Na}$ avaliação linfonodal o NX impossibilidade de avaliação do tecido, N0 indica ausência de metástase linfonodal adjacente, N1 indica metástase em linfonodos axilares, homolaterais, móveis; o N2 refere-se à metástase em linfonodos axilares homolaterais fixos ou metástase clinicamente aparente em linfonodos mamários internos, homolaterais; N3seria metástase em linfonodos infraclaviculares homolaterais com ou sem envolvimento de linfonodos axilares. A verificação do M0 estabelece ausência de metástase à distância, em outros órgãos do corpo, já o M1 confirma a metástase.

A partir desta classificação é possível realizar uma graduação histopatológica como apresentado na figura a seguir:

\section{Grupamento por Estádios}

$\begin{array}{llll}\text { Estádio 0 } & \text { Tis } & \text { N0 } & \text { M0 } \\ \text { Estádio I } & \text { T1 }^{*} & \text { N0 } & \text { M0 } \\ \text { Estádio IIA } & \text { T0 } & \text { N1 } & \text { M0 } \\ & \text { T1* } & \text { N1 } & \text { M0 } \\ & \text { T2 } & \text { N0 } & \text { M0 } \\ \text { Estádio IIB } & \text { T2 } & \text { N1 } & \text { M0 } \\ & \text { T3 } & \text { N0 } & \text { M0 } \\ \text { Estádio IIIA } & \text { T0 } & \text { N2 } & \text { M0 } \\ & \text { T1* } & \text { N2 } & \text { M0 } \\ & \text { T2 } & \text { N2 } & \text { M0 } \\ & \text { T3 } & \text { N1, N2 } & \text { M0 } \\ \text { Estádio IIIB } & \text { T4 } & \text { N0, N1, N2 } & \text { M0 } \\ \text { Estádio IIIC } & \text { Qualquer T } & \text { N3 } & \text { M0 } \\ \text { Estádio IV } & \text { Qualquer T } & \text { Qualquer N } & \text { M1 }\end{array}$

Figura 1: Grupamento por estadios do câncer de mama proposto pela UICC. Fonte: BRASIL, 2004, p146 
O estadiamento da doença, historicamente iniciou-se no meio do século $X X, e$ durante muito tempo foi o principal critério para escolha terapêutica (HENDERSON, 2015). Entretanto, estudos e observações clínicas detectaram que, apesar de possuírem o mesmo estadio, algumas pessoas não respondiam ao tratamento padrão, ou ainda apresentavam uma progressão da doença muito rápida e de prognóstico desfavorável (GAJDOS, 2002; KUERER et al., 1998; MACHIAVELLI et al., 1998).

Estas diferenças seriam parcialmente entendidas posteriormente, no final da década de 80, com os avanços nas técnicas de estudo de genômica e proteômica (COLLET et al. 2002; VENTER et al., 1987; NATALI, 1990; BORG, et al., 1989), foi possível identificar subtipos moleculares dos tumores da mama dentro de um mesmo estadio histopatológico o que influenciou os protocolos recentes de tratamento. Se o método clássico de estadiamento do câncer de mama apoiava-se na microestrutura tumoral. A forma contemporânea tem na identificação de genes e proteínas expressas pelo câncer seu alvo-principal.

O proto-oncogene ERBB2 também conhecido como c-erbB2, neu, ERBB2 e CD340, é um gene localizado no braço esquerdo do cromossomo 17 (17q12) que codifica proteínas (NATIONAL CENTER FOR BIOTECHNOLOGY INFORMATION, 2008). Ele expressa uma glicoproteínatransmembrana chamada p185 homóloga ao fator de crescimento epidermal (EGF) conhecida como fator de crescimento epidermalhumano tipo 2 (HER 2) também chamada ErbB. Esse ligante no meio intracelular ativa a cascata tirosina-cinase promovendo atividade mitogênica $\mathrm{e}$ diferenciação em tecidos adultos (YARDEN, 2001). A amplificação ou superexpressão dessa proteína gene tem sido fortemente associado ao desenvolvimento do câncer de mama (SIEGEL, 1994).

No câncer alterações gênicas e nas proteínas por eles expressas, bem como, nos fatores de crescimento, nos receptores ou ainda nas vias de transdução de sinais, podem favorecer fenótipos negativos. Estes aspectos conferem algumas características cruciais às células tumorais como: aquisição de autossuficiência na produção de fatores de crescimento, baixa resposta aos inibidores do crescimento, indução de angiogênese, mutações, instabilidade genômica, favorecimento de mecanismos invasivos e metásticos, resistência à morte celular, de escape à 
destruição imune, de ativação da invasão e metastização, dentre outros (LEITE, et al., 2012, KUMAR, 2011).

Alterações relatadas, principalmente, no proto-oncogenes HER2/neu (NATALI, 1990; BORG, et al., 1989; VENTER et al., 1987) serviram como fio condutor para a identificação dos subtipos moleculares do câncer de mama. Além disso, houve então o surgimento de nova taxonomia, ainda em debate na atualidade, e a demonstração do valor prognóstico dos classificadores multigênicos (assinaturas genéticas). Quando Solieret al. (2001) propõe então a primeira diferenciação tumoral a partir da diferenciação da expressão gênica. Estes passaram a ser identificados como Luminal A, B e C, sendo a categoria c a mais controversa; Basal-like, HER 2 positivo e normal-like (SOLIER et al. 2001; AHR et al., 2001; PERROU, 2000).

Apesar dessa nova categorização as técnicas genéticas ainda não são uma realidade na prática clínica. Entretanto, estudos recentes, identificaram que os subtipos moleculares estão fortemente associados aos receptores de estrogênio $(R E)$, receptores de progesterona $(R P)$ e expressão da proteína HER 2 no tecido tumoral (BAUER et al., 2010; PARISE et al., 2009). A detecção imunohistoquimica destes receptores de hormônios no tecido tumoral; e o teste de hibridização In Situ com fluorescência (FISH) passou, então a ser utilizada com finalidade diagnóstica e favorecerem as indicações terapêuticas (LEE et al., 2015; PUSZTAl et al., 2006). A imunohistoquimica indica a quantidade de proteína receptora HER2 na parede celular e o teste de FISH indicaria o numero excessivo de cópias do gene HER2.

Os tumores classificados como luminal A seriam aqueles com receptores de estrogênio positivo $(R E+)$ e/ou receptores de progesterona positivo $\left(R P_{+}\right)$e sem superexpressão do fator de crescimento epidermal humano do tipo 2 (HER2-); os luminais b apresentariam RE+ e/ou RP+ e HER2+; HER 2 onde RE-, RP- e somente HER2+ seria positivo; e o basal-likeRE-, RP- e HER2 -, também chamado de triplonegativo; sendo os luminais c e o normal-likemenos caracterizados que as outras formas tumorais (SCHNITT, 2010). O entendimento destas características celulares permitiu um novo reagrupamento dos casos de câncer de mama. E a partir desta nova forma de classificação, a partir do final do século passado e início da década de 2000 foram identificadas diferentes taxas de sobrevida, progressão da doença e resposta objetiva terapêutica (FALCK et al., 2013; BAUER et al., 2010). Sendo reorganizadas a partir dos critérios moleculares e revelaram uma forma inusitada de entender a doença. 
Foram descobertas, por exemplo, que a superexpressão do HER2 correlacionava-se a um pior prognóstico com maior taxa de recorrência e mortalidade (SOTIROU et al., 2003). Também, Parise e Caggiano (2014) concluíram que as mulheres que apresentavam tumores com estadio I e II apresentavam maior risco de morte quando o tumor apresentava-se RE- quando comparado àquelas com RE+. $E$ que a presença dos receptores hormonais estava associada a alguma vantagem prognóstica, porém um quimiossensitividade diferenciada (ANDRE et al., 2007). No estudo de Krijgsmanet al. (2012) foi identificado que apenas 9\% dos tumores classificados como luminais apresentavam resposta patológica completa, contra 50\% para o tipo HER2 e 56\% para aqueles classificados como basal-like, após serem submetidos à quimioterapia neoadjuvante.

Além dos marcadores clássicos acima citados, uma nova linhagem de biomoléculas vem sendo estudadas, como a proteína nuclear Ki67, o anticorpo monoclonal MIB-1, as ciclinas D1 e E dentre outros, tendem a ser alvo de futuros estudos e poderão colaborar no entendimento da biologia do câncer (BUITARGO et al., 2011).

Passada a euforia de uma possível substituição dos sistemas anatomopatológicos de estadiamento pelos marcadores genéticos e taxonomia molecular, a oncologia clínica caminha para a combinação destas formas de caracterização tumoral na busca de tratamentos cada vez mais eficientes e menos nocivos às mulheres diagnosticadas (RAKHA; ELLIS, 2011). Atualmente uma forma mais compreensiva de tratar a doença vem sendo aplicada graças à ampliação do conhecimento sobre a biologia do câncer de mama.

\subsection{Tratamento do Câncer de Mama}

Historicamente as terapias antineoplásicas evoluíram à medida que as tecnologias aplicadas à saúde foram surgindo e possibilitando a descoberta de novos agentes e substâncias que impediam o crescimento tumoral. Os recursos tecnológicos permitiram o desenvolvimento de novos procedimentos e técnicas médicas para o tratamento e manejo da doença. Entretanto, apesar da inegável evolução, as terapias oncológicas apresentam-se socialmente como um conjunto de práticas mutilantes, incapacitantes, dolorosas e com elevado risco ao indivíduo (FERRANDES, ANDREU, GALDÓN, 2002). As experiências familiares e sociais, os 
casos abordados pelos meios de comunicação em massa, e mais recentemente, imagens e vídeos divulgados na internet reforçam a imagem dolorosa do tratamento antineoplásico.

Hoje ele agrupa técnicas e procedimentos extremamente diferenciados e incomuns em outras condições médicas, o que dificulta o entendimento dos clientes sobre a sua necessidade, a sequencia cronológica e o motivo de tantas intervenções combinadas. A incurabilidade, até o presente momento, foi o principal motivo desta complexa realidade.

Registros históricos norte-americanos indicam que somente a partir da década de 1990 a mortalidade por câncer obteve uma redução significativa, quando comparada a outras condições crônicas. Esta redução deveu-se principalmente pelo aumento da sobrevida das pessoas diagnosticadas (SIEGEL, MILLER, JEMAL, 2016; CRIMMINS; BELTRÁN-SÁNCHEZ, 2010). Que por sua vez, resulta das novas modalidades de rastreamento da doença, e o desenvolvimento de novos protocolos de tratamento (WINGO et al., 2003).

As terapias antineoplásicas tiveram um desenvolvimento lento e complexo, devido a etiologia ainda duvidosa da doença, suas diversas formas de manifestação e sua complexidade, indo de técnicas mais antigas como as intervenções cirúrgicas até a utilização de fármacos que reconhecem proteínas nos tumores.

\subsubsection{Cirurgia}

A cirurgia é o método antineoplásico mais antigo, sendo utilizado desde os tempos egípcios como método excisional permanecendo assim até o início do século XX (PAPAC, 2001). Epistemologicamente a retirada da massa tumoral, consistiu numa prática justificável e coerente, uma vez que, o medo da entidade maligna dentro do corpo humano, e o risco de proliferação e complicações sempre acompanharam a historia clinica do câncer. E foi apoiado nessa concepção que as intervenções cirúrgicas desenvolveram-se.

Sempre extensas e com grandes lacerações as cirurgias seguiam incapazes de promover a cura da doença e ainda conduziam à morte em curto espaço de tempo por complicações pós-intervenção (COTLARet al., 2003). Os recursos terapêuticos para a realização dos procedimentos cirúrgicos como: anestésicos, drogas antiinflamatórias, substâncias esterilizantes, cauterizantes, antibióticos eram pouco 
desenvolvidos até 0 início do século $X X$, e resultavam em procedimentos extremamente dolorosos, com elevada taxa de letalidade e sérios comprometimentos para os que sobreviviam (RAYTER; MANSI, 2003).

Entretanto, com a descoberta da penicilina em 1929 e o surgimento das primeiras técnicas anestésicas em 1846 as cirúrgicas da mama tornaram-se ainda mais extensas (figura 2). A tendência a ampliar a área cirurgiada cresce ainda mais neste período com a descoberta da invasão dos tecidos linfáticos adjacentes pelas células cancerosas (JENNINGS, 1926). Passou-se, então a recomendar-se a retirada da cadeia linfonódica adjacente à mama, da pele e do músculo peitoral maior objetivando uma maior eficácia da intervenção (SAKORAFAS, 2001). Este tipo de procedimento ficou conhecido como mastectomia radical (MR) e foi postulada por Halsted em 1894. Apesar da extensão da área cirurgiada, este procedimento reduziram as taxas de recorrência local para 6\%, comparado aos valores da época que giravam em torno de 50\% a 80\% (HALSTED, 1894; BORGEN, 2000).

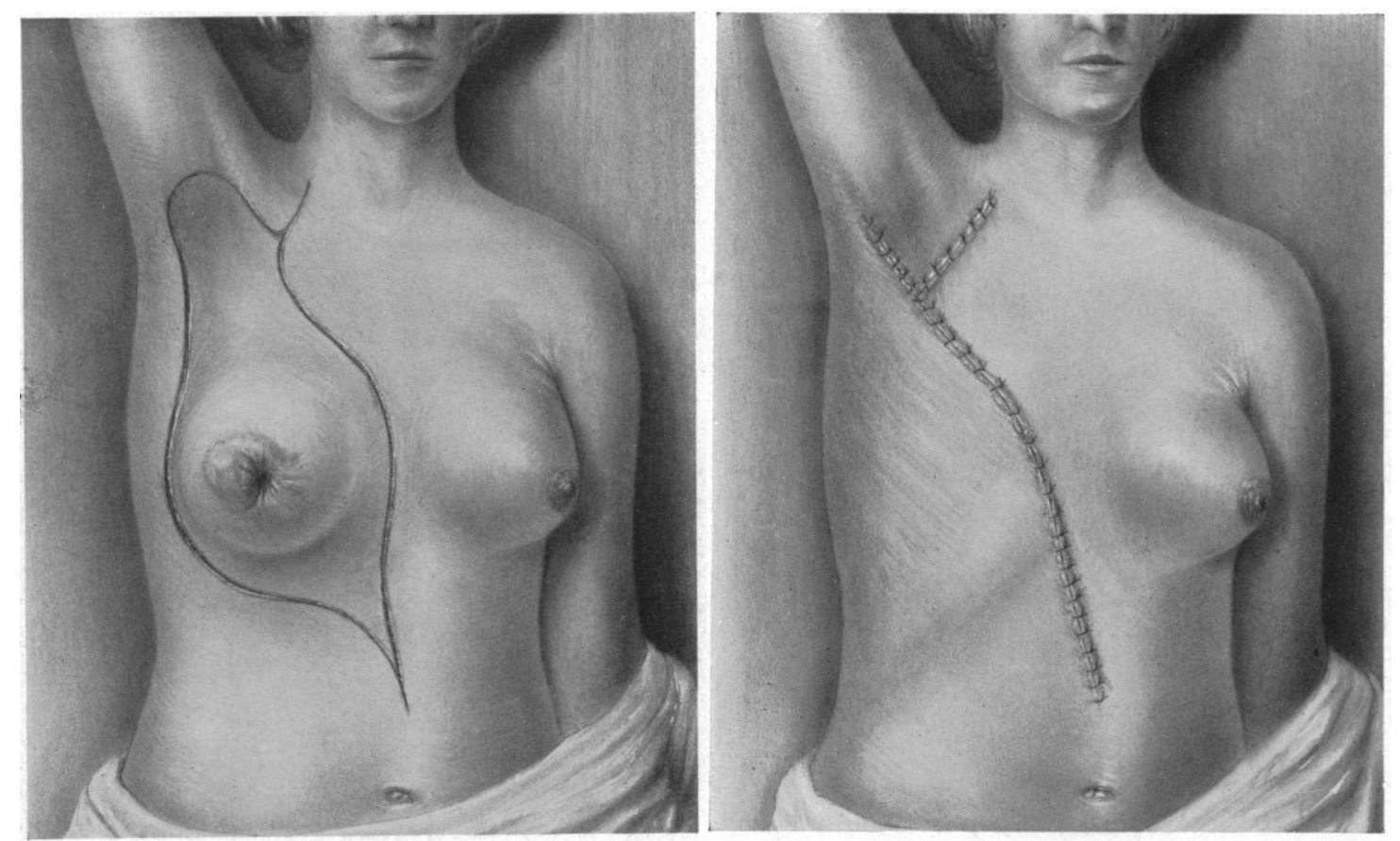

Figura 2: Incisão e ferida suturada para tratamento do câncer de mama do início do século XX

Fonte: Jennings, 1926, págs. 771 e 772.

Somente em 1948 é apresentada uma nova técnica cirúrgica, onde o músculo peitoral é conservado, e a área extirpada reduz pela primeira vez. Esta nova operação passou a ser chamada de mastectomia radical modificada (MRM) e foi proposta por Patey e Dyson (1948). Este método tornou-se predominante no mundo 
inteiro e substituiu a MR a partir da década de 80 (WINCHESTER, MENCK, WINCHESTER, 1997; VANA et al., 1981, DONEGAM, 1984).

O desenvolvimento da patologia microscópica por meio de punções, ações de educação em saúde e os avanços das técnicas diagnósticas como a mamografia, favoreceram, o que é conhecido atualmente, como diagnóstico precoce (RAYTER; MANSI, 2003). A detecção de tumores com extensão cada vez menores, o estudo do linfonodo sentinela e o surgimento da quimioterapia e radioterapia reduzem cada vez mais a extensão das cirurgias (SAKORAFAS, 2001).

Então, aproximadamente 10 anos após os postulados da MRM, no ano 1960 surge a primeira técnica conservadora de cirurgia da mama, chamada de tumorectomia, que consistia na retirada do tumor e uma margem de tecido livre da doença ao seu redor (SARRAZIN et al. 1998). Esta técnica só pode ser desenvolvida a partir do advento da radioterapia que seria a nova terapia loco regional e garantiria o sucesso da cirurgia (MONTAGUE; FLETCHER, 1985).

A partir de 1980 desenvolvem-se novas técnicas de mastectomia chamadas quadrantectomia ou mastectomia segmental, que consiste na retirada de aproximadamente um quarto (1/4) da mama, incluindo a massa tumoral e tecidos subjacentes (VERONESI et al., 1990). As técnicas conservativas de cirurgia da mama só foram possíveis graças aos tratamentos adjuvantes para os tecidos mamários preservados e também pela atuação sistêmica (SAKORAFAS, 2006).

Como terapias adjuvantes são compreendias todas as intervenções após o tratamento cirúrgico que tenham como objetivo minimizar as chances de recorrência da doença e atualmente incluem radioterapia, quimioterapia, hormonioterapia, terapias-alvo ou biológicas (GARCIA-SAENZ et al., 2015; EISEN et al., 2015).

\subsubsection{Radioterapia}

O surgimento da radioterapia foi possibilitado por achados na área da química e da física no final do século XIX. A descoberta do raio-X, das leis da radioatividade e o isolamento de elementos químicos que emitiam energia espontaneamente, como o rádio; conduziram a uma nova possibilidade terapêutica para 0 câncer (INTERNATIONAL ATOMIC ENERGY AGENCY - IAEA,2010).

Paradoxalmente, a radiação pode causar e tratar o câncer. Este parece ter sido o princípio que levou cientistas que apresentavam lesões teciduais após 
manipular elementos radioativos por dias consecutivos a deduzirem que estes também serviriam para eliminar células malignas no corpo (CONNEL et al., 2009). A partir do ano de 1904, então, iniciam-se as técnicas de exposição de pessoas acometidas com câncer a elementos radioativos. As técnicas de braquiterapia foram as primeiras a serem desenvolvidas, uma vez que, não haviam sido inventados equipamentos que extraíssem e direcionassem a energia radioativa. A braquiterapia, utilizadas até os dias atuais consiste na colocação da fonte de radiação dentro do corpo ou junto ao tecido que necessita de tratamento (THARIATH et al., 2012). Com as descobertas e inovações tecnológicas subsequentes na área física, química e médica culminaram na criação de aparelhos capazes de transferir a energia radioativa de forma linear, de modo que, posteriormente foi possível irradiar tecidos profundos e assim destruir células cancerosas em quase todas as partes do corpo (IAEA, 2010).

A radioterapia foi a mais efetiva forma de tratamento antitumoral na primeira metade do século $X X$ e permitiu o aperfeiçoamento das técnicas cirúrgicas menos agressivas. Ela foi desenvolvida como tratamento indicado para erradicar resíduos locais microscópicos da doença (SAKORAFAS, 2006) e por isso entendida como tratamento loco regional.

Controversamente, a radiação pode causar e tratar o câncer uma vez que as partículas radioativas interferem no material genético das células saudáveis e cancerosas, conduzindo os tecidos à morte, ou provocando alterações estruturais e funcionais. O motivo exato da morte celular a partir do uso da radiação ainda é uma área de investigação em evolução. As teorias sobre os danos ao DNA e a integridade celular são os efeitos direto mais amplamente suportados. Ao passo que, a formação de intermediários de radicais livres a partir da ionização da água presente nas células seria a forma indireta de ação (BARKER et al., 2015).

Se por um lado, as taxas de sobrevida e respostas patológica completa aumentaram a partir da utilização desta terapia (HARMS et al., 2016), o risco de ocorrência de um segundo tumor (HAN et al, 2016) e o surgimento de comorbidades (ORDING et al., 2015) são fatos indesejáveis associados ao tratamento por radiação. As principais complicações do tratamento radioterápico seriam danos cosméticos (COLES et al.,2005), fraturas de costelas nas áreas irradiadas, plexopatia braquial, linfedema, pneumonite (PIERCE, 2001), citotoxicidade cardiopulmonar (HOONING et al., 2006; TOKALTI et al., 2005; WONDERGEM et al., 2001), e risco de recorrência 
de um segundo câncer (KIROVA et al., 2007), podendo estes prejuízos ser agravados pela extensão da cirurgia e pelo tratamento sistêmico (PIERCE, 2001).

Diante disso, as perspectivas futuras para a radioterapia seriam melhorar 0 entendimento sobre os aspectos biológicos e desenvolver equipamentos que permitam reduzir as doses e a toxicidade do tratamento (POWELL et al., 2010).

Concomitantemente ao desenvolvimento desta terapêutica outras frentes de intervenções contra o câncer surgiram. Estas, apoiadas fármacos com diferentes alvos terapêuticos.

\subsubsection{Quimioterapia e Terapias-alvo}

O tratamento quimioterápico é, sem dúvida, a grande esperança para a cura de uma doença que não pode ser combatida pela extirpação da massa tecidual primária e que tem a possibilidade de migrar livremente pelo corpo a partir da corrente sanguínea ou linfática (GOLAN et al., 2014). Uma terapia que pudesse igualmente percorrer o corpo e detectar as células cancerosas e eliminá-las antes de uma possível instalação, até mesmo nos dias atuais, seria a melhor possibilidade de tratamento.

Desde a antiguidade egípcia há relatos de terapias com pastas cauterizantes, elixires e ervas para tratamentos de feridas, possivelmente neoplásicas (HADJU, 2010). O arsênio, por ser já conhecido desde períodos remotos, foi provavelmente, o primeiro elemento químico a fazer parte da quimioterapia antiga (MORRISSON, 2010). Durante todo período medieval e renascimento a variedade de produtos químicos e fitoterápicos oferecidos na tentativa de curar o câncer serviam apenas como medida paliativa (MACGREGOR, 1996). Somente nos meados de 1970 um cirurgião francês propõe o modelo de disseminação do câncer, Henry LeDran (16851770), afirmava que a doença em seus estágios iniciais permanece em um local, entretanto, com o desenvolvimento ela atinge os linfonodos e subsequentemente a circulação (RAYTER; MANSI, 2003). Posteriormente, os grandes descobridores da patologia e da bacteriologia moderna Louis Pasteur (1822-1895), Robert Koch (1843-1910), e Joseph Lister (1827-1912) desenvolvem os mecanismos e as teorias básicas sobre proliferação e morte celular. O que por sua vez, conduziram ao entendimento de que o câncer poderia estar no sangue ou em outros tecidos. Estabelecendo assim uma nova frente de ataque à doença (HADJU, 2010). 
Isso se tornou um fato a partir da famosa e catastrófica exposição de soldados alemães e ingleses na I Guerra Mundial ao gás mostarda onde, estudos posteriores, detectaram supressão de células sanguíneas e da medula nos contaminados (KRUMBHAAR; KRUMBHAAR, 1919) eforneceram indícios de um futuro fármaco anticarcinogênico.Testados posteriormente em animais como modelo de estudo possibilitando o desenvolvimento das drogas hoje conhecidas como antineoplásicas (PAPAC, 2001). A Segunda Guerra Mundial foi outro período de largo avanço da indústria farmacêutica na busca de antibióticos e drogas que pudessem tratar feridas de guerra, conter infecções e inflamações o que também favoreceu a politerapiaquimioterápica (DEVITA; CHU, 2008).

As quatro décadas posteriores foi o período de desenvolvimento da oncologia clínica e de um impacto real sobre a tratabilidade do câncer (MORRISSON, 2010). Hoje são conhecidas diversas drogas com ação sobre todas as formas de neoplasias. Para o tratamento do câncer de mama as mais comuns e utilizadas no sistema público brasileiro são: doxorrubicina e epirrubicina; 5-fluorouracil, ciclofosfamida, metotrexato, paclitaxel e docetaxel; carboplatina (BRASIL, 2015a).

Os mecanismos básicos de ação destas drogas atingem alguma fase da duplicação celular, ou mecanismos de síntese de DNA, conduzindo à morte celular. Os agentes alquilantes como a ciclofosfamida, ligam-se ao DNA causando a ruptura da cadeia, ou a sua replicação defeituosa, o que deflagra a apoptose, atuando durante todas as fases do ciclo celular (SKEEL, KHLEIF, 2011). Já os antimetabólicos como metotrexato e a fluopirimidinas como o 5-fluorouracil são agentes que bloqueiam a síntese de DNA ao impedir que as enzimas necessárias a esse processo atuem ao fraudarem seus substratos, atuando na fase $S$ do ciclo celular (SKEEL, KHLEIF, 2011). Os antibióticos citotóxicos, como a doxorrubicina, inibem a síntese de DNA ao intervirem nas enzimas envolvidas no processo (DNAgirase, RNA polimerase) ou através da formação de um agente alquilante(GOLAN et al., 2014). Os derivados de vegetais como paclitaxel e docetaxel agem sobre a enzima topoisomerase, ou se ligam a tubulina ou aos microtúbulos, inibindo a mitose ou a formação do DNA. Interferem na formação do fuso mitótico durante a fase $\mathrm{M}$ do ciclo celular (GOLAN et al., 2014).

Os maiores benefícios da quimioterapia surgiram quando as drogas foram combinadas em esquemas, os mais comuns traz uma droga de cada classe exemplo: adriamicina, ciclofosfamida (AC); 5-fluorouracil, adriamicina, ciclofosfamida (FAC); 5- 
fluorouracil, epirrubicina, ciclofosfamida (FEC); adriamicina, ciclofosfamida, paclitaxel (ACT), dentre outros (BERGH et al., 2001).

Certo é, que pela primeira vez na história a mortalidade por câncer registrou quedas expressivas a partir da utilização dos quimioterápicos (JEMAL; WARD; THUM, 2010; WINGO et al., 2003).

Infelizmente, os efeitos adversos provocados por estas terapias tornaram-se outro grande problema dentro da oncologia e da saúde pública. As comorbidades cardiovasculares, o risco de aparecimento de outro tumor induzido pelo tratamento, alterações pulmonares, fadiga e dores excessivas e persistentes, astenia, depressão, ansiedade, são sintomas comumente relatados pelas pessoas submetidas ao tratamento quimioterápico (BOEKEL et al., 2016; THILL;PISA; ISBARY; 2016; ORDING et al., 2015). A tolerabilidade individual a estes efeitos tem sido o fator limitante à utilização das doses de quimioterapia.

A última inovação da indústria farmacêutica na luta contra o câncer foram as terapias-alvos ou terapias biológicas (SKEEL, KHLEIF, 2011). Essa nova classe de drogas só foram desenvolvidas a partir do entendimento das características moleculares do câncer. No final da década de 60 e início da década de 70 com a descoberta da expressão de receptores de hormônios esteroides (ER e PR) pela membrana tumoral adveio, então, um anticorpo monoclonal humanizado, o trastuzmab ou herceptin ${ }^{\circledR}$ como conhecido comercialmente (SLEDGE et al., 2014). Este é capaz de ligar-se à porção externa da proteína HER-2 e a partir daí inibir cascatas sinalizadoras internas ainda não bem definidas e que conduziram às respostas superiores em pessoas com tumores HER2+(BESELGA et al., 1998), metástico, em idades avançadas, dentre outros (ASIFet al., 2016; LEE et al., 2014).

A superioridade das terapias de anticorpos monoclonais é que somente as células cancerosas apresentariam as mutações necessárias e reconhecidas pelos fármacos, ou seja, elas seriam específicas ao tecido doente (SCOTT; WOLCHOCK; OLD, 2012). Entretanto, os mecanismos apresentam falhas e, novamente, o elevado risco de cardiotoxicidade e outros efeitos colaterais têm requerido atenção e medidas complementares ao uso do trastuzmab (HONDA et al., 2016; MANTARRO et al., 2016; O'SULLIVAN; SMITH, 2014).

Além das técnicas de imunoterapia os receptores hormonais já serviam como alvo terapêutico desde a década de 50 , sendo inicialmente utilizado como mediador da endocrinoterapia (SLEDGE et al., 2014). 


\subsubsection{Hormonioterapia}

A associação entre uma via hormonal-esteroide e o câncer de mama, incialmente observada no modelo animal, confirmou-se quando mulheres que passavam por cirurgias de histerectomia apresentavam resultados positivos sobre a remissão do câncer de mama (MACGREGOR, 1996). Inicialmente as técnicas de tratamento hormonais baseavam-se na castração ativa a partir das cirurgias de ooferectomia e adrenalectomia (LAKHTAKIA, 2014). Apesar de não conhecerem o mecanismo atuante, o resultado destes tratamentos conseguia ser positivo para um grande numero de mulheres (CLARKEet al., 1998). Somente em 1939 surgem uma nova forma de terapia sistêmica, que tinha como princípio a supressão do hormônio estrógeno, conhecida como terapias antiestrogênicas seu princípio era impedir a proliferação do tecido mamário à partir da recepção hormonal. Os tumores REpositivos usam o esteroide hormonal estradiol como seu principal estímulo para crescimento, logo, este seria o alvo direto das terapias endócrinas (BUITRAGO et al., 2011). A droga mais difundida da hormonioterapia em sua primeira fase foi 0 tamoxifeno um modulador seletivo dos receptores de estrogênio que age ligando-se ao receptor tumoral para estradiol, competindo assim com este hormônio pelo sítio de ligação. Na maioria das vezes o tamoxifeno é administrado oralmente e pode ser contínua ou intermitente por vários anos. A disseminação do seu uso proporcionou uma elevação no período de sobrevida (INWALD et al., 2015; COOMBES et al., 2004; NOMURA et al., 1980).

A terceira classe dessas drogas o anastrozol que é um inibidor seletivo da aromatase com atividade progestogênica, androgênica ou estrogênicaque ocupa o lugar do tamoxifeno, devido aos menores eventos adversos entretanto,consideravelmente mais caro (EARLY BREAST CANCER TRIALISTS' COLLABORATIVE GROUPet al., 2015; LOCKERet al., 2007; MANSEL et al., 2007). Atualmente, uma nova classe de fármacos com ação nos receptores de estrogênio, o fulvestranto, vem sendo prescrito como hormonioterapia para de câncer de mama avançado. Este se liga e bloqueia o receptor celular de estrogênio, causando degradação da proteína deste receptor, com consequente inibição da sinalização intracelular(ROBERTSON, 2007). Entretanto, sua eficácia comparada à de outras drogas ainda está sendo testada (ELLIS et al., 2015). 
Os eventos tromboembolíticos, fogachos, perda de massa óssea, deposição de tecido adiposo na região abdominal, hipercolesterolemia, hipertensão, fraqueza, insônia, sintomas depressivos e favorecimento de câncer endometrial são alguns dos eventos adversos relatados por este tipo de terapia (CHEN et al., 2015; HOJAN; MOLIŃSKA-GLURA; MILECKI; 2013; BURSTEIN et al., 2010; REDDY; CHOW, 2000).

A maioria dos eventos adversos deste e de outros tratamentos nos chama a atenção por apresentar alguma aproximação às consequências da obesidade. As alterações da composição corporal então surge como uma variável de interesse associado ao tratamento quimioterápico.

\subsection{Composição Corporal}

A composição corporal tem sido avaliada por meio de inúmeros métodos, e em diversas condições da vida humana, entretanto, as alterações na composição corporal ainda é um tema parcialmente esclarecido, uma vez que, envolvem diversas variáveis como idade, nível de atividade física, ingesta calórica, perfil hormonal e presença de doenças (HEYMSFIELD et al., 2005).

O estado nutricional pode ser entendido como as alterações da massa corporal e da estatura que resultam em condições adequadas ou alterações como sobrepeso, obesidade, desnutrição dentre outros (WHO, 1995). Estes podem ser gerados por diversas condições, inclusive, doenças crônicas como o diabetes, o hipo ou hipertireoidismo, a AIDS e o câncer (LOUE, SAJATOVICK, 2008; WAITZBERG, 2009, HEYMSFIELD et al., 2005).

A antropometria tem sido utilizada a mais de 50 anos como método de mensuração do estado nutricional, empregado inicialmente para detectar estados de desnutrição principalmente em crianças (WHO, 1986). Na atualidade os dados antropométricos são largamente aplicados à prática clínica servindo como indicativo de doença, auxiliam na adequação de tratamentos como hemodiálise, na prescrição de fármacos, podendo indicar ainda a presença de risco para uma série de condições (WILLIAMS et al., 2006).

De acordo com Ulijaszek e Kerr (1999) antropometriaé "a medida do homem", entretanto esse envolve traços fisiológicos, psicológicos e anatômicos; e que no final 
do século passado referia-se a características morfológicas mensuradas externamente, como massa corporal, estatura, circunferência da cintura, diâmetros ósseos, dentre outros. $\mathrm{Na}$ atualidade, com a expansão dos recursos tecnológicos e a aplicação de técnicas como a tomografia axial computadorizada, o ultrassom, a absorciometria de dupla energia de raio-x componentes íntimos da composição corporal como a densidade mineral óssea e a massa gorda e a massa livre de gordura passaram a ser inferidos.

\subsubsection{Composição Corporal, prognóstico, recorrência e sobrevida em câncer de mama}

No câncer os fenômenos da caquexia e da obesidade concentram a maioria dos estudos, visto que, estas modificações podem ocorrer ao longo de todo o processo de adoecimento, tratamento e sobrevida (PRADO et al., 2011; MACCIO, MADEDDU, 2011).

Apesar de a caquexia ser um sintoma considerável, principalmente, nos estadios avançados da doença; especificamente, no câncer de mama, relevância maior tem sido dada ao sobrepeso/obesidade. E essa condição associa-se a uma gama de aspectos desfavoráveis até mesmo nos estágios iniciais da doença.

O Índice de Massa Corporal (IMC) elevado tem sido descrito como um dos maiores fator de risco para o desenvolvimento do câncer de mama, para um estadio avançado da doença no momento do diagnóstico, e também, prognóstico desfavorável, tanto em mulheres na pré como na pós-menopausa.

A sobrevivência em mulheres com obesidade foi significativamente reduzida quando comparado às outras classes de IMC (LITTONet al., 2008). Dados antigos da população norte-americana indicavam que os padrões de obesidade no ano de 2003, seriam responsáveis por $14 \%$ a $20 \%$ de toda a mortalidade por câncer naquele país (CALLE et al., 2003). Havendo, ainda, indícios que o grau de obesidade confere diferentes riscos a sobrevivência no câncer de mama (KWANet al., 2012).

Um estudo de follow-up de 10 anos com 53.816 mulheres tratadas de câncer de mama detectaram que aquelas com $\mathrm{IMC} \geq 30 \mathrm{Kg} / \mathrm{m}^{2}$ tinham tumores significativamente maiores, elevada frequência de tumores classificados como ductais, de grau 3 e mais linfonodos removidos e positivos. Identificaram também, elevação da chance de metástase à distância após três anos, com o aumento do 
IMC. Esse quadro apresentou-se ainda mais desfavorável no período de 5 a 10 anos, para mulheres com IMC $\geq 25 \mathrm{Kg} / \mathrm{m}^{2}$ quando comparadas aquelas com IMC $\leq 25$ $\mathrm{Kg} / \mathrm{m}^{2}$. O risco de morte, também, foi aumentado com o acréscimo do IMC (EWERTZ et al., 2011).

Outro trabalho com 1.169 mulheres detectou que o sobrepeso e obesidade estavam associados a uma idade avançada no momento do diagnóstico, ao estado pos-menopausal, a etnia afro-americana. Sendo que aquelas que apresentavam IMC $\geq 30 \mathrm{~m} / \mathrm{kg}^{2}$ exibiam maior percentual de tumores ER negativo, estadio3 ou 4 quando comparadas a mulheres com sobrepeso ou eutrofia. Além disso, o grupo de mulheres com sobrepeso ou obesidade teve maior incidência do subtipo triplo-negativo.

Os estudos de Phippset al. (2008) e Linet al. (2012), também, identificaram associação entre o IMC elevado e a ocorrência de câncer de mama do tipo triplonegativo em mulheres na pré-menopausa, entretanto devido a diferenças na composição da amostra, os autores sugerem novos estudos para confirmar seus achados. Em oposição, Ademuyiwaet al. (2011) não encontraram associação entre o IMC e a sobrevida total e a sobrevida livre de recorrência em mulheres diagnosticadas com câncer de mama triplo negativo.

Apesar dos dados não apresentarem unanimidades Azambuja et al. (2010) afirmam que o efeito prejudicial da obesidade não se restringe apenas à mortalidade e aos aspectos fisiopatológicos da doença. Em seu estudo, além da maior redução na sobrevida global, para mulheres mais jovens e de IMC elevado quando comparado a idosas, os autores também propõem que, aquelas com grau 3 e 4 e obesidade, apresentaram mais efeitos colaterais como: diarreia, hiperglicemia, hipertensão e hospitalização, devido a eventos adversos do tratamento antineoplásico.

Os efeitos adversos são outro aspecto que pode ser precipitados pela alteração da composição corporal em pessoas diagnosticadas submetidas às terapias antineoplásicas. Reações adversas ao tratamento geralmente refletem de forma negativa na eficácia terapêutica e na qualidade de vida dos indivíduos. Podendo ainda ocasionar incapacidades permanentes, comorbidades e prejudicar a sobrevida e mortalidade.

Griggset al. (2005) relataram que mulheres com sobrepeso e obesidade foram mais propensas à hospitalização devido à febre neutropênica, e naquelas com 
obesidade severa foram associadas a uma baixa probabilidade de serem admitidas por este motivo (oddsratio, 0.61; 95\% intervalam de confiança, 0.38-0.97).

A febre neutropênica é um evento adverso indesejado, uma vez que, requer manipulação das doses de quimioterapia, o que geralmente incide sobre sua eficiência, eleva o numero de hospitalizações e no uso de antibióticos. Há, ainda, indícios de que indivíduos com obesidade e sobrepeso possuam valores plasmáticos reduzidos de doxorrubicina, devido ao maior volume de distribuição da droga no estado estável, provavelmente, advindo das características lipossolúveis da medicação e alterações fisiológicas provocadas pelo excesso de peso como: aumento do volume sanguíneo, do débito cardíaco, na filtração glomerular, mudança nas concentrações das proteínas plasmáticas carreadoras de fármacos, dentre outros (BARPE, 2009).

Carrolet al. (2012) concluíram em sua revisão que mulheres com obesidade têm maior tolerância à quimioterapia quando comparadas a mulheres com peso desejável. Nesse estudo as mulheres com IMC $\geq 30 \mathrm{~m} / \mathrm{kg}^{2}$ também apresentaram menor neutropenia, sugerindo uma redução na eficácia da quimioterapia nestas mulheres, o que por usa vez, poderia explicar os pobres prognósticos.

Chan et al. (2012) realizaram um estudo de coorte retrospectivo com 198 mulheres diagnosticadas com câncer de mama em estágios iniciais e tratadas com $\mathrm{AC}$ identificaram que o $\mathrm{IMC} \leq 23 \mathrm{Kg} / \mathrm{m}^{2}$ foi considerado um fator de risco associado à ocorrência de febre neutropênica durante o período de quimioterapia. Sendo que, as pessoas com este IMC, classificadas como eutróficos, apresentavam 4,4 vezes maiores risco de desenvolvimento de neutropenia febril.

Chen et al. (2012) avaliaram em seu estudo 307 mulheres chinesas submetidas ao tratamento quimioterápico neoadjuvante com carboplatina e paclitaxel, e detectaram que o IMC elevado foi um preditor independente de baixa resposta patológica completa, após o tratamento para o câncer de mama, sendo esta resposta um indicador de eficácia da quimioterapia. Del Fabroet al. (2012) também encontraram resultados negativos associados ao sobrepeso e a resposta patológica completa em mulheres com câncer de mama $(n=123)$ nos estágios iniciais, sem metástase, tratadas com terapia neoadjuvante. Além disso, o tempo de sobrevida livre da doença foi maior em mulheres com IMC $\geq 25 \mathrm{Kg} / \mathrm{m}^{2}$ do que naquelas com valores acima deste. Um resultado intrigante detectado neste estudo foi que em indivíduos com IMC $\leq 25 \mathrm{Kg} / \mathrm{m}^{2}$ e sarcopenia apresentaram maior proporção de 
respostas patológicas do que indivíduos sem sarcopenia. Entretanto, os autores não conduziram maiores explicações, associando a massa magra corporal ao melhor funcionamento do fígado e mecanismo associado ao volume de distribuição da droga.

Obesidade e sobrepeso também foram associados a uma baixa resposta patológica completa em mulheres submetidas à terapia neoadjuvante quimioterapia (LITTON et al., 2008). Em contraposição, Lee et al. (2012) não detectaram em seu estudo influência do IMC na resposta patológica completa entre mulheres coreanas ( $n=319)$ entre o estadio II e III do câncer de mama submetidas ao tratamento neoadjuvante.

Também Ewertzet al. (2011) identificaram que após 10 anos de acompanhamento os efeitos da quimioterapia e da hormonioterapia mostraram-se menos efetivos em mulheres com IMC $\geq 30 \mathrm{Kg} / \mathrm{m}^{2}$.

Outro fenômeno que vem sendo estudado e que associa composição corporal e tratamento quimioterápico é o da alteração da dose de fármacos em indivíduos com IMC elevado. Barpe, Rosa, Froelich (2010) numa avaliação da farmacocinética da doxorrubicina em mulheres com sobrepeso constataram que, as doses de quimioterapia calculadas com base na área de superfície corporal (ASC) não apresentam a mesma concentração plasmática entre mulheres com sobrepeso, quando comparado a mulheres com eutrofia. Levantando, ainda, algumas incertezas sobre o cálculo para as doses quimioterápicas baseadas na superfície corporal.

Um estudo retrospectivo com 9.672 mulheres com câncer de mama loco regional e submetidas ao tratamento com doxorrubicina e ciclofosfamida (AC) evidenciaram que as doses de quimioterapia reduziram significativamente em mulheres com sobrepeso e obesidade, mas, principalmente, entre aquelas com obesidade severa. Detectou-se, também, que além dessas, a idade elevada e a presença de comorbidades severas como doenças cardiovasculares, diabetes, doenças hepáticas, renais e pulmonares, também foram indicadores de reduções no primeiro ciclo de tratamento. Os autores justificam, ainda, que foi utilizado o primeiro ciclo como critério de avaliação por ser esta redução um comportamento intencional do médico e não uma resposta a efeitos adversos. Sendo que, aumentos subsequentes nas doses não foram identificados (GRIGGSet al., 2005). Em estudo posterior o mesmo autor continuou a relatar redução das doses de quimioterapia em 
função da elevação do IMC, de baixos níveis educacionais e econômicos (GRIGGSet al., 2007).

Diminuições também foram percebidas no esquema de 5- fluorouracil, epirrubicina e adriamicina (FEC), em 662 mulheres com câncer de mama, onde o objetivo do estudo foi avaliar a intensidade relativa do tratamento quimioterápico. Nesta pesquisa utilizaram-se dois critérios para determinar a obesidade que foram a área de superfície corporal $\geq 2 \mathrm{~m}^{2}$ e o IMC $\geq 25 \mathrm{Kg} / \mathrm{m}^{2}$. Foram percebidas diminuições no tratamento quimioterápico naquelas com IMC elevado (JENKINS; ELYAN; FREEMAN, 2007). Em contraposição, Brewster et al. (2011) não identificaram alteração nas doses de quimioterapia para o tratamento de câncer de mama entre mulheres com sobrepeso e obesidade e mulheres eutróficas.

Tanto a manifestação de efeitos colaterais devido ao tratamento, quanto à redução nas doses podem atrasar a progressão do tratamento quimioterápico e diminuir seus efeitos. Jung et al. (2012) corroboram com essa afirmação ao constatar que, atrasos no tratamento quimioterápico representaram um impacto negativo na sobrevivência em mulheres com metástase à distância.

Ainda não se sabe quais os mecanismos que associam o prognóstico desfavorável em mulheres com sobrepeso e obesidade, entretanto, parece que até o momento três propostas são as que apresentam maior respaldo científico são: 1) elevação dos níveis de estrogênios circulantes advindos da aromatização periférica de andrógenos, principalmente pelo tecido adiposo; 2) a síndrome metabólica, associada à obesidade, liberaria dos níveis circulantes de insulina e fator de crescimento semelhante à insulina (IGF) que apresentam um efeito mitogênico sobre as células epiteliais da mama, estimulando seu crescimento e degeneração neoplásica; 3) a ação endócrina, parácrina e autócrina dos adipócitos como centro de um mecanismo etiopatogenético. De acordo com esta teoria as adipocinas produzidas pelo tecido adiposo como: leptina, fator de necrose tumoral- $\alpha$ (TNF- $\alpha$ ), adiponectina, interleucina-6 (IL-6), fator de crescimento do hepatócito (HGFs); estariam associadas diretamente ao crescimento tumoral, modificando o fenótipo das células cancerosas levando-as a um comportamento mais agressivo. Entretanto, todas estas teorias ainda necessitam de suporte científico (MACCIOÓ; MADEDDU, 2011; MACCCIOOet al., 2009). Sinicropeet al. (2001) detalha o mecanismo na imagem a seguir (figura 3 ) 


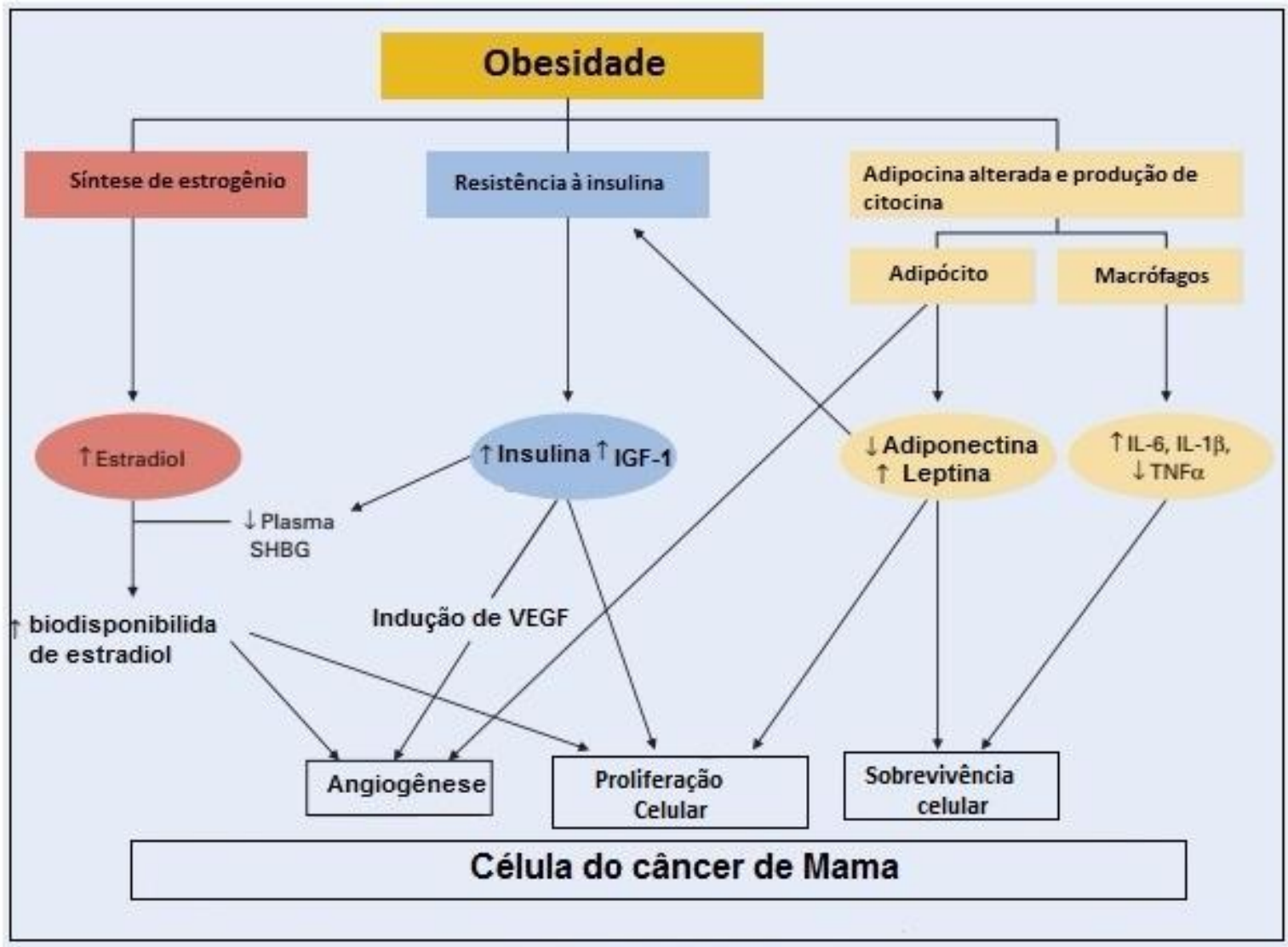

FIGURA 3: Vias de associação direta entre obesidade e câncer de mama proposta por Sinicropeet al. (2001) e adaptada pelo autor.

SHBG = Globulina liberadora de hormônios sexuais; IGF-1 = fator de crescimento similar à insulina tipo 1; IL-6 = Interleucina -6; IL-1 $\beta=$ Interleucina do tipo 1 beta; TNF $\alpha=$ fator de necrose tumoral do tipo alfa; VEGF =fator de crescimento endotelial vascular.

Fonte: Sinicropeet al. (2001)

\subsubsection{Alterações na composição corporal induzidas pelo tratamento antineoplásico}

Além dos estudos sobre os prejuízos ao tratamento em pessoas com sobrepeso e obesidade, outra corrente inversa vem tentando entender as consequências do tratamento antineoplásico sobre a composição corporal. Embora as alterações da massa corporal possam ocorrer em qualquer fase do tratamento e do período de sobrevida Gadeaet al. (2011) informam que o risco de ganho de peso é de aproximadamente $65 \%$ para a quimioterapia quando comparado aos tratamentos não sistêmicos. Além do tipo de drogas, o tempo de duração do tratamento, também, pode estar associado a esse ganho.

O estudo de Thivatet al. (2010) com 20 anos de follow-up retrospectivo (19761989) mensurou 111 voluntárias com estadio de I a III do câncer de mama tratadas 
com quimioterapia. Neste estudo, foi observada a variação de peso no período da quimioterapia, onde o ponto de corte para ganho ou perda de peso clinicamente relevante foi considerado $5 \%$ da massa corporal. Os resultados indicaram que, 17\% das mulheres perderam peso, 69\% permaneceram estáveis e 14\% ganharam peso; dentre esses $31 \%$ ganharam peso acima dos 5\%. Esta elevação na massa corporal foi associada ao aumento do risco de morte de 2.1; 95 IC: 1.21-3.66. Além disso, a variação no peso foi associada ao risco de recorrência de 2.28; 95 IC: 1.29 - 4.03.

Makari-Judsonet al. (2007) encontraram em seu estudo retrospectivo com 185 mulheres no estadio I a III do câncer de mama que, em $71 \%$ da amostra houve ganho médio de $3.7 \mathrm{Kg}$ no intervalo de 1 ano, sendo que, aquelas que haviam sido submetidas à quimioterapia e apresentavam IMC $\leq 25 \mathrm{~m} / \mathrm{kg}^{2}$ obtiveram um ganho significativamente maior. A variação global do peso no primeiro ano foi de $1.5 \mathrm{Kg}$. No segundo ano de acompanhamento, o aumento da massa corporal foi significativamente maior do que no primeiro ano (diferença de $1.1 \mathrm{Kg}$ ), $70 \%$ das pacientes haviam ganhado peso quando comparado ao período inicial. Apenas $25 \%$ daquelas que ganharam peso no primeiro ano haviam reduzido o excesso de peso ao final do segundo ano. Dentre as que não haviam aumentado o peso no primeiro ano, $32 \%$ ganharam peso no ano seguinte em proporções significativamente maiores do que no primeiro período. No terceiro ano de acompanhamento houve um ganho médio de peso de $2.8 \mathrm{Kg}$, não sendo essa diferença significativa quando comparada ao segundo ano. As alterações de peso não foram associadas à sobrevivência livre da doença, sobrevida livre de recidiva e sobrevida global. No terceiro ano de observação $43 \%$ das mulheres que haviam perdido peso no primeiro ano, obtiveram um ganho de peso além da sua medida de referência em três anos.

Outro trabalho realizado com 368 mulheres tratadas de câncer de mama na Malásia com estadio em I a III, que tiveram seu peso avaliado em três períodos distintos: (1) um ano anterior ao diagnóstico, (2) a partir do diagnóstico até a entrada no estudo, (3) do ano que precedeu o diagnóstico ao início do estudo. A média de tempo de acompanhamento foi de $4.86 \pm 3.46$ anos. Os resultados indicaram que as mulheres aumentaram a massa corporal significativamente nos períodos 2 e 3 e reduziram no momento 1 . O ganho de peso foi de cerca $3-4 \mathrm{Kg}$, sendo que a elevação do peso foi maior para aquelas submetidas ao tratamento quimioterápico (2.5 Kg no ano após o diagnostico) do que naquelas submetidas apenas as outras intervenções (cirurgia e hormonioterapia $=0.6 \mathrm{Kg}$ ). Também foi revelado que 
mulheres na pós-menopausa, e com idade inferior a 50 anos são mais prováveis a ganhar peso do que mulheres na pré ou pós-menopausa com idades superiores (YAWet al., 2011).

Demark-Wahnefriedet al. (2002) verificaram alterações da composição corporal de mulheres na pré-menopausa e no estágio I e II do câncer de mama $(n=9)$ após o tratamento quimioterápico. Os resultados indicaram que as mulheres do grupo controle $(n=36)$ ganharam cerca de $2.0 \pm 0.4 \mathrm{~kg}$ de massa corporal, sendo esse ganho em massa gorda, aproximadamente $2.0 \pm 0.3 \mathrm{~kg}$, e havendo ainda uma redução da massa magra $0.3 \pm 0.1 \mathrm{~kg}$. Em contrapartida, o grupo que realizou exercícios aeróbios e resistidos obteve redução da massa corporal, aproximadamente $2.0 \pm 1.3 \mathrm{~kg}$ e da massa magra $1.2 \pm 1.5 \mathrm{~kg}$, e ainda, um discreto ganho de massa magra $0.1 \pm 1.5 \mathrm{~kg}$. As mudanças no tecido magro não foram estatisticamente significantes entre o período pré e pós-treinamento e entre os grupos.

Por outro lado Freedmanet al. (2004) estudou 20 mulheres com câncer de mama, estadio entre I a IIIA e tratadas com adriamicina isolada ou associada ao paclitaxel e comparadas a um grupo controle sem a doença $(n=51)$. Estes autores concluíram que apesar de não haver alteração no peso de mulheres submetidas ao tratamento quimioterápico e 6 meses após, houve uma redução significativa da massa livre de gordura e tecidos moles, além de um aumento na massa gorda. Os autores conjecturam que a hiperfagia, regime quimioterápico multiagente longos e que incluem glicocorticoides e a mudança no estado menopausal durante o tratamento poderiam estar associado a estas alterações.

Rockenbachet al. (2011) sugerem que o aumento do peso e do IMC em mulheres submetidas aos tratamentos antineoplásicos dar-se-ia por hiperfagia, principalmente de alimentos ricos em gordura. Já Kwanet al. (2012) identificaram uma redução no nível de atividade física de 1.696 mulheres diagnosticadas com câncer de mama durante o período de tratamento. As atividades recreativas foram aquelas que sofreram maior redução, seguidas das atividades domésticas e transporte, e ainda as atividades sociais. O comportamento sedentário foi associado a questões sociais, ao estado pos-menopausal, ao IMC elevado e também ao tratamento quimioterápico e ao tipo de cirurgia.

Não há consenso sobre a causa da variação de peso durante a quimioterapia, se este seria um desequilíbrio energético entre a ingestão e a inatividade física, uma 
consequência da alta toxicidade do tratamento que geraria distúrbios como fadiga, náusea, êmese, distúrbios do sono; ou deriva da ação direta da quimioterapia sobre as vias metabólicas como da adipocinas (leptina e adiponectina) níveis de estrogênio, insulina e a família dos IGFs (GADÉAet al. 2011).

Além das questões de alteração da massa corporal e do IMC torna-se importante, também, compreender o comportamento da massa gorda e da massa livre de gordura nos indivíduos em tratamento, uma vez que sua proporção e localização no corpo são indicadores de saúde relevantes. Análises a partir do IMC e da área de superfície corporal dificultam um entendimento mais detalhado da composição corporal que pode ser clinicamente importante e que é largamente ignorado na clinica oncológica (PRADO et al., 2008).

\subsubsection{Massa livre de gordura, massa gorda e o tratamento antineoplásico}

Não somente o excesso de gordura, mas a sua distribuição no corpo, podem influenciar de forma diferenciada na sobrevida, foi o que detectou Abrahamsonet al. (2006) ao observar quetanto o IMC elevado quanto à relação cintura/quadril (RCQ) estão associados ao risco de morte em mulheres jovens diagnosticadas com câncer de mama, sendo que a concomitância destes dois fatores eleva exponencialmente este risco.

O estudo de Nissen, Shapiro, Swenson (2011) utilizou a Absortometria Radiológica de Dupla Energia (DEXA) para mensurar a composição corporal em 49 mulheres, idade entre 40 e 59 anos, submetidas ao tratamento quimioterápico, que foram acompanhadas por 12 meses. Os resultados apontaram que, aquelas com IMC $\leq 25 \mathrm{Kg} / \mathrm{m}^{2}$ no período inicial apresentaram elevação na massa gorda no tronco e nos membros superiores. Sendo que, o ganho de peso também foi significativamente maior neste grupo, cerca de $1,5 \mathrm{Kg}$, quando comparados a mulheres com sobrepeso ou obesidade. Neste estudo, a redução no nível de atividade física foi associada ao ganho de peso e não houve associação com a dieta.

Gadéaet al. (2011) afirmam que durante a quimioterapia há um aumento significativo da massa gorda com uma tendência a perda ou estabilização da massa livre de gordura (MLG). Uma redução da MLG pode resultar num baixo volume de distribuição dos fármacos, resultando em uma elevada toxicidade do tratamento 
quimioterápico com uma dosagem adequada para a área de superfície corporal (DEL FABRO et al., 2012).

A perda involuntária de massa livre de gordura, e principalmente do tecido muscular esquelético, tem sido uma marca das doenças malignas, o qual são resultados do próprio câncer ou dos efeitos colaterais do tratamento. A exata contribuição do tumor para o balanço energético negativo tem sido pouco estudada, entretanto, hipotetiza-se que a elevada demanda energética para gerar metástase pode colaborar com esse déficit de energia.

Outro argumento estaria associado processo inflamatório gerado pelo câncer, as citocinas pro-inflamatórias não somente contribuiriam para o catabolismo, como também inibiriam o anabolismo muscular, alguns dos mecanismos seriam: a inibição da síntese proteica muscular, o aumento da proteólise muscular mediada pela ubiquitina-proteassoma, hipermetabolismo e resistência à insulina e diminuição de outros fatores tróficos na musculatura esquelética.

Por outro lado, grande parte das drogas administradas ao longo do tratamento pode ter uma ação catabólica sobre os músculos como as classes de corticosteroides, inibidores da tirosina quinase, antraciclinas, além dos regimes adjuvantes multidrogas (PRADOet al., 2011). A combinação dos fatores acima citados com uma nutrição inadequada, redução da atividade física, presença de comorbidades, doses quimioterápicas baseadas apenas na área de superfície corporal podem resultar em um tratamento com baixa eficiência, elevada toxicidade e resultados negativos para as pessoas acometidas pelo câncer.

Nesse contexto estudos recentes tem buscado compreender melhor as proporções de tecido magro e gordo em indivíduos com câncer, uma vez que, estes podem estar associados à toxicidade e sobrevivência. Uma condição conhecida como obesidade sarcopênica caracterizada pela presença da massa muscular reduzida em indivíduos de IMC eutrófico ou com obesidade configuraria uma situação grave para o tratamento do câncer, pois ela associaria os riscos à saúde advindos da obesidade e da redução do tecido magro (PRADOet al., 2009).

Em estudo com 325 indivíduos acometidos por diversas formas de câncer, onde 38 apresentavam obesidade sarcopênica foi relatado menor status funcional quando comparado àqueles sem essa condição (PRADO et al., 2008). A sobrevivência também foi reduzida em indivíduos com obesidade (aproximadamente 21 meses) e ainda mais naqueles com obesidade sarcopênica (aproximadamente 11 
meses). Entretanto, a sobrevivência não foi afetada pela variação na massa corporal. Obesidade sarcopênica apresentou-se como um preditor independente de sobrevivência ( $\mathrm{HR}=4.2[2.4-7.2], \mathrm{p}<0.0001)$.

Além disso, em mulheres com câncer de mama metástico $(n=55)$ submetidas ao tratamento com capecitabina, dentre essas $25.5 \%$ apresentavam obesidade sarcopênica $(n=14)$. Esse grupo recebeu uma maior dose do fármaco por unidade de massa magra e também foi percebida uma alta prevalência de toxicidade quando comparado à condição não-sarcopênica (PRADO et al., 2009). O tempo de progressão tumoral foi significativamente reduzido no grupo com obesidade sarcopênica (62 dias, IC 47.3 - 76.7) comparada com aquelas sem essa condição (105 dias, IC 52.3 - 157.7) após o ajuste para variáveis clinicas e antropométricas.

Apesar do volume de estudos que tratam sobre o câncer de mama, composição corporal e o tratamento antineoplásico alguns aspectos ainda dificultam as conclusões sobre estes temas. $\mathrm{O}$ grande de número de estudos retrospectivos e que obtiveram os dados de prontuários médicos, a utilização do IMC e do peso corporal como medidas mais frequentes para caracterizar a composição corporal, escassa informação sobre aspectos intervenientes da composição corporal como o nível de atividade física e a conduta alimentar dos voluntários ainda impedem afirmações mais acuradas sobre o que ocorre com a composição corporal ao longo do tratamento quimioterápico. De modo que, estudos com maior controle das variáveis intervenientes, com acompanhamento dos sujeitos e que utilizem metodologias mais minuciosas de mensuração da composição ainda fazem-se necessários. 


\section{MATERIAIS E MÉTODOS}

\subsection{Delineamento do estudo}

Trata-se de um estudo analítico e transversal. Uma vez que buscou estabelecer associações e correlações entre as variáveis estudadas em apenas um momento (PEREIRA, 2000).

\subsection{População e amostra}

As voluntárias do presente estudo foram identificadas e selecionadas em 3 Unidades de Alta Complexidade em oncologia do Distrito Federal.

Os critérios de elegibilidade foram:

- Diagnóstico clínico de câncer de mama;

- Idade acima de 18 anos;

- Indicação para tratamento quimioterápico adjuvante ou neoadjuvante.

Os critérios de exclusão foram:

- Diagnóstico de outro tipo de câncer além do câncer de mama;

- Diagnóstico de câncer de mama durante o ciclo gravídico-puerperal;

- Mulheres que realizaram o tratamento antes que se possam realizar os exames iniciais;

- Mulheres em fase terminal da doença;

- Mulheres que apresentarem amputação de braços ou pernas;

Entre junho de 2015 e fevereiro de 2016 foram acessados o registro de 1076 pessoas com câncer no Distrito Federal. Destas, 229 foram registradas nos setores de oncologia clínica com câncer de mama (CID 50), neste grupo havia indicação de tratamento radioterápico para 81 mulheres, restando 148 mulheres possíveis de tomarem parte no presente estudo. Do total de mulheres com diagnóstico de câncer de mama 22\% (36) não puderam ser localizadas (não atenderam ao telefone, ou número fornecido não pertencia à pessoa, ou havia erro no número registrado, ou ainda, o número estava impossibilitado de receber chamadas ou desligado). Assim, 
112 mulheres foram contatadas.O fluxograma (figura 4)a seguir apresenta a descrição detalhada do processo de apuração da amostra.

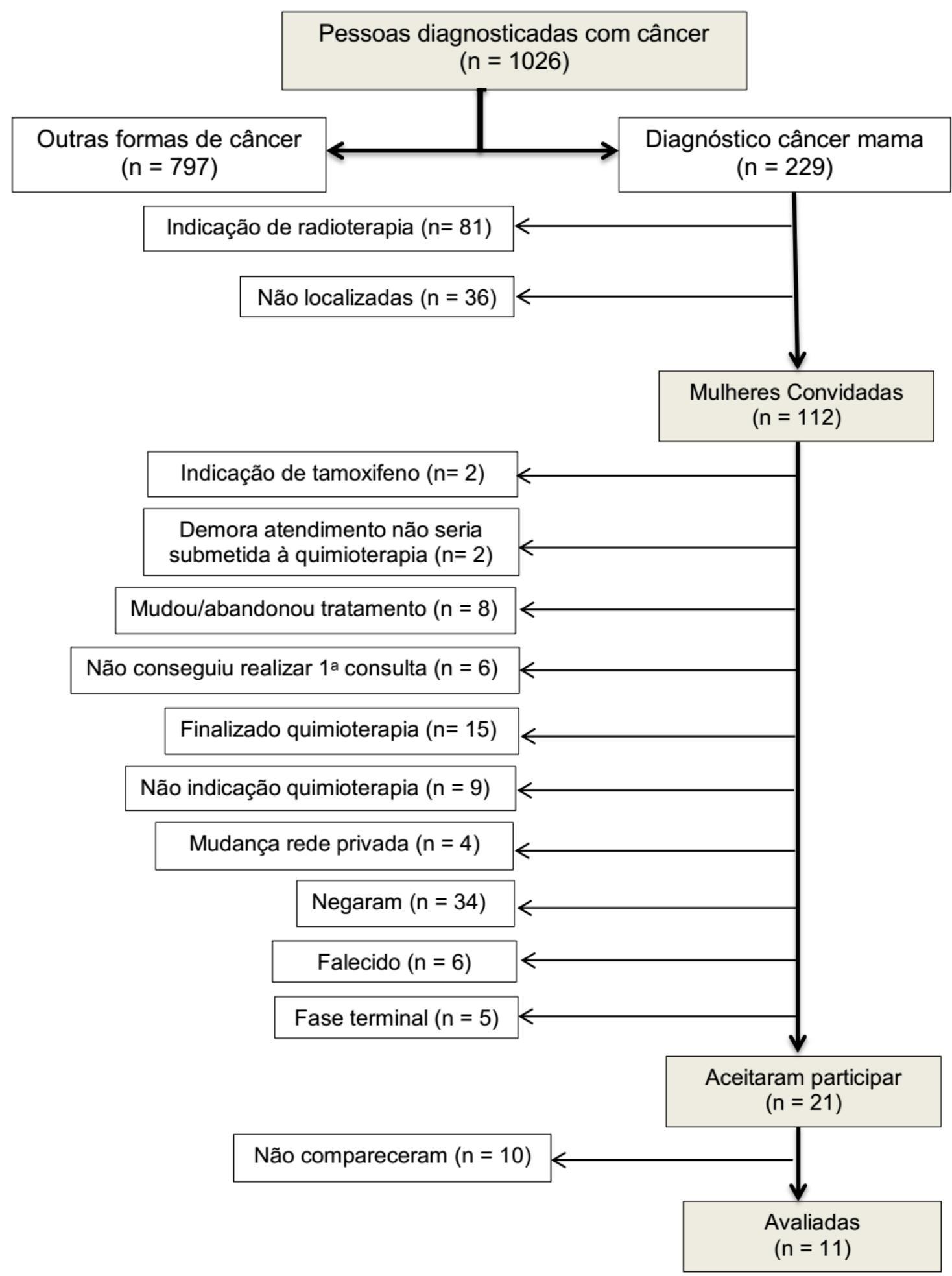

Figura 4: Fluxograma de seleção da amostra

Fonte: próprio autor 
Houve a tentativa de contato por telefone com $100 \%$ da amostra. Foram realizadas 3 tentativas para cada número e em pelo menos dois dias diferentes para ampliar a possibilidade de localização das possíveis voluntárias.Dentre as possíveis voluntárias 2 receberam indicação para hormonioterapia somente, 2 não seriam submetidas ao tratamento quimioterápico devido à delonga entre o período de intervenção cirúrgica e a primeira consulta da oncologia clínica; 8 mudaram de hospital ou abandonaram o tratamento, 15 haviam finalizado o tratamento quimioterápico, 9 não receberam confirmação clínica para realizar a quimioterapia,4 migraram para o sistema privado,6 não haviam conseguido realizar a primeira consulta até o momento do contato telefônico; 5 estavam em fase terminal, 6 haviam falecido.

Á recusa em tomar parte do estudo foi o principal motivo de mortalidade da amostra, representando 30,36\% (34) do total de mulheres convidadas. Destas, 4 pediram pra retornar em outro momento e não receberam mais as chamadas.A tabela 1 apresentam os principais motivos de negação. A necessidade de assentimento e colaboração de um cuidador ou responsável (geralmente filhos ou cônjuge) foi o maior empecilho observado. Geralmente, os familiares não identificavam um benefício nas avaliações propostas e alegavam não ter tempo disponível para acompanhar a voluntária, ou então afirmavam que iriam ponderar e posicionariam em outro momento, havendo negação posterior.

Tabela 1: Frequência (f) e percentual (\%) dos motivos de recusa à participação no estudo.

\section{Motivo de recusa}

Demora atendimento SUS

Contraindicação médica

Realizou DEXA pouco tempo

Sem autorização acompanhante cuidador responsável

Complicações cirurgia

Dependência física locomover

Fraqueza, indisposição

Distância

Não informou o motivo

Total

$\begin{array}{ll}\mathbf{f} & \% \\ 1 & 2,9 \\ 1 & 2,9 \\ 1 & 2,9 \\ 7 & 20,6 \\ 3 & 8,8 \\ 3 & 8,8 \\ 6 & 17,6 \\ 1 & 2,9 \\ 11 & 32,35 \\ 34 & 100\end{array}$

$\mathrm{f}=$ frequência; $\%$ =percentual 
Apenas 21 mulheres concordaram em participar do estudo, das quais, 10 não compareceram às avaliações, sendo que, 4 destas por motivos de coincidências de dias com o tratamento quimioterápico e não concordaram em remarcar os exames devido aos agravamento dos efeitos colaterais das terapias. Outras 3 não compareceram devido a consultas médicas é outras 4 não informaram o motivo. Nenhuma delas concordarem em remarcar os exames. Ao final, as análises do presente estudo foram conduzidas em 11 mulheres $(n=11)$.

Observou-se que o receio em atrapalhar o tratamento, a concorrência com a agenda hospitalar, as constantes mudanças e atrasos nas marcações de consultas e retornos deixavam as voluntárias inseguras quanto a assumirem e cumprirem compromissos no período ativo de tratamento. Outro aspecto percebido durante o processo de convencimento para avaliação inicial ou remarcação foi que as mulheres não percebiam o exame como algo de valor para o período em que se encontravam. Apesar de ser reiterado diversas vezes que as mensurações serviriam como acompanhamento em saúde, indicativos da saúde geral da pessoa, as mulheres estavam interessadas em realizar somente procedimentos indicados pela equipe oncológica, ou que agilizassem a admissão ao sistema de tratamento e ainda pudesse colaborar na cura do câncer.

Apesar da limitação numérica, não foram identificados outros estudos em mulheres na fase ativa de tratamento quimioterápico no DF. Das pesquisas encontradas que tratavam do assunto somente a de Castellar (2014) informou mulheres em tratamento quimioterápico $(n \cong 9)$. Os trabalhos Albuquerque (2014) $(n=$ 21), Vieira (2014) ( $n=16)$ e Tolentino (2007) ( $n=22)$ obtiveram amostras maiores, entretanto, nestes estudos não foi considerada a fase do tratamento. Outros trabalhos detectados não foram coletados no DF (RIBEIRO, 2010; DIETTRICH, 2007, SANTOS JÚNIOR, 2010), utilizaram apenas amostra do sistema privado de saúde (BERGEROT, 2013), no período anterior ao tratamento (IRALA, 2012), ou estavam avaliando protocolos pós-mastectomia (FERRAZ, 2007).

Uma possível estratégia para ampliar a seleção amostral seria a indicação do médico ou outro profissional de saúde da equipe hospitalar para que as possíveis voluntárias realizassem 0 exame. Entretanto, essa orientação poderia ser compreendida como prescrição e assim interferir no livre-arbítrio do cliente em participar ou não da pesquisa. Sendo este considerado um método indutivo e/ou 
coercitivo podendo infringir regras éticas da pesquisas com seres humanos. Thonget al. (2013) chama a atenção para as dificuldades metodológicas em estudos de qualidade de vida e câncer, principalmente no recrutamento da amostra e na dependência do profissional médico para o sucesso dos estudos. Este é um aspecto extremamente desfavorável, uma vez que, o acesso às informações coerentes, com qualidade e até mesmo a conclusão ficam ameaçadas e dependentes de facilitadores pessoais.

\subsection{Protocolo de Avaliação}

As avaliações realizadas no presente estudo foram:

Perfil socioeconômico e cultural: através deste instrumento foram obtidos os dados de caracterização da amostra como: idade, estado civil, nível de escolaridade, números de dependentes, hábitos de vida (tabagismo, etilismo), estado menopausal e dados referentes aos custos do tratamento (Apêndice A).

Dados clínicos: devido à necessidade de caracterização e estratificação da amostra, bem como para mensuração dos resultados do tratamento quimioterápico, foi realizado um levantamento sobre os dados clínicos nos prontuários médicos. Os dados identificados foram: diagnóstico histopatológico e/ou citopatológico da doença, estadiamento de acordo com a classificação TNM (BRASIL, 2004), fenótipo molecular, tempo de diagnóstico, confirmação do estado menopausal, tipos de tratamentos submetidos, área de superfície corporal, esquema quimioterápico e dosagemutilizada, eventos adversos pós-quimioterapia, atrasos no ciclo e motivos de internação durante o período, reduções de doses e motivos (GOZZO, 2010).

Estratificação dos eventos adversos: a amostra foi separada de acordo com os sintomas adversos apresentados de duas formas: a) quantidade de eventos relatados onde o grupo $1 \leq 4$ eventos, grupo $2>4$ eventos, b) tipos de eventos adversos de modo que o grupo 1 foi composto por eventos hematológicos e astenia e o grupo 2 demais eventos. Optou-se por essa estratificação, admitindo a hipótese de que, ocorrências como alopecia, descamação da pele, vômitos não estariam diretamente relacionados à composição corporal, embora possam ser consequências indiretas. 
Avaliações antropométricas: a massa corporal foi mensurada através de uma balança digital da marca Wiso ${ }^{\circledR}$, modelo W-721 com precisão de 100 gramas e capacidade de $150 \mathrm{~kg}$. Os indivíduos forma pesados em posição ortostática, estando vestidos com roupas leves e descalços. A estatura será avaliada através de um dispositivo eletrônico que acompanha a balança no qual um sensor infravermelho é colocado no vertex da cabeça do indivíduo e acionado, emitindo um feixe de raios que é recebido por outro dispositivo localizado na base na balança. Os valores da estatura são resultantes da distância entre o sensor localizado na superfície frontal da balança e o dispositivo posicionado sobre o ápice da cabeça do indivíduo. Esta distância é obtida por um método de ultrassom e raios infravermelhos. Os dados produzidos nesta avaliação foram utilizados para o cálculo do Índice de Massa Corporal (IMC) através da fórmula de Quetelet onde a massa corporal é dividida pelo quadrado da estatura, eos resultados classificados de acordo com a World Health Organization (WHO, 2000) apresentado na figura 5.

\begin{tabular}{|ll|}
\hline Valores de IMC & Classificação \\
\hline$<18.5 \mathrm{~kg} / \mathrm{m}^{2}$ & Baixo peso \\
\hline Entre 18.5 e $24.9 \mathrm{~kg} / \mathrm{m}^{2}$ & Eutrófico \\
\hline entre 25 e $29.9 \mathrm{~kg} / \mathrm{m}^{2}$ & Sobrepeso \\
\hline Entre 30 e $39.9 \mathrm{~kg} / \mathrm{m}^{2}$ & Obesidade \\
\hline$>40 \mathrm{~kg} / \mathrm{m}^{2}$ & Obesidade mórbida \\
\hline
\end{tabular}

Figura 5: Classificação do Índice de Massa Corporal segundo a WHO Fonte: WHO (2000).

\section{Medical OutcomesStudy 36 - Item Short-Form Health Survey (SF-36): A} qualidade de vida relacionada à saúde foi mensurada a partir do SF-36. Este é um instrumento genérico de avaliação da qualidade de vida, comumente utilizado em populações clínicas, validado no Brasil por Ciconelli, et al. (1998). Ele é composto por 36 itens que avaliam as seguintes dimensões da qualidade de vida: capacidade funcional; aspectos físicos; dor; estado geral de saúde; vitalidade; aspectos sociais; aspectos emocionais e saúde mental. Para cada uma das oito dimensões obtém-se 
um escore que pode variar entre 0 e 100. Sendo que, quanto maiores os valores obtidos, mais positiva seria a qualidade de vida (Anexo A). Além disso, estes domínios podem ser agrupados em duas variáveis, resumo dos componentes físicos (PCS) e resumos dos componentes mentais (MCS) da saúde. O SF-36 contempla, ainda, uma escala de transição em saúde (Pergunta 2) que mede variações na saúde geral, quando comparado a um ano atrás.

Estratificações dos domínios da qualidade de vida relacionada à saúde: As três variáveis que não alcançaram o ponto médio da escala (valor $=50$ ), limitações por aspectos físico, dor e saúde mental foram agrupados a partir da mediana de cada domínio. Foram criados, então, 3 grupos de análises: a) limitações aspectos físicos baixa e elevada (mediana $=0,00)$, dor reduzida e dor elevada (mediana $=45,00$ ) e pobre saúde mental e saúde mental adequada (mediana $=32,00$ ).

Composição Corporal: foram mensurada através da técnica de absorciometria de dupla energia de raios-XenCORE ${ }^{\mathrm{TM}}$ (DEXA) do marca General Eletric GE healthcare ${ }^{\circledR}$ e modelo Lunar ProdygyPro ${ }^{T M}$ (GE Lunar, Madison, WI) e os dados analisados através do softwares GE Medical Systems Lunar $^{T M}$. Além da densidade mineral óssea este software avalia também, o tecido adiposo e muscular e calcula outros valores derivados o Índice Musculo Esquelético Relativo (RSMI). Dentre os modelos teóricos de análise da composição corporal o aparelho utiliza o conceito molecular de compartimentação do ser humano. Onde são contabilizados os 6 maiores componentes água, lipídeos, proteínas, carboidratos, conteúdo mineral ósseo e não ósseo. Estes podem ser agrupados em 2 componentes: a massa gorda e a massa livre de gordura. A massa gorda massa livre de gordura água, proteínas, carboidratos, conteúdo mineral e não mineral, são os tecidos com atividade metabólica sendo utilizado como índice de referência funcional. Por massa gorda entende-se os depósitos intracelulares de triglicerídeos (SHILLS; SHIKE, 2006).

Apesar de diversos autores indicarem que não há um padrão de percentual de gordura estabelecido (ROSS et al., 2014; KELLY et al., 2009), classificações tem sido propostas a partir de certos critérios como posicionamento de especialistas e revisões sistemáticas, além da associação ao IMC (PADWALL et al., 2016; ROSS et al., 2014; GALLAGHER et al., 2000). No presente estudo adotou-se a proposta de 
Flegalet al. (2009) onde os valores do percentual da massa gorda foram agrupados por idade e comparados ao IMC.

Já o RSMI foi proposto por Baumgartner et al. (1998) representa a massa muscular dos membros, serve como parâmetro para identificação da sarcopenia, tendo a formula a seguir como base para o cálculo:

$\mathrm{RSMI}=($ massa magra dos braços $[\mathrm{kg}]+$ massa magra das pernas $[\mathrm{kg}]) /(\text { altura }[\mathrm{m}])^{2}$

Estratificações das variáveis da composição corporal: o percentual de gordura corporal, percentual de massa livre de gordura o índice músculo esquelético relativo foram estratificados para permitirem uma classificação da amostra. O percentual de gordura foi comparado ao IMC a partir dos pontos de corte propostos por Flegalet al. (2009) para a população norte americana, baseado no National Health andNutritionExaminationSurvey (NHANES). Optou-se por esta classificação, uma vez que, não foram detectados estudos com mulheres ponderados pela idade na população brasileira. As voluntárias foram classificadas a partir da eutrofia, sobrepeso e obesidade. Já o percentual de gordura e o RSMI foram classificados de acordo com os valores de referência propostos por Souza et al. (2013) para mulheres brasileiras. O RSMI e o \%MLG foram classificados como elevado ( $\geq 1 \mathrm{dp}$ acima da média) adequado ou baixos ( $\leq 1 \mathrm{dp}$ abaixo da média).

Tabela 2: Prevalência ponderada do percentual de gordura categorizada por idade e correspondentes percentis do IMC adaptado de Flegalet al. (2009).

\section{Percentagem de gordura corporal}

\begin{tabular}{cccccccc}
\hline Percentis IMC & $<25$ & $25 a<30$ & $30 a<35$ & $35 a<40$ & $40 a<45$ & $45 a<50$ & $\geq 50$ \\
\hline $20-39$ anos & $<19$ & $19 a<21$ & $21 a<23$ & $23 a<27$ & $27 a<34$ & $34 a<42$ & $\geq 42$ \\
$40-59$ anos & $<18$ & $18 a<20$ & $20 a<23$ & $23 a<26$ & $26 a<33$ & $33 a<41$ & $\geq 41$ \\
$60-79$ anos & $<17$ & $17 a<19$ & $19 a<22$ & $22 a<25$ & $25 a<30$ & $30 a<38$ & $\geq 38$ \\
$\geq 80$ & $<18$ & $18 a<19$ & $19 a<22$ & $22 a<24$ & $24 a<29$ & $29 a<38$ & $\geq 38$ \\
\hline
\end{tabular}

Fonte: Flegalet al. (2009).

Sobre o levantamento de dados 9 mulheres responderam ao questionário sf36, 7 responderam ao questionário de dados demográficos, 11 passaram pelas avaliações físicas, e foram localizadas 11 prontuários médico. No entanto, um deles estava completamente vazio, e outros 2 preenchidos de forma precária, não sendo 
possível identificar informações essenciais como protocolo quimioterápico, eventos adversos. Além disso, a maioria dos prontuários não trazia as dosagens das drogas quimioterápicas, o cálculo da área de superfície corporal o qual foram baseadas as prescrições, peso no início do tratamento, além de não descrever com exatidão os eventos adversos a cada retorno.

\subsection{Procedimentos}

Após a aprovação do estudo pelos Comitês de Ética em Pesquisa e da operacionalização da coleta de dados junto às chefias imediatas dos setores oncológicos iniciaram os levantamentos dos possíveis voluntários. A identificação era feita semanalmente alternando as Instituições de saúde, o que resultou num intervalo médio de 20 dias para o retorno a cada uma das 3 instituições autorizadas. Os livros de registros ou fichas de triagem eram fotografados, e arquivados para posterior seleção de dados duplicados, pessoas que haviam sido registrado em duplicidade ou mudado de hospital e ainda par retirada daqueles q ainda não haviam sido atendidos e ainda aguardavam na triagem (figura 6).

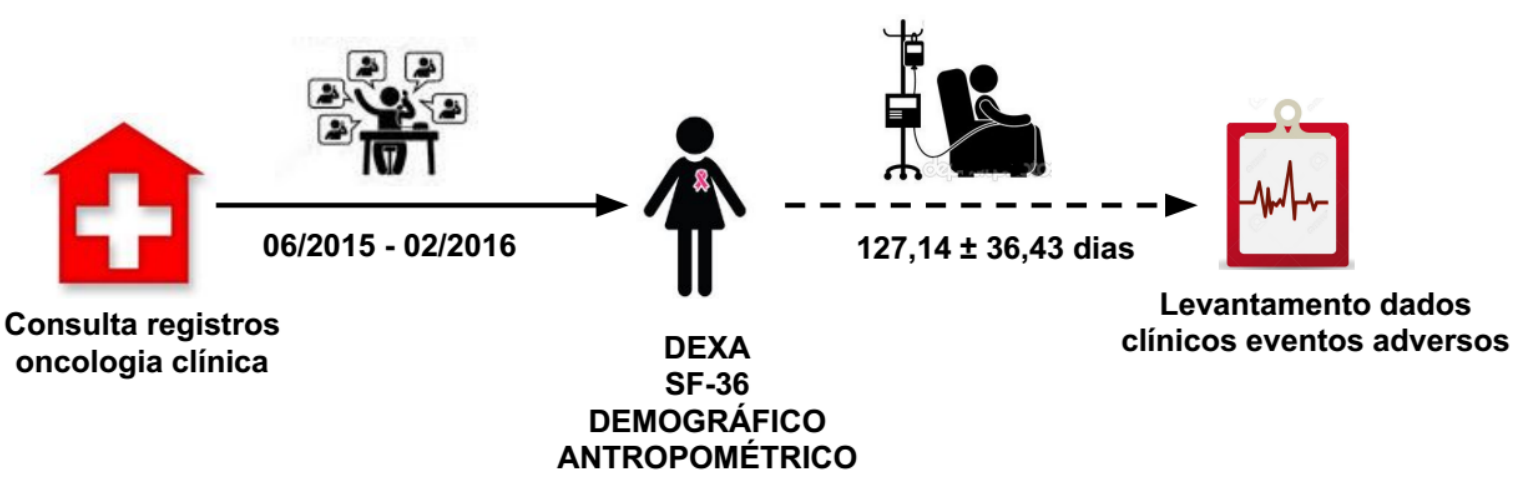

Figura 6: Procedimentos de identificação da amostra e coletas de dados Fonte: próprio autor

Após a tabulação da lista geral, eram identificados os registros de mulheres com diagnóstico de câncer de mama e transferido para outro arquivo. Neste, foram inseridos informações de identificação dos possíveis voluntários, a partir daí, iniciouse o processo de aplicação dos critérios de inclusão/exclusão. 
Àquelas pré-selecionadas foram contatadas por meio de telefone, onde foi explicado o motivo do contato, a forma como a voluntária foi localizada e como a pesquisadora teve acesso aos dados da mesma. Aquelas que assentiram à participação foi oferecido transporte até a Faculdade de Educação Física da UnB, num horário mais adequado à voluntária. Foi explicado que elas deveriam vir de roupa confortável, sem material metálico, que mantivesse uma hidratação adequada no dia anterior e na data do exame, que o consumo de café fosse reduzido. E ainda, que se a pessoa fizesse uso de suplementação de cálcio esse fosse suspenso pelo menos 24 horas antes do exame. Visando a segurança das mulheres foi certificado que as mesmas não haviam ingerido contrastes radiológicos na semana da realização do DEXA.

Até a data da coleta 18 das 21 mulheres que aceitaram foram monitoradas pelo aplicativo móvel whatsapp ${ }^{\circledR}$, o objetivo do contato era lembrar as mulheres das indicações, confirmar as datas, alterar datas, adequar à busca nas casas ou nos locais pré-combinados e tentar remarcação das que não compareceram.

No dia da coleta o primeiro foi reiterado os motivos da pesquisa e solicitado à participante que assinasse o tremo de consentimento livre e esclarecido (Apêndice B). Após foram aplicados os questionários e realizadas as avaliações antropométricas e o exame de composição corporal.

Após a coleta de dados inicias a voluntária passava a ser monitorada a partir dos dados disponíveis nos prontuários médicos. O período médio de acompanhamento das mulheres foi de 127,14 $\pm 36,43$ dias (90 - 172 dias) e 0 número médio de sessões coletadas foi de 6,42 $\pm 2,07$ (4 - 9 ciclos). A coleta em um dos hospitais era realizada online, onde foi conferido ao pesquisador um login de acesso ao sistema de registro e evolução do cliente. Nesta Unidade um prontuário não estava completamente preenchido na forma digital e o formato físico não dispunha de nenhum dado. Nas outras duas unidades havia registros online, porém o pesquisador não possuía acesso. Os prontuários físicos podiam ser consultados no arquivo do hospital, entretanto, estes dispunham de pouco informação. Uma vez que, o profissional médico deveria preencher o formato online e imprimir uma versão e arquivar, o que era infrequente. Um prontuário não foi localizado nem na forma digital nem física. $E$ dois prontuários apresentavam escassas informações sobre 0 tratamento quimioterápico. 
Somente em 4 prontuários haviam as dosagens das drogas prescritas. E somente 5 relatavam a massa corporal, a estatura e a área de superfície corporal ao qual foram realizados os cálculos para prescrição da quimioterapia. Em 5 prontuários houveram desencontros das informações iniciais e finais sobre o número de sessões de quimioterapia e as drogas utilizadas. Não havendo esclarecimentos ou indicações para alterações nos registros médicos.

\subsection{Análises Estatísticas}

As variáveis demográficas, relacionadas aos hábitos de vida, as características clinico patológicas, histológicas e moleculares da doença; além das variáveis associadas ao tratamento e a escala de transição de saúde foram organizadas a partir de estatística descritiva em frequência, percentual, media e desvio-padrão. As variáveis relacionadas á composição corporal inicialmente foram apresentadas em média, desvio-padrão, valores mínimos e máximos.Ocomportamento médio das dimensões da qualidade de vida relacionada à saúde foram plotadas em gráfico e descritas no texto a partir da média e desviopadrão.

A normalidade da amostra foi testada a partir do teste de Shapiro-willk. Utilizou-se o test $t$ de student para amostras independentes para comparação das variáveis da composição corporal massa magra $(\mathrm{kg})$, percentual da massa magra (\%), massa gorda $(\mathrm{kg})$, percentual de massa gorda (\%) e índice músculo esquelético relativo entre os grupos de efeitos colaterais hematológico-musculares e os sem efeito colaterais; e ainda para as classes de limitações por aspectos físicos, dor e saúde mental. A comparação da qualidade de vida relacionada à saúde entre os grupos de efeitos colaterais foi realizada a partir do teste $U$ de Mann- Whitney. A correlação entre as variáveis foi realizada à partir do teste de Spearman. O nível de significância adotado foi $p \leq 0,05$.

\subsection{Aspectos éticos}

O projeto de pesquisa do presente estudo foi aprovado pelo Comitê de Ética em Pesquisa da Faculdade de Ciências da Saúde da Universidade de Brasíliasob o número 083/2013 (Anexo B) e pelo Comitê de Ética em Pesquisa da Fundação de Ensino e Pesquisa da Escola Superior de Ciências da Saúde - FEPECSsob o 
número 186/2012 havendo uma prorrogação no ano de 2014 (Anexo C). Após o recrutamento, explicação sobre os objetivos e procedimentos do estudo os voluntários, antes de serem avaliados através do protocolo de avaliação, foram solicitados a assinarem um Termo de Consentimento Livre e Esclarecido. 


\section{RESULTADOS}

Os dados de caracterização da amostra revelaram que a média de idade da amostra foi de 47,77 $\pm 8,54$ anos. Que a maioria delas era solteira $(36,4 \%)$, com escolaridade inferior a8 anos de educação formal (27,2\%), católicas $(45,4 \%)$ e não possuíam plano de saúde (63,6\%) (tabela 2). Além disso, 2 delas eram aposentadas, 3 exerciam a atividades de faxineira, 1 copeira e 5 delas trabalhavam em casa (tabela 3).

Tabela 3: Características demográficas das mulheres avaliadas

\begin{tabular}{lll}
\hline Estado civil & F & $\%$ \\
\hline Solteira & 4 & 36,4 \\
Casada & 1 & 9,1 \\
Divorciada & 2 & 18,2 \\
Dados não informados & 3 & 27,2 \\
Educação formal & & \\
Inferior a 8 anos de escolarização & 3 & 27,2 \\
8 anos de escolarização completos & 1 & 9,1 \\
11 anos de escolarização completos & 2 & 18,2 \\
Ensino superior & 1 & 9,1 \\
Dados não informados & 4 & 36,4 \\
Religião & & \\
Católica & 5 & 45,4 \\
Evangélica & 5 & 9,1 \\
Espírita & 1 & 9,1 \\
Dados não informados & 1 & 36,4 \\
Possui plano de saúde & 4 & \\
Sim & & 9,1 \\
Não & 1 & 36,4 \\
Dados não informados & 7 & \\
\hline frequencia; =percentua, & 3 & \\
\hline
\end{tabular}

$\mathrm{f}=$ frequência; \% = percentual 
Com relação aos hábitos de vida (tabela 4) apenas duas mulheres afirmaram que praticavam exercícios físicos regulares (18,2\%), quase metade da amostra fazia uso de medicação controlada $(27,2 \%)$ para tratar diabetes, hipertensão arterial, osteoporose e depressão. Nenhuma delas fumava na atualidade, entretanto, 18,2\% informaram que fumavam antes do diagnostico do câncer. Quanto ao consumo de álcool apenas uma voluntária reportou o hábito $(9,1 \%)$, enquanto que duas mulheres afirmaram consumir bebidas alcoólicas antes do diagnóstico (18,2\%).

Tabela 4: Frequência (f) e percentual (\%) dos hábitos de vida das mulheres avaliadas

\begin{tabular}{|c|c|c|}
\hline Prática regular de exercícios físicos & $\mathbf{f}$ & $\%$ \\
\hline Sim & 2 & 18,2 \\
\hline Não & 5 & 45,4 \\
\hline Dados não informados & 4 & 36,4 \\
\hline \multicolumn{3}{|l|}{ Uso de medicação controlada } \\
\hline Sim & 3 & 27,2 \\
\hline Não & 4 & 45,4 \\
\hline Dados não informados & 4 & 36,4 \\
\hline \multicolumn{3}{|l|}{ Hábito fumar } \\
\hline Não & 7 & 63,6 \\
\hline Dados não informados & 4 & 36,4 \\
\hline \multicolumn{3}{|l|}{ Hábito fumar antes do diagnóstico } \\
\hline Sim & 2 & 18,2 \\
\hline Não & 5 & 45,4 \\
\hline Dados não informados & 4 & 36,4 \\
\hline \multicolumn{3}{|l|}{ Hábito consumir bebidas alcoólicas } \\
\hline Sim & 1 & 9,1 \\
\hline Não & 6 & 54,5 \\
\hline Dados não informados & 4 & 36,4 \\
\hline \multicolumn{3}{|c|}{ Hábito consumir bebidas alcoólicas antes do diagnóstico } \\
\hline Sim & 2 & 18,2 \\
\hline Não & 5 & 45,4 \\
\hline Dados não informados & 4 & 36,4 \\
\hline
\end{tabular}

$\mathrm{f}=$ frequência; \% = percentual 
O levantamento dos dados clínicos indicou que as maiorias das mulheres encontravam-se no estado pré-menopausal (54,5\%). Metades destas também se encontravam nas fases iniciais da doença, sendo que $50 \%$ foram classificadas até 0 estágio T2. Sobre o estadio da doença $40 \%$ das mulheres não apresentavam esta informação no prontuário, e18,2\% indicavam diagnóstico de doença avançada, grau IV e III (tabela 5). Seguindo a tendência mundialmente relatada 81,9\% das mulheres apresentaram o diagnóstico histopatológico de carcinoma ductal infiltrante.

Tabela 5: Frequência (f) e percentual (\%) das características clínico patológicas da amostra

\begin{tabular}{lll}
\hline Estado menopausal & $\mathbf{F}$ & $\%$ \\
\hline Pré-menopausa & 6 & 54,5 \\
Pós-menopausa & 5 & 45,5 \\
Classe TNM & & \\
T1N0M0 & 1 & 9,1 \\
T1N0M1 & 1 & 9,1 \\
T2N0MX & 1 & 9,1 \\
T2N0M0 & 1 & 9,1 \\
T2N1M0 & 1 & 9,1 \\
T3NXM0 & 1 & 9,1 \\
T3N1MX & 1 & 9,1 \\
T3N1M0 & 1 & 9,1 \\
T3N3bM0 & 1 & 9,1 \\
Não classificados & 2 & 18,2 \\
Estadio & & 9,2 \\
I & 1 & 9,1 \\
II & 1 & 9,1 \\
IIA & 1 & 9,1 \\
IIB & 2 & 18,2 \\
IIIB & 1 & 9,1 \\
IV & 1 & 9,1 \\
Não estadiado & & \\
Tipo Histológico & & \\
Carcinoma Ductal Infiltrante & & \\
Carcinoma Medular & & \\
\hline & & \\
\hline
\end{tabular}




\begin{tabular}{l}
\hline Não classificado 119,1 \\
\hline $\mathrm{f}=$ frequência; \% = percentual; TNM = classificação Internacional de Tumores; $\mathrm{T}$ = tamanho do tumor; \\
$\mathrm{N}=$ acometimento linfonodal, $\mathrm{M}$ =metástase; $\mathrm{X}=$ não presente ou avaliado.
\end{tabular}

As análises imuno-histoquímicas indicaram que a maioria dos tecidos tumorais analisados possuíasuperexpressão tanto de receptores de membrana do estrogênio $(72,7 \%)$ quanto da progesterona (63,3\%). Foi identificado ainda que 45,4\% apresentavam HER2 positivo (tabela 6). A maioria dos prontuários não trazia a classificação molecular dos tumores, apenas três foram relatados, sendo um deles luminal A e um basal-like ou triplo negativo.

Tabela 6: Frequência (f) e percentual (\%) dos marcadores tumorais da amostra

\begin{tabular}{lll}
\hline Receptores hormonais & $\mathbf{F}$ & $\%$ \\
\hline $\mathrm{RE}+$ & 8 & 72,7 \\
$\mathrm{RE}-$ & 2 & 18,2 \\
Dados não localizadaos & 1 & 9,1 \\
\hline $\mathrm{RP}+$ & 7 & 63,6 \\
$\mathrm{RP}-$ & 3 & 72,2 \\
Dados não localizadaos & 1 & 9,1
\end{tabular}

Expressão proteica tumoral

\begin{tabular}{lll}
\hline HER2 + & 4 & 36,4 \\
HER2- & 5 & 45,4 \\
Dados não localizadaos & 2 & 18,2
\end{tabular}

$\mathrm{RE}_{+}=$receptor de estrogênio positivo; RE- = receptor de estrogênio negativo; RP+ = receptor de progesterona positivo; RP- = receptor de progesterona negativo; HER $2+=$ fator de crescimento epidermalhumano tipo 2 positivo; HER2- =fator de crescimento epidermalhumano tipo 2 negativo.

As informações médicas revelaram que as maiores partes das mulheres estavam em tratamento adjuvante $(54,5 \%)$, sendo que $36,4 \%$ não haviam realizado intervenção cirúrgica, 32,4\% passaram por cirurgias conservadoras e 27,2\% pelo tratamento radical (tabela 6). Das sete mulheres que foram submetidas à cirurgia três haviam realizado mamoplastia oncológica. Em 60\% delas a mama acometida foi à esquerda (tabela 7).

Sobre o tratamento quimioterápico observou-se que $18,2 \%$ fizeram uso do esquema FAC, sendo que uma mulher ele foi associado ao docetaxel. A combinação AC foi utilizada por 6 voluntárias, sendo que em 5 destas houve a combinação com o paclitaxel, 2 ainda utilizaram os anticorpos monoclonais herceptin. 
Dentre os casos avaliados uma voluntária utilizou a combinação $A C+$ Paclitaxel + Carboplatina, que foi prescrito em dose densa. Esta técnica consiste em administrar a dose máxima possível devido à toxicidade com o menor espaço de tempo entre elas, este esquema foi indicado para a voluntária classificada como triplo negativo.

Observou-se, ainda, que uma mulher apresentou metástase óssea num tumor em fase inicial. Esta foi tratada com radioterapia e hormonioterapia, entretanto, após a falha destas terapias e progressão da doença, houve prescrição do esquema AC+Paclitaxel+Pamidronato. Este último é da classe dos bifosfonados drogas utilizadas para tratar a desmineralização óssea. $O$ número total de ciclos avaliados ao final do período de coleta foi de 51 .

Tabela 7: Caracterização do tratamento clínico recebido pelas voluntárias

\begin{tabular}{lll}
\hline Modalidade quimioterápica & $\mathbf{f}$ & $\%$ \\
\hline Neoadjuvante & 4 & 36,4 \\
Adjuvante & 5 & 54,5 \\
Dados não localizados & 2 & 18,2 \\
Tipo de cirurgia & & \\
MRM & 3 & 27,2 \\
Setorectomia & 2 & 18,2 \\
Tumorectomia & 2 & 18,2 \\
Não realizou & 4 & 36,4 \\
Mama operada & & \\
Direito & 6 & 54,5 \\
Esquerda & 4 & 36,4 \\
Dados não localizados & 1 & 9,1 \\
Prescrição quimioterápica & & \\
FAC & 2 & 18,2 \\
FAC+Docetaxel & 1 & 9,1 \\
AC & 1 & 9,1 \\
AC+Paclitaxel & 3 & 27,2 \\
AC+Paclitaxel+Herceptin & 2 & 18,2 \\
AC+ Paclitaxel+ Carboplatina & 1 & 9,1 \\
Dados não localizadaos & 1 & 9,1
\end{tabular}

$\mathrm{FAC}=$ 5-fluorouracil, adriamicina, ciclofosfamida; $\mathrm{AC}$ = adriamicina, ciclofosfamida; 
Os efeitos adversos das drogas antineoplásicas foram observados em todas as voluntárias sendo a maior frequência ocorreu após a quarta sessão (23 eventos). Todas as mulheres avaliadas relataram algum evento adverso ao longo do tratamento (tabela 8).O número de eventos adversos foi correlacionado positivamente ao número de drogas $(r=0,845, p=0,034)$.

Tabela 8: Eventos adversos registrados durante o período de quimioterapia (QT).

\begin{tabular}{lll}
\hline Períodos de Quimioterapia (QT) avaliados & $\mathbf{f}$ & $\%$ \\
\hline Após QT 1 & 7 & 17,5 \\
Após QT 2 & 7 & 17,5 \\
Após QT 3 & 2 & 2,5 \\
Após QT 4 & 16 & 40,0 \\
Após QT 5 & 3 & 7,5 \\
Após QT 6 & 1 & 2,5 \\
Após QT 7 & 1 & 2,5 \\
Após QT 8 & 2 & 5 \\
Total de intercorrências & 39 & 100 \\
\hline
\end{tabular}

$\mathrm{f}=$ frequência; \% =percentual; $\mathrm{QT}$ = quimioterapia.

Somente em 8 prontuários médicos havia a descrição de eventos adversos. A média de eventos foi 5,5 $\pm 3,12$ (2 - 11 ocorrências). Os mais prevalentes foram àalopecia, a náusea, o vômito, a astenia e a neutropenia (tabela 9). Em uma das voluntárias a neutropenia foi classificada como evento adverso à medicamento grave, uma vez que, resultou em internação médica.

Devido á presença de intercorrências medicamentosas houve atrasos entre os ciclos de duas pessoas. Uma terceira cliente sofreu redução na dose de quimioterapia de $10 \%$ no terceiro ciclo. 
Tabela 9: Classe de eventos registrados durante o período de acompanhamento

\begin{tabular}{lcc}
\hline Eventos adversos & f & $\%$ \\
\hline Gerais & 2 & \\
fogachos/atraso menstrual & 1 & 5,4 \\
Cefaleia & 1 & 2,7 \\
mal-estar & & 2,7
\end{tabular}

Cosméticos

Alopecia 6

$6 \quad 16,22$

descamação pele mãos $\quad 1 \quad 2,7$

$\begin{array}{lll}\text { escurecimento das unhas } & 1 & 2,7\end{array}$

Gastrointestinais

Náusea

5

13,5

Vômito

3

8,1

Neuromotores

Astenia

$3 \quad 8,1$

Parestesia

$1 \quad 2,7$

dor óssea

2

5,4

Neuropatia

2

5,4

Vertigem

1

2,7

\section{Comportamentais}

Insônia

$2 \quad 5,4$

Lipotimia

$1 \quad 2,7$

Depressão

12,7

Hiporexia

1

2,7

Hematológicos

Neutropenia

3

8,1

Total

$\mathrm{f}=$ frequência; \% =percentual

Os dados relativos à composição corporal indicaram em média a população estudada foi classificada como sobrepesada de acordo com o IMC (28,08 $\pm 4,48$ $\mathrm{Kg} / \mathrm{m}^{2}$ ). Uma análise por classes identificou-se que $27,3 \%$ das mulheres eram 
eutróficas, 36,4\% com sobrepeso e 36,4\% acometidas pela obesidade. Este quadro torna-se ainda mais inapropriado quando analisado o percentual de massa gorda. Seguindo a classificação de Flegalet al. (2009) somente 27,3\% apresentaram níveis de gordura considerados adequados, em $9,1 \%$ o percentual de gordura classificavaos com sobrepeso e $63,3 \%$ com obesidade.

A partir dos valores de referência propostos por Souza et al., (2013) 18,2\% (2) das mulheres apresentavam quantidades insuficientes de massa livre de gordura (Kg), 45,4\% (5) possuíam apresentavam valores adequados e ainda 36,36\% (4) estariam acima dos valores médios populacionais. Seguindo a tendência anterior a classificação do RSMI 18,2\% (2) das mulheres foram classificadas com insuficientes, $36,36 \%$ (4) como adequado e 45,4\% (5) como superiores aos valores médios (tabela 9).

Não foi possível realizar um estudo da variabilidade da massa corporal ao longo do tratamento, uma vez que, os dados de massa corporal não foram evoluídos na maioria dos prontuários.

Tabela 9: Valores médios das variáveis relacionadas à composição corporal

\begin{tabular}{llll}
\hline Variáveis & Media \pm DP & Min- Max & Amplitude \\
\hline Massa Corporal (kg) & $68,52 \pm 9,77$ & $53,8-80,8$ & 27 \\
Estatura (cm) & $156,4 \pm 7,99$ & $144,5-170$ & 25,5 \\
IMC (Kg/m²) & $28,08 \pm 4,48$ & $21,2-35,3$ & 14,1 \\
Massa Livre de Gordura (Kg) & $37,21 \pm 4,64$ & $27,73-43,73$ & 16 \\
\%Massa Livre de Gordura & $54,5 \pm 4,6$ & $45,7-61,4$ & 15,7 \\
Massa Gorda & $29,1 \pm 6,99$ & $18,96-39,98$ & 21,02 \\
\% Massa Gorda & $43,53 \pm 4,95$ & $36-52,8$ & 16,8 \\
RSMI & $6.68 \pm 0,92$ & $5,71-8,29$ & 2,58
\end{tabular}

$\mathrm{DP}=$ desvio-padrão; $\mathrm{Kg}$ = quilogramas; $\mathrm{cm}$ = centímetros; $\mathrm{Kg} / \mathrm{m}^{2}$ = quilogramas por metro ao quadrado; $\%$ = percentual; RSMI - índice Músculo Esquelético Relativo.

Não foram identificadas correlações estatisticamente significantes entre os dados clínicos, a toxicidade geral do tratamento e as variáveis da composição corporal. Entretanto, ao estratificar a amostra por tipos de efeitos colaterais, detectouse diferença significativa entre os grupos. A massa corporal $(\boldsymbol{\Delta}=-12,9, p=0,047)$, a massa gorda $(\boldsymbol{\Delta}=-10,8, p=0,014)$ e o percentual de massa gorda $(\boldsymbol{\Delta}=-6,37$ $p=0,029)$ foram reduzidos no grupo que apresentou efeitos colaterais hematológicos 
e motores. Inversamente, este grupo possuía um maior percentual de massa livre de gordura $(\Delta=5,85 p=0,015)$.

Tabela 11: Valores médios da composição corporal associados aos efeitos colaterais da quimioterapia

\begin{tabular}{lccc}
\hline Composição corporal & $\begin{array}{c}\text { Efeitos hematológico- } \\
\text { motores }\end{array}$ & Outros efeitos & \\
& Média \pm DP & Média \pm DP & p \\
\hline Massa Corporal (kg) & $64,40 \pm 8,37$ & $77,3 \pm 3,36$ & 0,047 \\
Estatura (cm) & $158,8 \pm 9,75$ & $157,6 \pm 4,16$ & 0,858 \\
IMC $\left(\mathbf{K g} / \mathbf{m}^{2}\right)$ & $25,60 \pm 4,19$ & $31.17 \pm 2,27$ & 0,083 \\
Massa Livre de Gordura $\mathbf{( K g )}$ & $36,89 \pm 4,04$ & $41,15 \pm 2,29$ & 0,153 \\
\%Massa Livre de Gordura & $57,68 \pm 3,37$ & $51,83 \pm 1,06$ & 0,015 \\
Massa Gorda & $24,81 \pm 6,99$ & $35,61 \pm 1,33$ & 0,014 \\
\% Massa Gorda & $40,06 \pm 3,64$ & $46,43 \pm 1,3$ & 0,029 \\
RSMI & $6,37 \pm 1,09$ & $7,56 \pm 0,3$ & 0,123
\end{tabular}

$\mathrm{DP}=$ desvio-padrão; $\mathrm{Kg}$ = quilogramas; $\mathrm{cm}$ = centímetros; $\mathrm{Kg} / \mathrm{m}^{2}=$ quilogramas por metro ao quadrado; $\%$ = percentual; RSMI - índice Músculo Esquelético Relativo; $p=$ nível de significância.

As análises correlacionais confirmaram os resultados anteriores. Na tabela 12 observou-se que os efeitos motores apresentaram uma coocorrência negativa com a massa corporal, a massa gorda e o percentual da massa gorda; e positiva com o percentual de massa livre de gordura.

Tabela 12: Correlações e níveis de significância entre eventos indesejados e a composição corporal

\begin{tabular}{lccc}
\hline & Sintomas motores & neutropenia & HER 2+ \\
\hline Massa Corporal (kg) & $0,732^{\star}$ & -0.504 & $0,779^{*}$ \\
\%MLG & 0,039 & 0,203 & 0,013 \\
& $-0,845^{\star}$ & 0,504 & 0,550 \\
MG & 0,008 & 0,203 & 0,125 \\
& $0,845^{\star}$ & 0,504 & 0,433 \\
\% MG & 0,008 & 0,203 & 0,244 \\
& $0.845^{\star}$ & 0,378 & 0,520 \\
RSMI & 0.008 & 0,356 & 0,152 \\
& $-0,507$ & $-0,745^{\star}$ & 0,346 \\
\hline
\end{tabular}


$\mathrm{Kg}=$ quilogramas; \% = percentual; MLG = Massa Livre de Gordura; MG = Massa Gorda; RSMI índice Músculo Esquelético Relativo; HER2+ = =fator de crescimento epidermalhumano tipo 2 negativo.

Estes achados indicam que pessoas com outros efeitos colaterais como vômitos, náuseas, insônia e fogachos/atrasos menstruais seriam aquelas com maior massa corporal e maior massa gorda e percentual de massa gorda. E aquelas com efeitos neutropênicos e motores teriam maior percentual de massa magra, maior índice músculo esquelético relativo e menor massa gorda. Como as correlações não estabelecem sentido causal, as análises acima podem ser consideradas em sentido retrógrado.

A avaliação subjetiva do estado de saúde iniciou-se com a escala de transição em saúde (questão 2) que mede variações na saúde geral, quando comparado a um ano atrás. Os resultados indicaram que metades das mulheres avaliadas consideraram sua saúde boa, permanecendo quase a mesma quando comparada ao ano anterior.

Tabela 13: Percepção da transição subjetiva sobre a saúde Comparada a um ano atrás, como você se classificaria sua idade em geral, agora?

\begin{tabular}{lccccc}
\hline & $\begin{array}{c}\text { Muito } \\
\text { Melhor }\end{array}$ & $\begin{array}{c}\text { Um pouco } \\
\text { Melhor }\end{array}$ & $\begin{array}{c}\text { Quase a } \\
\text { mesma }\end{array}$ & $\begin{array}{c}\text { Um pouco } \\
\text { pior }\end{array}$ & Muito Pior \\
\hline$f(\%)$ & $1(10 \%)$ & $1(10 \%)$ & $5(50 \%)$ & $2(20 \%)$ & - \\
\hline
\end{tabular}

$\mathrm{f}=$ frequência; \% =percentual

Os resultados dos domínios da qualidade de vida relacionada à saúde (figura 7) revelaram que a capacidade funcional foi o aspecto com maior escore referido (72 $\pm 18,13)$. As facetas estado de saúde geral $(53,5 \pm 14,35)$, vitalidade $(51,50 \pm 12,92)$, limitações por aspectos sociais $(57,5 \pm 17,87)$, limitações por aspectos emocionais $(53,3 \pm 44,99)$, alcançaram o ponto médio da escala. Por outro lado, os limitações por aspectos físicos $(37,5 \pm 48,94)$, a dor $(39 \pm 23,31)$ e a saúde mental $(32 \pm 7,54)$ apresentaram os menores valores.

As escalas acima foram agrupadas em duas variáveis, o componente físico e componente mental da saúde. A ponderação final destes dois itens permaneceu abaixo do ponto médio da escala (pcs $=42,24 \pm 6,69$; $\mathrm{mcs}=38,25 \pm 8,1$ ). 


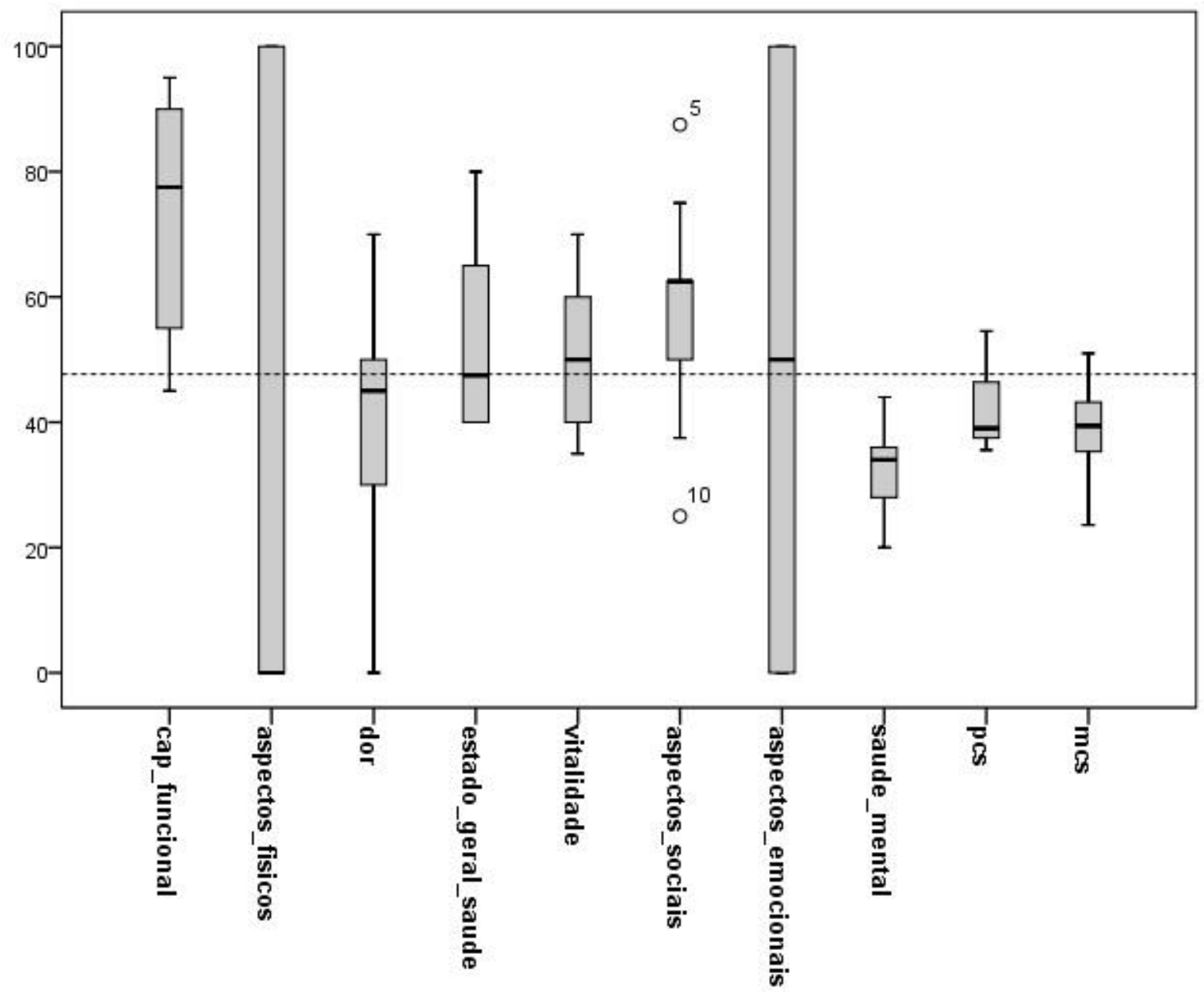

Figura 7: Descrição da Qualidade de vida relacionada à saúde

pcs = resumo dos componentes físicos; mcs = resumo dos componentes mentais.

Fonte: próprio autor

As análises das classes saúde mental não revelaram diferença estatisticamente significante entre as variáveis da composição corporal. Em contrapartida as análises entre os grupos de elevada e baixa dor, e entre os grupos com baixa e elevada limitações por aspectos físicos salientaram diferenças entre as variáveis da composição corporal.

Foi observado que na auto avaliação da dor aqueles que relataram quadros negativos apresentaram maior massa corporal, IMC, massa gorda e percentual de massa gorda; e ainda menor massa livre de gordura (tabela 14). Apesar de não ter apresentado diferença estatisticamente significante o índice músculo esquelético relativo apresentou efeito clinico considerado elevado entre os grupos, sendo maior naqueles com menor dor. 
Tabela 14: Comparação dos valores médios da composição corporal entre os grupos com maior ou menor dor

\begin{tabular}{lccc}
\hline Composição corporal & >dor & $<$ dor & \\
\hline & Média \pm DP & Média \pm DP & p \\
\hline Massa Corporal (kg) & $75,24 \pm 7,29$ & $64,72 \pm 7,59$ & 0,049 \\
IMC $\left(\right.$ Kgm $\left.^{2}\right)$ & $31,68 \pm 3,58$ & $24,94 \pm 2,75$ & 0,010 \\
MLG $(\mathbf{K g})$ & $38,36 \pm 3,38$ & $37,94 \pm 4,19$ & 0,856 \\
\%MLG & $51,36 \pm 3,5$ & $58,1 \pm 3,31$ & 0,014 \\
Massa Gorda & $33,92 \pm 5,08$ & $39,62 \pm 3,52$ & 0,050 \\
$\%$ MG & $46,92 \pm 3,70$ & $39,62 \pm 3,52$ & 0,013 \\
RSMI & $6,37 \pm 1,09$ & $7,56 \pm 0,3$ & 0,161
\end{tabular}

$\mathrm{DP}=$ desvio-padrão; $\mathrm{Kg}$ = quilogramas; $\mathrm{Kg} / \mathrm{m}^{2}$ = quilogramas por metro ao quadrado; \% = percentual; $M L G=$ Massa Livre de Gordura; $M G$ = Massa Gorda; RSMI =Índice Músculo Esquelético Relativo; $p=$ nível de significância.

Com relação aos grupos de limitações por aspectos físicos detectou-se que aqueles que apresentavam maiores limitações por aspectos físicos apresentavam menor quantidade de massa livre de gordura maior quantidade de massa gorda e percentual de gordura.

Tabela 15: Comparação dos valores médios da composição corporal entre os grupos com maior ou menor dor

\begin{tabular}{lccc}
\hline Composição corporal & $\begin{array}{c}\text { > limitações } \\
\text { aspectos físicos }\end{array}$ & $\begin{array}{c}\text { < limitações } \\
\text { aspectos físicos }\end{array}$ & \\
\hline Massa Corporal (kg) & Média \pm DP & Média \pm DP & p \\
IMC (K/gm $\left.{ }^{2}\right)$ & $73,27 \pm 7,44$ & $67,78 \pm 9,81$ & 0,372 \\
MLG (Kg) & $30,62 \pm 4,3$ & $26,77 \pm 4,56$ & 0,217 \\
\%MLG & $38,23 \pm 4,28$ & $38,10 \pm 3,5$ & 0,962 \\
Massa Gorda & $51,2 \pm 3,79$ & $57,08 \pm 4,01$ & 0,049 \\
\% MG & $34,13 \pm 5,67$ & $26,66 \pm 6,74$ & 0,107 \\
RSMI & $47,02 \pm 4,02$ & $40,77 \pm 4,36$ & 0,05 \\
& $7,05 \pm 0,86$ & $6,56 \pm 1,01$ & 0,452
\end{tabular}

$\mathrm{DP}=$ desvio-padrão; $\mathrm{Kg}=$ quilogramas; $\mathrm{Kg} / \mathrm{m}^{2}=$ quilogramas por metro ao quadrado; $\%=$ percentual; $M L G$ = Massa Livre de Gordura; $M G$ = Massa Gorda; RSMI =Índice Músculo Esquelético Relativo; $p=$ nível de significância.

\section{DISCUSSÃO}




\subsection{Associação e correlação entre as variáveis clínicas, histopatológicas com a qualidade de vida relacionada à saúde e com as variáveis da composição corporal.}

Não foram detectadas associações e correlações entre as variáveis histopatológicas e clínicas com a QVRS ou as variáveis da composição corporal. Uma das possíveis explicações para este dado estaria no tamanho amostral reduzido e na qualidade precária das informações contidas nos prontuários. A heterogeneidade das características clínicas, como estadio da doença, modalidades terapêuticas e esquemas quimioterápicos; bem como a falta de prontuários podem ter diluído o efeito estatístico no presente estudo.

O resultado mais expressivo detectado no que se refere às características clínicas da doença surgiram da estratificação da amostra a partir dos eventos adversos. Onde se verificou que as mulheres que apresentavam efeitos hematológicos e/ou neuromusculares ao longo do tratamento quimioterápico possuíam menor massa corporal, maior percentual de massa livre de gordura, menor massa gorda e menor percentual de massa gorda no início do tratamento. As análises correlacionais, também, reforçaram esses resultados.

Estes achados estão de acordo com outro estudo onde foi detectado maior incidência de eventos graves hematológicos ou musculares na população com eutrófica ou com massa livre de gordura adequada (GOUERANT et al, 2013; PRADO et al., 2007).

Em contraposição o estudo de Prado et al. (2011) encontraram uma associação inversa ao do presente estudo. Entretanto, a medida utilizada para avaliar a massa livre de gordura foi tomografia computadorizada e a unidade de medida foi 0 cálculo da massa muscular a partir do corte realizado na região lombar. Apesar de esse ter sido um estudo de grande impacto, por avaliar a farmacocinética da doxorrubicina a hipótese da correlação da massa magra com o ponto mais baixo da contagem de neutrófilos apresentou uma correlação moderada $(r=0,05, p=0,023)$, não foram encontrados valores preditivos entre essas variáveis nas regressões realizadas. Não se identificou trabalhos posteriores destes autores que retestassem essa correlação. 
Contudo o estudo de Wong et al. (2014) que também utilizou a tomografia para calcular o volume muscular total $\left(\mathrm{cm}^{3}\right)$ avaliado a partir da terceira vértebra lombar não foi preditor de neutropenia ou leucopenia de grau 4 induzido pela doxorrubicina. No entanto, aquelas que apresentaram neutropenia de grau 4, apresentaram massa muscular total estatisticamente maior $\left(76.1-19.1 \mathrm{~cm}^{3}\right)$ quando comparadas às que apresentaram neutropenia de grau $3(52.6$ - 17.5, p =0,05). Uma possível discussão realizada pelos autores considerou que a doxorrubicina seria uma droga com características hidrofílicas, sendo distribuída rapidamente para os tecidos altamente perfundidos como pulmões, fígado e tecido muscular, havendo uma mínima distribuição para o tecido adiposo. Logo, àquelas pessoas com maior massa muscular e menor massa gorda teriam uma ação da droga ampliada. Conduzindo a uma maior mielossupressão e citotoxidade muscular, o que poderiam explicar os efeitos motores e hematológicas detectados no presente estudo.

Entretanto, Barpe, Rosa, Froelich(2010) demonstra outro lado da relação lipofilia/hidrofilia das drogas antineoplásicas. Em seu estudo mulheres diagnosticadas com câncer de mama e sobrepeso, a concentração plasmática de doxorrubicina estaria reduzida, pessoas com baixa massa gorda teriam maior volume de distribuição da droga Sugerindo que a lipofilia da doxorrubicina poderia interferir na sua biodisponibilidade e eficiência. Esta teoria é suportada por outros estudos que não detectam efeitos colaterais em pessoas com obesidade, sugerindo que 0 excesso de gordura corporal conferiria alguma "proteção" aos indivíduos, por armazenar a droga no tecido adiposo, reduzindo dessa forma sua ação nos outros tecidos (SPARREBOOM et al., 2007; WONG et al., 2006). O raciocínio inverso, então, explicaria a elevada taxa de eventos adversos naqueles com baixa massa gorda. Onde as pessoas com elevada massa livre de gordura e baixa massa gorda, estariam expostas à toxicidade real do fármaco, enquanto que, aquelas com excesso de tecido gordo estariam sendo protegidas dos efeitos colaterais imediatos.

A maioria dos trabalhos que analisaram a relação entre a composição corporal e os efeitos adversos dos esquemas quimioterápicos em mulheres com câncer de mama utilizou o IMC ou a massa corporal como parâmetro (IWASE et al., 2016; ARPINOet al., 2015; CARROL et al., 2014; JAIN et al., 2013; CHAN et al. 2012; CARROL et al., 2012; CHEN et al., 2012; KIM et al., 2011; JENKINS et al., 2007: GRIGGS et al., 2005; POIKONNEM; BLOMQVIST; JOENSUU, 2001; ROSNER et al., 1996), o que impossibilita a comparação direta. Entretanto um número relevantes 
destes identificou associação positiva ou maior risco de ocorrência de efeitos adversos em pessoas classificadas como IMC $\leq 30$ e eutróficas (IWASE et al., 2016; CARROL et al., 2014; POIKONNEM; BLOMQVIST; JOENSUU, 2001; CHAN et al. 2012; CARROL et al., 2012; CHEN et al, 2012; KIM et al., 2011; JENKINS et al., 2007; ROSNER et al., 1996).

O estudo de Azambuja et al. (2010) com uma amostra expressiva de mulheres $(n=2.887)$, não identificaram qualquer diferença entre àquelas com obesidade e sem obesidade e o aparecimento de febre neutropenil, distúrbios neurossensoriais, trombocitopenia ou anemia.

Apesar de haver teorias que correlacionam a afinidades das drogas antineoplásicas ao tecido adiposo ou ao tecido magro (PRADO et al., 2011; PRADO, et al., 2007; SPARREBOOM et al., 2007; GURNEYet al., 1998). Estas, geralmente avaliam uma droga específica, e são dependentes de diversos outros fatores que podem alterar a farmacocinética das substâncias antineoplásicas, além de extremamente controversas. Deve ser mencionado, ainda, que alterações na composição corporal estão associadas às alterações fisiológicas como débito cardíaco, variação do fluxo sanguíneo renal e hepático, da taxa de filtração glomerular, e que também podem influenciar na farmacocinética da quimioterapia (PRADO et al., 2013).

Indo além das questões farmacológicas estudos que tratam das alterações metabólicas e inflamatórias resultantes do estado nutricional tem lançado teorias apoiados no entendimento da Interleucina-6 (IL-6) que explicariam por que a elevada massa magra não conferiu um efeito protetor sobre as mulheres do presente estudo.

A IL-6 é uma citocina biologicamente ativa envolvida em respostas inflamatórias agudas e que também é secretada pelo tecido adiposo e muscular, na ausência de inflamação, para modificar o metabolismo (YUEN et al., 2009). Presumivelmente, devido ao maior conhecimento da sua função inflamatória e da associação ao tecido adiposo, os estudos de câncer tem sua atenção concentrada nas interações negativas entre a IL-6 e o câncer de mama como risco, pior prognóstico, presença de efeitos adversos dentre outros (SIMONEet al., 2016; BABAEl et al., 2016; CHAN; NORAT, 2015; ELSEA et al., 2015; KHAN et al., 2013; SIMPSON; BROWN, 2013; PAREKH; CHANDRAN; BANDERA, 2012; BROWN; SIMPSON, 2012; MACCIÒ; MADEDDU; MANTOVANI, 2009; SLATERRY et al., 2008). 
O estudo do tecido adiposo como tecido secretor ganhou destaque nos últimos 20 anos, e uma nova vertente busca compreender o tecido muscular a partir da mesma perspectiva.

Apoiado nas evidências de que o exercício físico produz efeitos protetores sobre a saúde, previne doenças crônicas; alguns autores tentam identificar mecanismos contrabalanceadores e atenuantes do tecido muscular sobre as ações pro-inflamatórias e metabólicas do tecido adiposo e a IL-6 liberada pelo músculo (IL6LM) surge como uma citocina muscular de interesse (ELSEA et al., 2015; PEDERSEN; FEBBRAIO, 2012; PEDERSENet al., 2003; FEBRAIO; PEDERSEN, 2002; YUEN et al, 2009).

A IL6-LM, possivelmente, seria liberada por mioblastos e miotubos não apresentaria um efeito inflamatório, mas sim anti-inflamatório e hormonal (PEDERSEN et al., 2003). Essa conjectura surgiu a partir da observação que o gene do IL-6 seria ativado pelo trabalho muscular, bem como a concentração plasmática do IL-6 sem a presença de outros fatores inflamatórios indutores da IL-6 (exemplo: IL-1 e TNF-a) (PODBREGAR et al., 2013; FEBRAIO; PEDERSEN, 2002). Os possíveis mecanismos de atuação da IL6-LM seriam: a) favorecimento da função endotelial, b) favorecimento da sensibilidade muscular à glicose, á própria IL-6 pelo músculo. c) oxidação de ácidos graxos intramuscular, d) favorecimento da lipólise, dentre outros (PEDERSEN; FEBBRAIO, 2012).

Entretanto, o efeito benéfico da massa livre gordura somente adviria da musculatura ativa (FEBRAIO, PEDERSEN, 2002). Contudo, no presente estudo cerca de $70 \%$ da amostra afirmaram que não realizavam nenhuma forma sistematizada de exercícios físicos. Logo, apesar de possuírem uma massa livre de gordura adequada, esta, não conferiria a proteção advinda da atividade metabólica contrátil, ou dos chamados fatores induzidos pela contração ou fatores de trabalho.

A partir de um mecanismo análogo à resistência à insulina Pedersen (2003) hipotetiza que o desuso muscular levaria à dificuldade de absorção da IL-6 pelos músculos o que elevaria sua concentração plasmática. A IL-6 plasmática poderia induzir ao aumento do TNF-a, outra citocina inibida pelo exercício físico e que, na sua ausência, teriam níveis plasmáticos elevados (YUEN et al, 2009). Essas duas substâncias além de estarem relacionadas à imunidade e a oncogênese também participam na indução da febre, o que as tornam citocinas de interesse para justificar 
os aparecimentos dos eventos musculoesqueléticos e da neutropenia febril nas voluntárias.

Enfim, diversas cascatas imunohistoquimicas poderiam estar desreguladas na musculatura devido à presença das células tumorais no organismo, e do tratamento quimioterápico. Sendo que, os achados do presente estudo, sugerem que nem sempre a quantidade, mas talvez, a qualidade muscular possa estar mais associada ao efeito protetor da massa muscular ao longo do tratamento quimioterápico.

\subsection{Associação da qualidade de vida relacionada à saúde com as variáveis da composição corporal e os eventos adversos.}

No presente estudo optou-se pela avaliação da saúde não somente a partir de medidas objetivas como a MLG, MG, massa corporal, ausência ou presença de efeitos colaterais, mas também a partir da auto percepção do indivíduo sobre sua saúde; apoiada na ideia de que o próprio sujeito pode fornecer informações valiosas sobre seu estado de saúde.

A escala transição em saúde revelou que a maioria das mulheres iniciou o tratamento quimioterápico com um padrão de saúde próximo ao período anterior ao diagnóstico da doença.

Como as mulheres foram avaliadas no início do tratamento quimioterápico, 4 destas não haviam sido submetidas à cirurgia, e outras 04 de um total de 07, haviam sido submetidas á cirurgia conservadoras com reconstrução imediata, elas poderiam sentir-se bem, por haver a extirpação do tumor e por ainda não sofrerem prejuízos graves à saúde das terapias combinadas. Em nenhum prontuário foi identificado intercorrências durante ou após o tratamento cirúrgico. Este cenário pode ter contribuído para o julgamento positivo da própria saúde.

A única voluntária que arbitrou sua saúde como muito melhor, quando comparada ao ano anterior, relatou graves problemas de saúde num período anterior ao diagnóstico de câncer de mama, e que colaborou para a descoberta do mesmo; motivo pelo qual considerava sua saúde muito melhor no momento atual.

Estas avaliações positivas em pessoas na fase inicial de quimioterapia foram relatadas por Van Der Klootet al. (2016) estes autores referiram-se o sentimento de 
estar sendo cuidado e protegido como o principal motivo paraas avaliações positivas na saúde, conceito chamado de rede de segurança médica.

Diante da delonga no atendimento oncológico registrado por diversos meios de comunicação de pelo próprio governo brasileiro (BRASIL, 2014), onde as taxas de início do tratamento em um prazo inferior a 60 dias após o diagnóstico não atingem $50 \%$ das clientes. Sendo que, naquelas encaminhadas aos centros de altacomplexidade advindas de outros centros de saúde, não atingido 35\%. Deste modo, hipotetisa-se que conseguir acesso ao tratamento parece conferir segurança psicológica às mulheres para avaliação positiva em saúde.

Os domínios da qualidade de vida relacionado à saúde que já se apresentavam reduzidos no momento da avaliação foram à dor, a saúde mental e as limitações por aspectos físicos. O que provavelmente contribuíram para os valores abaixo do ponto médio da escala dos aspectos físicos (pcs) e mentais (mcs) resumidos.

A redução dos escores nos aspectos físicos e da dor foram relatados por diversos estudos com mulheres diagnosticadas com câncer no Brasil (CASTRO FILHA et al., 2016; MENDESet al., 2014; PACHIONI, FREGONESI, MANTOVANI, 2014; SIMEÃO et al., 2013; KLUTHCOVSKYet al., 2012; VELLOSOet al., 2011; TOLENTINO et al., 2010; VEIGA et al., 2010; CONDE et al., 2005). Entretanto, nestes estudos as mulheres estavam em fase de acompanhamento da doença após o final do tratamento ativo. A redução na saúde mental não foi confirmada pelos estudos citados anteriormente.

Encontraram-se apenas três estudos que avaliaram qualidade de vida de mulheres no momento do tratamento quimioterápico com mulheres brasileiras (LÔBO et al., 2014;FREZEL PASTORE, GONZÁLES, 2013; FREITAS-SILVA et al., 2010). Infelizmente os questionários utilizados pelos estudos de Lôboet al., (2014) e Frezel, Pastore, Gonzáles (2013) para a mensuração da qualidade de vida não permitiram a comparação direta de todos os resultados. No estudo de Lôboet al. (2014) as mensurações da dor e dos aspectos físicos, a partir dos questionáriosEuropeanOrganization for ResearchandTreatmentofCancer 30-Item Qualityof Life Questionnaire(EORTC QLQ-C30) e Qualityof Life QuestionnaireBreastCancer- 23 (QLQ-BR23) não foram notadas reduções nos aspectos físicos nem avaliação desfavorável da dor durante o período de tratamento quimioterápico. No estudo de Frezel, Pastore, Gonzáles (2013) que acessou a 
qualidade de Vidaà partir do Briefversionofthelnstrument for AssessmentoftheQualityof Life ofthe World Health Organization (WHOQOL-bref) os resultados indicaram menores escores de qualidade de vida no domínio físico no primeiro ciclo de quimioterapia. Freitas-Silva et al.(2010) também identificaram reduções nas limitações por aspectos físicos e na dor em mulheres no período logo após a cirurgia da mama, não havendo diferença na qualidade de vida entre os tipos de cirurgias realizado, corroborando com os dados do presente estudo. Os autores não conduziram maiores explicações para seus achados, apenas relataram que após a cirurgia as mulheres apresentariam reduções nas atividades diárias.

Os decréscimos na qualidade de vida é um aspecto desfavorável para mulheres que iniciam as terapias sistêmicas. Alguns autores afirmam que a baixa qualidade de vida prediria negativamente a sobrevida livre da doença e a sobrevida total em mulheres tratadas de câncer (WIDSCHWENDTERet al., 2015; DE AGUIAR; BERGMANN; MATTOS, 2014; GROENVOLD et al., 2007; GANZ et al., 2002). Quitenet al., (2013) constataram um aumento no risco de morte em mulheresdiagnosticadas com câncer de mama que apresentaramreduções no aspectos físicos $(1,13(1,05-1,22 p=0,02))$ e elevada dor $(1,17(1.06-1,28 p=$ 0,018)).

Schwentneret al. (2016) chamam a atenção para perdas progressivas nos aspectos físicos em mulheres tratadas de câncer de mama, a partir do início da quimioterapia, ocorrendo até o final da radioterapia. Bloom et al. (2012) relataram reduções no funcionamento físico até 10 anos após o final do tratamento indicando que este pode ser um quadro irreversível caso intervenções assertivas não sejam implementadas.

Costa-Requena, Rodriguez e Fernandez-Ortega (2013) afirmam que apenas o diagnóstico de câncer de mama já atinge a saúde metal de mulheres, e que o início das terapias provoca um declínio em todos os aspectos da qualidade de vida, sendo as perdas mais pronunciadas na função física. Os autores relatam ainda, que o distresse psicológico o maior preditor das perdas na qualidade de vida, achado também confirmado por Kaminskaet al. (2015). O impacto do diagnóstico, o medo da doença, da morte, das terapias, o afastamento das atividades sociais, laborais, a dor, a demora no atendimento, a incerteza sobre o acesso às terapias e todo o estigma que acompanha o câncer são aspectos que tendem a interferir negativamente na vida, e na avaliação subjetiva das mulheres diagnosticadas. 
Não foram detectadas correlações estatisticamente significantes entre as variáveis clinica ou histopatológicas e os domínios que se apresentaram reduzidos na população estudada não sendo possível ratificar esta hipótese, apesar da plausibilidade.

Apenas a neutropenia foi correlacionada ao estado de geral. Ou seja, àqueles que apresentaram neutropenia possuíam escores mais baixos de estado geral de saúde no início do tratamento. O termo neutropenia refere-se a uma desordem hematológica, que afeta o sistema imune, onde o indivíduo apresenta uma contagem de neutrófilos inferior a $1500 \mathrm{~mm}^{3}$ (LEE et al., 2014a). A febre neutropênica é um efeito adverso previsto por muitas drogas antineoplásicas caracterizada pela contagem absoluta de neutrófilo $<1000 / \mathrm{mm}^{3}$ acompanhado de um evento febril $>38.3^{\circ}$ ou a manutenção da temperatura $>38^{\circ}$ graus por mais de uma hora (FREIFELDet al., 2011). O grande problema da contagem de neutrófilos reduzida é o elevado risco de infecção, condição altamente indesejada durante o tratamento quimioterápico, uma vez que, a mielossupressão é um dos principais efeitos de muitas drogas antineoplásicas. Logo, o corpo não teria a habilidade de proteger-se. Tornando assim, o risco de morte maior, naqueles que desenvolvem essa condição. Atualmente a neutropenia é prevenida de forma empírica, a partir do aconselhamento para que o indivíduo tenha alimentação adequada (relato no prontuário), evite exposição a possíveis ambientes de contaminação por vírus e bactérias (relato dos clientes). Sendo que, as intervenções só ocorrem a partir da manifestação da condição (BRASIL, 2015). Além disso, pessoas que apresentam o quadro de neutropenia tendem a ter reduções nas doses de quimioterapia o que influencia na eficácia do tratamento (CHEN et al., 2012).

A associação detectada no presente estudo entre estado de saúde geral auto relatado e a manifestação da neutropenia poderia servir como indicador para maior atenção ou delimitar grupo de risco à neutropenia nas populações com câncer. Apesar dos pontos de cortes estabelecidos por exames hematológicos e sintomas clínicos relatados nas consultas (SMITH et al., 2015). Os dados fornecidos pelo sf-36 forneceriam um valor de referência e de acompanhamento. Além de permitir futuras comparações e estratificações a partir do qual, medidas interventivas seriam necessárias para prevenir a neutropenia. Nas questões que inferem sobre o estado de saúde geral (questões 1 e 11a, b, c e d do SF-36) as mulheres são levadas a mensurar sua saúde e compará-la a outras pessoas, e ainda valorar positivamente e 
negativamente sua saúde. O estudo de Lee et al.(2014a) detectou alterações na qualidade de vida no período de quimioterapia, e sugere em seus resultados que a neutropenia poderia ter sido um fator causador das reduções na QVRS.

Se por um lado as variáveis relacionadas ao tratamento não foram associadas à qualidade de vida a composição corporal revelou-se vinculado às alterações na dor e das limitações por aspectos físicos. As mulheres com maior quadro de dor e maiores limitações físicas possuíam um estado nutricional mais desfavorável. Com elevação nas variáveis relacionadas ao acumulo de gordura do corpo e redução daquelas associadas à presença dos tecidos metabolicamente ativos. Esta teoria foi sustentada, também, pela correlação positiva entre o \% MG e a dor, detectadas no presente estudo.

Os estudos em câncer, composição corporal e quimioterapia têm, tradicionalmente, dois focos. O primeiro busca compreender a associação entre a farmacocinética da quimioterapia e as variáveis da composição corporal (ATALAY et al., 2015; WONG et al., 2014; GOUÉRANT et al., 2013; PRADO et al., 2011; GREENMANet al., 2008; PRADO et al., 2007; SPARREBOOM et al.,2007; GRIGGS et al., 2005; De JONGE et al., 2002). O segundo é voltado para as alterações da massa corporal durante a quimioterapia (MAKARI-JUDSON et al., 2014; LIU et al., 2014;RODRIGUÉZ, MARTÍNEZ, MANUEL-Y-KEENOY, 2013; MAKARI-JUDSON et al.,2007 FREEDMANet al., 2004; DEL RIO et al., 2002; MCINNES; KNOBF, 2001; DEMARK-WAHNEFRIED et al., 2001).

Foram extremamente escassos os estudos que realizaram a associação entre quimioterapia $X$ composição corporal $x$ qualidade de vida. Sendo que, a grande maioria utilizou o IMC como forma de mensuração da composição corporal, além de incluírem períodos de sobrevida (KROENKE et al., 2013; KWAN et al., 2012; PAXTONet al., 2012; MANDELBLATTet al., 2011; Al-NAGGAR et al., 2011).

No Brasil, o estudo Frezel, Pastore, Gonzáles (2013) identificou associação entre elevada massa gorda e baixo estado geral de saúde. Infelizmente os autores não realizaram maiores explicações sobre os achados. E o método para mensurar a massa livre de gordura foi a bioimpedância.

Entretanto, as teorias sobre e excesso de massa gorda e os prejuízos a pessoas com câncer seriam similares àqueles de pessoas sem o câncer. Como por exemplo, a manifestação da resistência à insulina e leptina, disfunção endotelial e autonômica, mecanismos inflamatórios crônicos, aromatização periférica de 
andrógenos, maior hipóxia e estresse oxidativo, infiltração de tecidos, alterações na coagulação sanguínea (BABAEl et al., 2016; SIMONE et al., 2016; SIMPSON; BROWN, 2013a; PAREKH; CHANDRAN; BANDERA, 2012; ZAMAN et al., 2012; VANCE et al., 2011; MACCIÒ; MADEDDU; MANTOVANI, 2009).

O mesmo ocorreria com a massa livre de gordura, entretanto num sentido inverso, por ser esse um tecido de ajuste positivo do metabolismo, os efeitos benéficos seriam: adequada regulação energética, e do sistema imune, flexibilidade metabólica, equilíbrio fluído/eletrólito, positiva regulação endócrina/autonômica e ventilação/perfusão (CARSON et al., 2016; ISACCO et al., 2013; WATERS,BAUMGARTNER, 2011).

A superexpressão dos mecanismos ligados à massa gorda e atenuação dos benefícios da massa livre de gordura poderia gerar o quadro de limitações por aspectos físicos e da dor registrado pelas voluntárias do presente estudo.

A dor corporal é um estado psicofisiológico complexo, de difícil quantificação, sendo, entretanto, uma constante ao longo do tratamento do câncer e nos períodos de sobrevida. As teorias mais remotas sobre esse fenômeno consideravam causas anatômicas como: compressão de tecidos moles e nervos, oclusão vascular e infiltração tecidual (PACHARINSAK;BEITZ, 2008) os principais motivos para a manifestação da dor oncológica. Entretanto, essas conjecturas eram insuficientes para explicar dores nas formas de câncer hematológicas, ou os agravos após a extirpação do tumor e, principalmente, os eventos adversos após a radio ou quimioterapia.

Recentemente, com base nas semelhanças entre as manifestações relacionadas ao tratamento do câncer e o comportamento de doenças induzidas por citocinas em modelo animal conduziram à noção de que os sintomas em sobreviventes ao câncer pode ter uma base inflamatória (FAGUNDES; LEROY; KARUGAet al.,2015). De acordo com essa teoria após infecções, inflamações ou exposição à citocinas pró-inflamatórias as pessoas tenderiam a exibir comportamentos e percepções alteradas, que poderia ser chamado de comportamento do doente. Que teria como objetivo adaptar o corpo e poupar recursos para combater os agentes infecciosos ou inflamatórios. A presença constante de citocinas produzidas pelo tumor, o distresse gerado pelo diagnóstico e as intervenções cirúrgicas poderiam colaborar para um persistente estado de doença 
no indivíduo, que logo apresentaria sintomas persistentes como, por exemplo, a dor, a astenia que conduziria à percebida limitações por aspectos físicos, etc.

Panis e Pavanelli (2015) corroboram com essa teoria e citam o TGF- $\beta$ a IL-6, IL-1 e TNF-a seriam citocinas candidatas a promotoras na dor no câncer. Undénet al.(2007) vai mais além, propondo um modelo estrutural entre o bem-estar psicológico, o estado de saúde auto relatado e as citocinas anteriormente citadas. Neste modelo, a presença das citocinas prediria pobre estado de saúde e maior sintomatologia do câncer.

O estudo de Imayamaet al. (2013) acompanhou as mudanças da composição, fatores inflamatórios e a qualidade de mulheres tratadas do câncer de mama $(n=661)$. Seus resultados indicaram que àquelas com maior IMC apresentavam menor qualidade de vida, com limitações por aspectos físicos e dor. E que, ao longo do período de 60 meses de acompanhamento, àquelas que reduziam (pessoas com IMC $\leqslant 23$ kgm2) ou aumentavam na massa corporal inicial em ate 5\%, experienciavam significativas perdas nas funções físicas. Além disso, as perdas na função física foram associadas a níveis elevados de proteína c-reativa. Apesar de utilizar o IMC, este foi um dos poucos trabalhos detectados que propuseram influências do excesso de massa gorda e perda de massa magra na qualidade de vida relacionada à saúde. Apesar de não identificarem relação causal devido ao delineamento do estudo, os autores defendem que o estado inflamatório induzido pelo excesso de peso seria um aspecto indutor de pobre qualidade de vida.

Numa tentativa de sumarizar os resultados do presente estudo e o confronto com as principais teorias revisadas sobre composição corporal, qualidade de vida relacionada à saúde e efeitos adversos advindos do tratamento quimioterápico elaborou-se a ilustração abaixo (figura 8).Sustentando a hipótese de que o excesso de massa gorda seria um tecido pró-inflamatório e a massa livre de gordura ativa teriam uma ação anti-inflamatória, via essa já exacerbada pela presença das células tumorais.

O tecido adiposo e o tecido tumoral são sabidamente indutores de estados inflamatórios persistentes no organismo. A presença da elevada massa gorda está associada a diversos quadros negativos ao longo do tratamento e sobrevida em câncer. No presente estudo, estes prejuízos à saúde de forma geral, já seriam percebidos pelos indivíduos a partir dos resultados da qualidade de vida relacionada à saúde. Onde a massa gorda, o percentual de massa gorda e o índice de massa 
corporal, em algum momento foram associados ou correlacionados a resultados mais pobres da saúde auto referida ou dos eventos adversos da quimioterapia.

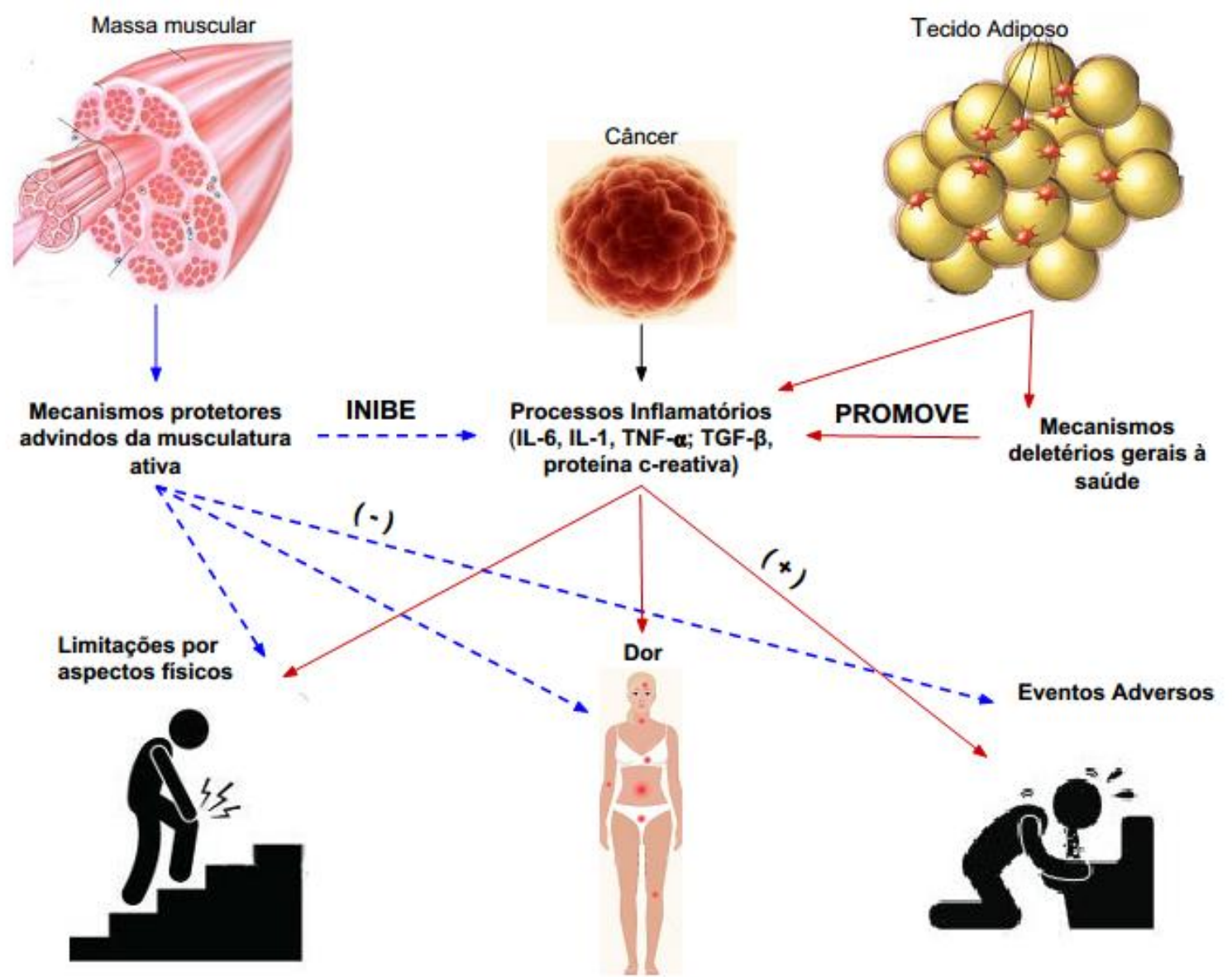

Figura 8: Proposta teórica sobre a interação entre a massa livre de gordura o tecido adiposo e a saúde auto relatada em mulheres submetidas à quimioterapia Fonte: próprio autor

Por outro lado, a massa livre de gordura seria um tecido protetor, preditor de boa saúde e que controlaria favoravelmente processos inflamatórios e metabólicos. Entretanto, no presente estudo as voluntárias apresentavam-se com massa muscular adequada, porém, inativa. Logo, estas não apresentariam mecanismos inibitórios ou protetores sobre a cascata infamatória adiposa e tumoral, sendo essa desregulação, já percebida pelo indivíduo no início do tratamento a partir das limitações físicas e da dor apresentadas anteriormente à quimioterapia; e ainda, durante o tratamento sob a forma de efeitos adversos hematológicos como a neutropenia e ainda efeitos musculoesqueléticos como astenia, parestesia, neuropatias. 
Ainda são necessários diversos estudos para ratificar essa proposta, entretanto, ele pode servir como orientação às novas pesquisas, bem como reorientar a relevância do entendimento da composição corporal e do exercício físico ao longo do diagnostico e sobrevida de câncer.

Seguindo este raciocínio (figura 8) e objetivando uma aplicação prática dos resultados detectados, as associações sugerem que intervenções físicas propostas às mulheres no início do diagnóstico seria uma forma de prevenir o aparecimento da dor, das limitações por aspectos físicos e da neutropenia, e favoreceria a qualidade de vida das mulheres já no início do tratamento. O benefício do exercício estaria no equilíbrio entre o efeito protetor da massa magra ativa e atenuação dos efeitos deletérios da massa gorda em excesso. 


\section{LIMITAÇÕES DO ESTUDO E DIRECIONAMENTOS FUTUROS}

A maior limitação do presente estudo encontra-se no tamanho amostral o que reduziu as possibilidades estatísticas e a elaboração de teorias robustas. Encontrase, também, na precariedade dos dados clínicos disponíveis nos registros médicos, que limitaram um acompanhamento com maior exatidão.

Os pontos fortes seriam o pioneirismo, a amostra em estado ativo de tratamento e aferição da composição corporal a partir de um método de maior valor diagnóstico. Revela-se importante, também, por revelar dados auto relatados sobre a qualidade de vida relacionada à saúde, que serviram como parâmetro de comparação para os dados objetivos da composição.

Sugere-se que estudos futuros com composição corporal e câncer atentem-se não somente à quantidade de massa muscular, mas também a qualidade da massa muscular, uma vez que, este aspecto pode ter mais relevância para o aparecimento de eventos adversos e maior impacto na qualidade de vida relacionada à saúde do que somente a quantidade.

Apesar dos custos elevados e das dificuldades no manejo do material biológico, aconselha-se a avaliação de citocinas alvos no período pré e pósquimioterapia para testar as conjecturas realizadas no presente estudo. 


\section{CONSIDERAÇÕES FINAIS}

As analises realizadas no presente estudo permitiram concluir que não foram identificadas correlações entre a massa corporal, o índice de massa corporal, massa livre de gordura, a massa gorda e o índice músculo esquelético relativono início do tratamento à ocorrência de efeitos colaterais ao longo do período quimioterápico. No entanto, a massa corporal, o percentual de massa livre de gordura, a massa gorda e o percentual de massa gorda foram associados aos eventos hematológicos e neuromusculares apresentados pelas mulheres durante o período quimioterápico.

Não foram observadas associações entre as variáveis da composição corporal e as características clínicas da doença.

Não foram identificadas associações entre as características clínicas e os eventos adversos e a qualidade de vida relacionada à saúde.

As variáveis da composição corporal mostraram associadas à qualidade de vida nos aspectos limitações por aspectos físicos e dor. Sendo a maior massa corporal, o maior IMC, o menor percentual de massa livre de gordura, e o maior percentual de massa gorda associada à presença de dor. No caso das limitações por aspectos físicos, eles foram mais acentuados nos indivíduos com menor percentual de massa livre de gordura e maior percentual de massa gorda. Propondo indícios de que estas variáveis quando em desequilíbrio podem refletir sobre a avaliação subjetiva que o indivíduo realiza sobre sua saúde. 


\section{REFERENCIAS}

ABRAHAMSON, P.E.; GAMMON, M.D.; LUND, M.J., FLAGG, E.W.; PORTER, P.L.; STEVENS, J.; SWANSON, C.A.; BRINTON, L.A.; ELEY, J.W.; COATES, R.J.. General and Abdominal Obesity and Survival among Young Women with Breast Cancer.Cancer Epidemiol Biomarkers Prev, v.15, n.10, p.1871-1877, 2006.

ADEMUYIWA, F.O.; GROMAN, A; O'CONNOR, T.; AMBROSONE, C; WATROBA, N.; EDGE, S.B. Impact of Body Mass Index on Clinical Outcomes in Triple-Negative Breast Cancer. Cancer, v.177, n.18, p. 4132-4140, 2011.

AHR, A.; HOLTRICH, U.; SOLBACH, C.; SCHAR, A.; STREBHARDT, K.; KAM, T.; KAUFMANN, M. Molecular classification of breast cancer patients by gene expression profiling. J Pathol, v.195, n.3, p. 312-320, 2001.

ALBUQUERQUE, V.T. Funcionalidade de membros superiores, autoimagem e autoestima de mulheres submetidas ao tratamento para câncer de mama segundo seus perfis psicológicos de gênero. 2014. 111 f. Dissertação (Mestrado) - Universidade Católica de Brasília, Brasília, 2014

AL-NAGGAR, R.A.; NAGI, N.M.; AKU, M.M.; ALMUASLI, M.

Qualityoflifeamongbreastcancerpatients in Yemen. Asian Pacific journal of cancer prevention, v.12, n.9, p. 2335-2341, 2011

AMERICAN CANCER SOCIETY.Cancer Facts and Figures 2016. Atlanta, Ga: American Cancer Society; 2016. Disponível em:

<http://www.cancer.org/acs/groups/content/@research/documents/document/acspc047079.pdf>. Acessadoem : 02/05/2016.

ANDRE, F.; DOMONT, J.; DELALOGE, S. What can breast cancer molecular subclassification add to conventional diagnostic tools?.Annals of oncology, v.18, supl 8 , p. 33-36, 2007.

ASIF, H.M.; SULTANA, S.; AHMED, S.; AKHTAR, N.; TARIQ, M. HER-2 Positive Breast Cancer - a Mini-Review.Asian Pac J Cancer Prev, v.17, n. 4, p.1609-1615, 2016.

AUNTOUN, S.; BORGET, I.; LANOY, E. Impact of sarcopenia on the prognosis and treatment toxicities in patients diagnosed with cancer.CurrOpin Support Palliat Care, v.7, n.4, p.383-389, 2013.

AZAMBUJA, E.D.E.; MCCASKILL-STEVENS, W.; FRANCIS, P.; QUINAUX, E.; CROWN, J.P.A.; VICENTE, M.; GIULIANI, R.; NORDENSKJOLD, B.; GUTIEREZ, J.; 
ANDERSSON, M.; VILA, M.M.; JAKESZ, R.; DEMOL, J.; DEWAR, J.; SANTORO, A.; LLUCH, A.; OLSEN, S.; GELBER, R.D.; DI LEO, A.; PICCART-GEBHART, M. The effect of body mass index on overall and disease-free survival in node-positive breast cancer patients treated with docetaxel and doxorubicin-containing adjuvant chemotherapy: the experience of the BIG 02-98 trial. Breast Cancer Res Treat, v.119, n.1, p.145-53, 2010.

AZRAD, M.; DEMARK-WAHNEFRIED, W. The association between adiposity and breast cancer recurrence and survival: A review of the recent literature. Current Nutrition Reports,v.3, n.1, p.9-15, 2014.

BABAEI, Z.; MOSLEMI, D.; PARSIAN, H.; KHAFRI, S.; POURAMIR, M.; MOSAPOUR, A. Relationship of obesity with serum concentrations of leptin, CRP and IL-6 in breast cancer survivors. Journal of the Egyptian National Cancer Institute,v. 27, n. 4, p. 223-229, 2015.

BARDWELL, W.A.; MAJOR, J.M.; ROCK, C.L.; NEWMAN, V.A.; THOMSON, C.A.; CHILTON, J.A.; DIMSDALE, J.E.; PIERCE, J.P. Health-related quality of life in women previously treated for early-stage breast cancer. Psychooncology, v.13, n. 9, p. 595-604, 2004.

BARKER, H.E.; PAGET, J.T.; KHAN, A.A.; HARRINGTON, K.J. The tumour microenvironment after radiotherapy: mechanisms of resistance and recurrence. NatureReviewsCancer, v.15, n.7, p. 409-426, 2015.

BARPE, D.R. Estudo preliminar da farmacocinética da doxorrubicina e avaliação do ajuste de dose em mulheres com câncer de mama. 2009, 119 f.[dissertação]. Porto Alegre, Universidade Federal do Rio Grande do Sul, 2009.

BARPE, D.R.; ROSA, D.D.; FROEHLICH, P.E. Pharmacokinetic Evaluation of doxorubicin plasma levels in normal and overweight patients with breast cancer and simulation of dose adjustment by different indexes of body mass. European Journal of Pharmaceutical Sciences.v.41, n.3-4, p. 458-463, 2010.

BASELGA, J.; NORTON, L.; ALBANELL, J.; KIM, Y.M.; MENDELSOHN, J. Recombinant humanized anti-HER2 antibody (Herceptin) enhances the antitumor activity of paclitaxel and doxorubicin against HER2/neu overexpressing human breast cancer xenografts. Cancer Res.v.58, n.13, p. 2825 - 2831, 1998.

BAUER, K.; PARISE, C.; CAGGIANO, V. Use of ER/PR/HER2 subtypes in conjunction with the 2007 St Gallen Consensus Satement for early breast cancer. BMC Cancer, v.21, n.10, 2010. Acessado em: 20/03/2016. doi: 10.1186/1471-240710-228. 
BERGEROT, C. D. Avaliação de distress para identificação de fatores de risco e proteção na experiência oncológica: contribuições para estruturação de rotinas e programas em psico-oncologia. 2013. viii, 199 f., il. Tese (Doutorado em Processos de Desenvolvimento Humano e Saúde) - Universidade de Brasília, Brasília, 2013.

BERGH, J.; JÖNSSON, P.E.; GLIMELIUS, B.; NYGREN, P. A systematic overview of chemotherapy effects in breast cancer.ActaOncologica, v. 40, n. 2-3, p. 253-281, 2001.

BLOOM, J. R.; STEWART, S. L.; OAKLEY-GIRVAN, I.; BANKS, P. J.; SHEMA, S. Quality of life of younger breast cancer survivors: persistence of problems and sense of well-being. Psycho-Oncology, v. 21, n. 6, p. 655-665, 2012.

BOEKEL, N.B., SCHAAPVELD, M., GIETEMA, J.A., RUSSELL, N.S., POORTMANS, P., THEUWS, J. C.; RUTGERS, E.J. Cardiovascular disease risk in a large, population-based cohort of breast cancer survivors. International Journal of

Radiation Oncology* Biology* Physics, v. 94, n. 5, p. 1060-1972, 2015.

BORG, A.; LINELL, F.; IDVALL, I.; JOHANSSON, S.; SIGURDSSON, H.; FERNÖ, M.; KILLANDER, D. HER2/neu amplification and comedo type breast carcinoma. Lancet, v.3, n.1, p.1268-1269, 1989.

BORGEN, P. Breast Cancer in the 20th Century: Quest for the Ideal Therapy.The Ochsnerjournal, v.2, n.1, p. 5 - 9, 2000.

BRASIL, Ministério da Saúde Secretaria de Atenção à Saúde. PORTARIA № 1.008, DE 30 DE SETEMBRO DE 2015. Diretrizes Diagnósticas e Terapêuticas do Carcinoma de Mama. 2015a. Disponível em:

http://conitec.gov.br/images/Protocolos/DDT/DDT CaMama 2015.pdf. Acessado em: 3/02/2016.

BRASIL, Ministério da Saúde. Instituto Nacional de Câncer José Alencar Gomes da Silva (INCA). Estimativa 2016: incidência de câncer no Brasil. 2015. Disponível em

$<$ https://www.google.com.br/url?sa=t\&rct=j\&q=\&esrc=s\&source=web\&cd=1\&cad=rja\& uact=8\&ved=0ahUKEwic1ljE9pzNAhWBGZAKHcDsBsMQFggeMAA\&url=http\%3A\%2 F\%2Fwww.inca.gov.br\%2Fbvscontrolecancer\%2Fpublicacoes\%2Fedicao\%2FEstimat iva_2016.pdf\&usg=AFQjCNFEz7UuFsQutIPjRGxDWcIDPyqcmA\&sig2=3AMrz4cGCqxgjEU6iZ9Uw> . Acessado em 22/04/2016.

BRASIL. Tribunal de Contas da União. Solicitação de fiscalização no Sistema Único De Saúde - SUS. Avaliação do cumprimento do disposto na lei 12.372/2012. TC 018.835/2013-9. [Relatório]. Brasília. 2014. Disponível em: 
$<$ http://www.tcu.gov.br/Consultas/Juris/Docs/judoc/Acord/20131107/AC 29734313 P.doc>. Acessado em: 13/05/2016.

BRASIL. Ministério da Saúde. Secretaria de Atenção à Saúde. Instituto Nacional de Câncer. TNM: classificação de tumores malignos. 6. ed. - Rio de Janeiro: INCA, 2004. Disponível em: <http://bvsms.saude.gov.br/bvs/publicacoes/inca/tnm2.pdf>. Acessadoem: 4/11/2014.

BREWSTER, A.M.; ETZEL, C.; ZHOU, R.; WONG, Y.; EDGE, S.; BLAYNEY, D.W.; WILSON, J,; HUDIS, C.; OTTESEN, R.; HUGHES, M.E; WEEKS, J.C.; THERIAULT, R.L. The impact of obesity on receipt of adjuvant chemotherapy for breast cancer in the National Comprehensive Cancer Network (NCCN) centers. Breast Cancer Res Treat, v.130, n.3, p. 897-904, 2011.

BROWN, K.A.; SIMPSON, E.R. Obesity and breast cancer: mechanisms and therapeutic implications. Front Biosci (Elite Ed), v. 4, p. 2515-2524, 2012.

BRUNTON, L.L.; CHABNER, B.A.; KNOLLMANN, B.C. As Bases Farmacológicas da Terapêutica de Goodman \& Gilman. Rio de Janeiro: Guanabara-Koogan, 2012.

BUERNET, M. Cancer- a biologycal approach. British medical journal, v.1, n.5023, p.779-786,1957.

BUITRAGO, F.; UEMURA, G.; SENA, M.C.F. Fatores prognósticos em câncer de mama. Com. CiênciasSaúde, v.22, supl. 1, p.69-82, 2011.

BURSTEIN H.J.; GRIGGS, J.J.; PRESTRUD, A.A.; TEMIN, S. American Society of Clinical Oncology Clinical Practice Guideline Update on Adjuvant Endocrine Therapy for Women With Hormone Receptor-Positive Breast Cancer. Journal of Clinical Oncology, v. 6, n. 5, .p: 243-246, 2010.

CAAN, B.J.; KWAN, M.L.; HARTZELL, G.; CASTILLO, A.; SLATERRY, M.L.; STERNFELD, B.; WELTZIEN, E. Pre-diagnosis body mass index, post-diagnosis weight change, and prognosis among women with early stage breast cancer. Cancer Causes Control, v.19, n.10, p.1319-1328, 2008.

CALLE, E.E.; RODRIGUES, C.; WALKER-THURMOND, K; THUN, M.J. Overweight, Obesity, and Mortality from Cancer in a Prospectively Studied Cohort of U.S. Adults. The New England Journal Of Medicine, v.348, n.17, p.1625-1638, 2003.

CARROLL, J.P.; PROTANI, M.M.; NGUYEN, L.; CHENG, M.E.; FAY, M.; SALEEM, M.; PILLAY, P.S.; WALPOLE, E.; MARTIN, J.H. Toxicity and tolerability of adjuvant breast cancer chemotherapy in obese women. Med Oncol, v.31, n.4, p.1-7, 2014. 
CARROLL, J.P.; PROTANI, M.M.; WALPOLE, E. Effect of obesity on toxicity in women treated with adjuvant chemotherapy for early-stage breast cancer: a systematic review. Breast Cancer Res Treat, v.139, n.2, p.323-330, 2012.

CARSON, J.A.; HARDEE, J.P.; VANDERVEEN, B.N.; The emerging role of skeletal muscle oxidative metabolism as a biological target and cellular regulator of cancerinduced muscle wasting.SeminCellDevBiol, v. 54, p. 53-67, 2016.

CASTELLAR, J.I. Efeitos da meditação prânica sobre o bem-estar físico e emocional e os níveis de melatonina de sobreviventes de câncer de mama. 2014. 94 f. [Tese]. Doutorado em Ciências Médicas - Universidade de Brasília, Brasília, 2014.

CASTRO FILHA, Jurema Gonçalves Lopes et al. Influências do exercício físico na qualidade de vida em dois grupos de pacientes com câncer de mama.

RevistaBrasileira de Ciências do Esporte, v. 38, n. 2, p. 107 - 114, 2016.

CHAN, A.; CHEN, C.; CHIANG, J.; TAN, S.H.; NG, R. Incidence of febrile neutropenia among early-stage breast cancer patients receiving anthracycline-based chemotherapy. Supportive Care in Cancer, v. 20, n. 7, p. 1525-1532, 2012.

CHAN, D.S.M.; NORAT, T. Obesity and breast cancer: not only a risk factor of the disease. Current Treatment Options in Oncology, v.16, n. 5, p. 1-17, 2015.

CHEN, J.C.; KUO, S.J.; LIAW, Y.P; AVITAL, I.; STOJADINOVIC, A.; MAN, Y.G.; MANNION, C.; JIANLIAN, CHOU, M.C.; TSAI, H.D.; CHEN, S.T.; HSIAO, Y.

Endometrial Cancer Incidence in Breast Cancer Patients Correlating with Age and Duration of Tamoxifen Use: a Population Based Study. J Cancer,v. 5, n. 2, p. 151155, 2015. Acessadoem: 9/05/2016. doi:10.7150/jca.8412

CHEN, S.; CHEN. C.; ZHOU, Y.; ZHOU, R.; YU, K.; SHAO, Z. Obesity or Overweight Is Associated with Worse Pathological Response to Neoadjuvant Chemotherapy among Chinese Women with Breast Cancer. PlosOne, v.7, n.7, e41380, 2012. Disponível em:

<http://journals.plos.org/plosone/article?id=10.1371/journal.pone.0041380>. Acessadoem: 13/02/2015.

CHEN, X.; LU, W.; ZHENG, W.; GU, K.; CHEN, Z.; ZHENG, Y.; SHU, X.O. Obesity and weight change in relation to breast cancer survival.BreastCancer Res Treat, v.122, n.3, p. 823-833, 2010. 
CICONELLI, R.M.; FERRAZ, M.B.; SANTOS, W. Tradução para a línguaportuguesa e validação do questionário genérico de avaliação de qualidade de vida SF-36 (Brasil SF-36). RevistaBrasileira de Reumatologia, v.29, p.143-150,1998.

CLARKE, M.J. Ovarian ablation in breast cancer, 1896 to 1998: milestones along hierarchy of evidence from case report to Cochrane review. British Medical Journal, v. 317, n. 7167, p. $1246,1998$.

CLEVELAND, R.J.; ENG, S.M.; ABRAHAMSON, P.E.;BRITTON, J.A.; TEITELBAUM, S.L.; NEUGUT, A.; GAMMON, M.D. Weight Gain Prior to Diagnosis and Survival from Breast Cancer. Cancer Epidemiol Biomarkers Prev, v.16, n.9, p.1803-1811, 2007.

CONDE, D.M.; PINTO-NETO, A.M.; CABELLO, C.; SANTOS-SÁ, D.; COSTA-PAIVA, L.; MARTINEZ, E.Z.; Quality of life in Brazilian breast cancer survivors age 45-65 years: associated factors. The Breast Journal, v.11, n.6, p. 425-432, 2005.

CONNELL, P.P.; HELLMAN, S. Advances in radiotherapy and implications for the next century: A historical perspective. Cancer Research, v.69, n.2, p. 383-392, 2009

COOMBES, R.C.; HALL, E.; GIBSON, L.J.; PARIDAENS, R.; JASSEM, J.; DELOZIER, T.; COATES, A.S. A randomized trial of exemestane after two to three years of tamoxifen therapy in postmenopausal women with primary breast cancer.New England Journal of Medicine, v. 350, n. 11, p.1081-1092, 2004.

COPSON, E.R.; CUTRESS, R.I.; MAISHMAN, T.; ECCLES, B.K.; GERTY, S.; STANTON, L; JONES, L. Obesity and the outcome of young breast cancer patients in the UK: the POSH study. Annals of Oncology, v. 26, n.1, p.101-112, 2015.

COSTA-REQUENA, G.; RODRÍGUEZ, A.; FERNÁNDEZ-ORTEGA, P. Longitudinal assessment of distress and quality of life in the early stages of breast cancer treatment.Scandinavian Journal of Caring Sciences, v. 27, n. 1, p. 77-83, 2013.

COTLAR, A.M.; DUBOSE, J.J.; ROSE, D.M. History of Surgery for Breast Cancer: Radical to the Sublime. Current Surgery, v.60, n.3, p. 329-337, 2003.

CRIMMINS, E.; BELTRÁN-SÁNCHEZ, H. Mortality and Morbidity Trends: Is There Compression of Morbidity?.Journal of Gerontology, v.668, n.1, p.75-86, 2010.

DAL MASO, L.; ZUCCHETTO, A.; TALAMINI, R.; SERRAINO, D.; STOCCO, C.F.; VERCELLI, M.; FALCINI, F.; FRANCESCH, S.; Prospective Analysis of Case-control studies on Environmental factors and health (PACE) study group. Effect of obesity and other lifestyle factors on mortality in women with breast cancer.Int. J. Cancer, v.123, n.9, p.2188-2194, 2008. 
DE AGUIAR, S.S.; BERGMANN, A.; MATTOS, I.E. Quality of life as a predictor of overall survival after breast cancer treatment.Quality of Life Research, v. 23, n. 2, p. 627-637, 2014.

DE JONGE, M.E.; MATHÔT, T.A.; VAN DAM, S.M.; BEIJNEN, J.H.; RODENHUIS, S. Extremely high exposures in an obese patient receiving high-dose cyclophosphamide, thiotepa and carboplatin. Cancer ChemotherPharmacol, v. 50, n.3, p.251-255, 2002.

DEGLISE, C.; BOUCHARDY, C.; BURRI, M.; USEL, M.; NEYROUD-CASPAR, I.; VLASTOS, G.; CHAPPUIS, P.O; CESCHI, M.; ESS, S.; CASTIGLIONE, M.; RAPITI, E.; VERKOOIJEN, H.M. Impact of obesity on diagnosis and treatment of breast cancer. Breast Cancer Res Treat, v.120, n.1, p.185-93, 2010.

DEL FABBRO, E.; PARSONS, H.; WARNEKE, C.L.; PULIVARTHI, K.; LITTON, J.K.; DEV, R.; PALLA, S.L.; BREWSTER, A.; BRUERA, E. The Relationship Between Body Composition and Response to Neoadjuvant Chemotherapy in Women with Operable Breast Cancer. The Oncologist, v.17, n.10, p.1240-1245, 2012.

DEL RIO, G. et al.Weight gain in women with breast cancer treated with adjuvant cyclophosphomide, methotrexate and 5-fluorouracil. Analysis of resting energy expenditure and body composition. Breast Cancer Research and Treatment, v. 73, n. 3, p. 267-273, 2002.

DEMARK-WAHNEFRIED, W.; KENYON, A. J.; EBERLE, P.; SKYE, A.; KRAUS, W.E. Preventing sarcopenic obesity among breast cancer patients who receive adjuvant chemotherapy: results of a feasibility study. Clinical Exercise Physiology, v.4, n.1, p. 44-49, 2002.

DEMARK-WAHNEFRIED, W.; PETERSON, B.L.; WINER, E.P.; MARKS, L.; AZIZ, N.; MARCOM, P.K.; BLACKWELL, K.; RIMER, B.K. Changes in Weight, Body Composition, and Factors Influencing Energy Balance Among Premenopausal Breast Cancer Patients Receiving Adjuvant Chemotherapy. Journal of Clinical Oncology, v.19, n.9, p.2381-2389. 2001.

DEVITA, V.T.; CHU, E. A history of cancer chemotherapy.Cancer Research, v. 68, n. 21, p. $8643-8653,2008$.

DIETTRICH, S.H.C. Eficácia de um programa de atividade física nos níveis de fadiga em pacientes em tratamento de câncer de mama. 2007. 116 f. Tese (Doutorado em Ciências da Saúde)-Programa Multiinstitucional em Ciências da Saúde, UnB, Campo Grande, 2007. 
DONEGAM, W. L. SurgicalClinicalTrials. Cancer, v.53, supl.3, p.691-699, 1984.

Disponível em <http://onlinelibrary.wiley.com/doi/10.1002/1097-

0142(19840201)53:3\%2B\%3C691::AID-CNCR2820531317\%3E3.0.CO;2-

X/abstract;jsessionid=87F8D6A88C5A628DBC4A2C52406CD3C7.f04t01>.

Acessadoem: 23/02/2014

DRYGALSKI, A.V.; TRAN, T.B.; MESSER, K.; PU, M. CORRINGHAN, S.; NELSON, C.; BALL, E.D. Obesity Is an Independent Predictor of Poor Survival in Metastatic Breast Cancer: Retrospective Analysis of a Patient Cohort Whose Treatment Included High-Dose Chemotherapy and Autologous Stem Cell Support. International Journal of Breast Cancer, v.2011, n.2011, p.1-8. 2011.

Disponívelem:<http://www.hindawi.com/journals/ijbc/2011/523276/>. Acessadoem: $06 / 08 / 2014$

EARLY BREAST CANCER TRIALISTS' COLLABORATIVE GROUP (EBCTCG), DOWSETT, M.; FORBES, J.F.; BRADLEY, R.; INGLE, J., AIHARA, T.; BLISS, J.; BOCCARDO, F.; COATES, A.; COOMBES, R.C.; CUZICK, J.; DUBSKY, P.; GNANT, M.; KAUFMANN, M.; KILBURN, L.; PERRONE, F.; REA, D.; THÜRLIMANN, B.; van de VELDE, C.; PAN, H.; PETO, R.; DAVIES, C.; GRAY, R.Aromatase inhibitors versus tamoxifen in early breast cancer: patient-level meta-analysis of the randomised trials. Lancet, v. 3, n. 386, p.1341-52, 2015.Acessadoem: 23/10/2015. doi: 10.1016/S0140-6736(15)61074-1.

EISEN, A.; FLETCHER, G.G.; GANDHI, S.; MATES, M.; FREEDMAN, O.C. ; DENT, S.F.; TRUDEAU, M.E. Optimal systemic therapy for early breast cancer in women: a clinical practice guideline. CurrOncol, v. 22, supl: 1, p. 67-81, 2015.

Acessadoem: 23/02/2016. doi: 10.3747/co.22.2320.

ELLIS, M.J.;LLOMBART-CUSSAC, A.;FELTL, D.;DEWAR, J.A.;JASIÓWKA, M.;HEWSON, N.;RUKAZENKOV, Y.;ROBERTSON, J.F. Fulvestrant 500 mg Versus Anastrozole $1 \mathrm{mg}$ for the First-Line Treatment of Advanced Breast Cancer: Overall Survival Analysis From the Phase II FIRST Study. J ClinOncol, v. 10, n. 33, p: 37813787, 2015. Acessado em: 23/02/2014. doi: 10.1200/JCO.2015.61.5831

ELSEA, C.R.; KNEISS, J. A.; WOOD, L.J. Induction of IL-6 by cytotoxic chemotherapy is associated with loss of lean body and fat mass in tumor-free female mice.

Biological Research for Nursing, v.17, n. 5, p. 549-557, 2015,

EVANS, E.S.; PROSNITZ, R.G.; YU, X.; ZHOU, S.M.; HOLLIS, D.R.; WONG, T.Z.; LIGHT, K.L.; HARDENBERGH, P. H.; BLAZING, M.A.; MARKS, L.B. Impact of patient-specific factors, irradiated left ventricular volume, and treatment set-up errors on the Development of myocardial perfusion defects after Radiation therapy for leftsided breast cancer. Int. J. Radiation Oncology Biol. Phys, v.66, n.4, p.1125-34, 2006. 
EWERTZ, M.; GRAY, K.P.; REGAN, M.M.; EJKERTSEN, B.; PRICE, K.N.; THURLIMANN, B.; BONNEFOI, H.; FORBES, J.H.; PARADAENS, R.J.; RABAGLIO, M.; GELBER, R.D.; COLLEONI, M.; LANG, I.; SMITH, I.E.; COATES, A.S.; GOLDHIRSCH, A.; MOURIDSEN, H.T.Obesity and Risk of Recurrence or Endocrine TherapyWithLetrozole or Tamoxifen in the Breast International Group 1-98 Trial. Death After Adjuvant Jounal of Clinical Oncology, v.30, n.32, p.25-31, 2012.

EWERTZ, M.;JENSEN, M.B.; GUNNARSDOTTIR, K.A.; HøJIRS, I.; JAKOBSEN, E.H.; NIELSEN, D.Stenbygaard LE, Tange UB, Cold S. Effect of Obesity on Prognosis After Early-Stage Breast Cancer. J ClinOncol, v.29, n.1, p.25-31, 2011.

FAGUNDES, C.; LEROY, A.; KARUGA, M. Behavioral Symptoms after Breast Cancer Treatment: A Biobehavioral Approach. Journal of Personalized Medicine, v. 5, n. 3, p. 280-295, 2015.

FALCK, A.; BENDAHL, P.; CHEBIL, G.; OLSSON, H.; FERNÖ, M.; RYDÉN, L; Biomarker expression and St Gallen molecular subtype classification in primary tumours, synchronous lymph node metastases and asynchronous relapses in primary breast cancer patients with 10 years' follow-up. Breast Cancer Res Treat, v.140, n.1, p.93-104, 2013.

FEBBRAIO, M.A.; PEDERSEN, B.K. Muscle-derived interleukin-6 mechanisms for activation and possible biological roles. The FASEB Journal, v.16, n.11, p.1335-1347, 2002.

FERRAZ, N.M.S. Mama fantasma no pós-operatório de mastectomia radical modificada. 2007. 139 f. Tese (Doutorado em Ciências da Saúde)-Universidade de Brasília, Brasília, 2007.

FLEGAL, K.M.; KIT, B.K.; ORPANA, H.; GRAUBARD, B.L. Association of all-cause mortality with overweight and obesity using standard body mass index categories: a systematic review and meta-analysis.JAMA, v.309, n.1, p. 71-82, 2013.

FLEGAL, K.M.; SHEPHERD, J.A.; LOOKER, A.C.; GRAUBARD, B.I.; BORRUD, L.G.; OGDEN, C.L.; HARRIS, T.B.; EVERHART, J.E.; SCHENKER, N. Comparisons of percentage body fat, body mass index, waist circumference, and waist-stature ratio in adults. Am J ClinNutr, v. 89, n.2, p.500-508, 2009.

FOULADIUN, M.; KORNER, U.; BOSAEUS, I.; DANERYD, P.; HYLTANDER, A.; LUNDHOLM, K.G. Body Composition and Time Course Changes in Regional Distribution of Fat and Lean Tissue in Unselected Cancer Patients on Palliative CareCorrelations with Food Intake, Metabolism, Exercise Capacity, and Hormones. Cancer, v.103, n.10, p.2189-2198, 2005. 
FREDMAN, R.J.; AZIZ, D.; ALBANES, D.; HARTMAN, T.; DANFORTH, D.; HILL, S.; SEBRING, N.; REYNOLDS, J.C.; YANOVSKI, J.A. Weight and Body Composition Changes during and after Adjuvant Chemotherapy in Women with Breast Cancer. $\mathbf{J}$ ClinEndocrinolMetab, v.89, n.5, p.2248-2253, 2004.

FREEDMAN, R.J.; AZIZ, N.; ALBANES, .; HARTMAN, T.; DANFORTH, D.; HILL, S.; SEBRING, N.; REYNOLDS, J.C.; YANOVSKI, A.A. Weight and Body Composition Changes during and after Adjuvant Chemotherapy in Women with Breast Cancer. The Journal of Clinical Endocrinology \& Metabolism, v.89, n.5, p.2248-2245, 2004.

FREIFELD, A.G.; BOW, E.J.; SEPKOWITZ, K.A.; BOECKH, M.J.; ITO, J.I.; MULLEN, C.A.; RAAD, I.I.; ROLSTON, K.V.; YOUNG, J.A.; WINGARD, J.R. Clinical practice guideline for the use of antimicrobial agents in neutropenic patients with cancer: 2010 update by the Infectious Diseases Society of America.Clinical infectious diseases, v. 52, n. 4, p. e56-e93, 2011.

FREITAS-SILVA, R.; CONDE, D.M.; DE FREITAS-JÚNIOR, R.; MARTINEZ, E.Z.; Comparison of quality of life, satsfaction with surgery and shoulder-arm morbidity in breast cancer survivors submitted to breast-conserving therapy or mastectomy followed by immediate breast reconstruction. Clinics (São Paulo), v.65, n.8, p.781787, 2010.

FRENZEL, P.A.; PASTORE, A.C.; GONZÁLEZ, M.C.The influence of body composition on quality of life of patients with breast cancer.NutrciónHospitalaria, v.28, n.5, p.1475-1482, 2013.

GADÉA, E.; THIVAT, E.; PLANCHAT, E.; MORIO, B.; DURANDO, X. Importance of metabolic changes induced by chemotherapy on prognosis of early-stage breast cancer patients: a review of potential mechanisms. Obesity Reviews, v.13, n.4, p.368-80, 2011.

GAJDOS, C.; TARTTER, P.I.;ESTABROOK, A.; GISTRAK, M.A.; JAFFER, S.; BLEIWEISS. Relationship of Clinical and Pathologic Response to Neoadjuvant Chemotherapy and Outcome of Locally Advanced Breast Cancer.Journal of Surgical Oncology, v.80, n.1, p. 4-11, 2012.

GANZ, P.A.; DESMOND, K.A.; LEEDHAM, B.; ROWLAND, J.H.; MEYEROWITZ, B.E.; BELIN, T.R. Quality of life in long-term, disease-free survivors of breast cancer: a follow-up study. J Natl Cancer, v.94, n.1, p.39-49, 2002.

GARCIA-SAENZ, J.A.; BERMEJO, B.; ESTEVEZ, L.G.; PALOMO, A.G.;GONZALEZFARRE, X.; MARGELI, M.; PERNAS, S.; SERVITJA, S.; RODRIGUEZ, C.A.; CIRUELOS, E. SEOM Clinical guidelines in early-stage breast cancer 2015. ClinTransIOncol,v.17, n.12, p.939-945, 2015. 
GOLAN, D.; JUNIOR, T.; ARMEN, H.; ARMSTRONG, E.J.; ARMSTRONG, A.W. Princípios de farmacologia: a base fisiopatológica da farmacoterapia. 3 ed; Rio de Janeiro: Guanabara Koogan, 2014.

GOUÉRANT, S.; LEHEURTEUR, M.; CHAKER, M.; MODZELEWSKI, R.; RIGAL, O.; VEYRET, C.; LAURIDANT, G.; CLATOT, F. A. Higher Body Mass Index and Fat Mass Are Factors Predictive of Docetaxel Dose Intensity. AnticancerResearch, v.33, n.12, p.5655-5662, 2013.

GOZZO, Thais de Oliveira. Toxicidade ao tratamento quimioterápico em mulheres com câncer de mama. 2008, 127 f. [Tese de Doutorado]. Faculdade de Enfergamegm. Universidade de São Paulo. 2008.

GREENMAN, C.G.; JAGIELSKI, C.H.; GRIGGS, J.J. Breast cancer adjuvant chemotherapy dosing in obese patients.Dissemination on information from clinical trials to clinical practice.Cancer, v.112, n.10, p. 2159-2165, 2008.

GRIGGS J. J.; SORBERO M. E.; LYMAN G. H. Undertreatment of Obese Women Receiving Breast Cancer Chemotherapy.Archives of Internal Medicine, v.165, n.11, p.1267-1273, 2005.

GRIGGS, J.J.; HAYES, D.F. Do All Patients with Breast Cancer Require Systemic Adjuvant Therapy?.Journal of National Cancer, v.103, n.18, p.1350-1351, 2011.

GRIGGS, J.J.; MANGU, P.B.; ANDERSON, H.BALABAN, E.P.; DIGNAM,J.J.; HRYNIUK, W.M.; MORISSON, V.A.; PINI, T.M.; RUNOWICZ, C.D.; ROSNER, G.L.; SHAYNE, M.; SPARREBOOM, A.; SUCHESTON, L.E.; LYMAN, G.H. Appropriate Chemotherapy Dosing for Obese Adult Patients With Cancer: American Society of Clinical Oncology Clinical Practice Guideline. Journal Of Clinical Oncology, v.30, n.13, p.1553-1561, 2012.

GRIGGS,J.J.; CULAKOVA, E.; SORBERO, M.E.S.; RYN, M.; PONIEWIERSKI, WOLFF, DEBRA; CRAWFORD, J.; DALE, D.C.; LYMAN, G.H. Effect of Patient Socioeconomic Status and Body Mass Index on the Quality of Breast Cancer Adjuvant Chemotherapy. Journal of Clinical Oncololy, v.25, n.3, p.277-284, 2007.

GROENVOLD, M.; PETERSEN, M.A.; IDLER, E.; BJORNER, J.B.; FAYERS, P.M.; MOURIDSEN, H.T. Psychological distress and fatigue predicted recurrence and survival in primary breast cancer patients. Breast Cancer Res Treat, v.105, n.2, p. 209-219, 2007. 
GURNEY, H.P.; ACKLAND, S.; GEBSKI, V.; FARRELL, Geoffrey. Factors Affecting Epirubicin Pharmacokinetics and Toxicity: Evidence Against Using Body-Surface Area for Dose Calculation.Journal of clinical oncololy, v.18, n.7, p.2299-2304, 1998.

HAJDU, S. I. A note from history: landmarks in history of cancer, part 1.Cancer, v. 117, n. 5, p. 1097-1102, 2011.

HALSTED, W.S. The results of operation for the cure of cancer of the breast performed at the johns hopkins hospital from June, 1889, to January, 1894. Annals of surgery, v.20, n.5, p.497-555, 1894.

HAN, E.Y.; PAUDEL, N.; SUNG, J.; YOON, M.; CHUNG, W.K.; KIM, D.W. Estimation of the risk of secondary malignancy arising from whole-breast irradiation: comparison of five radiotherapy modalities, including TomoHDA. Oncotarget, 2016, [NO PRELO].

HAN, H.S.; REIS, I.M.; ZHAO, W.; KUROI, K.; TOI, M,; SUZUKI, E.; SYME, R.; CHOW, L.; YIP, A.Y.S.; GLÜCK, S. Racial differences in acute toxicities of neoadjuvant or adjuvant chemoterapy in patients with early-stage breast cancer. European Journal of Cancer, v.47, n.17, p. 2537-2545, 2011.

HARMS, W.; BUDACH, W.; DUNST, J.; FEYER, P.; FIETKAU, R.; HAASE, W.; KRUG, D.; PIROTH, M;D; SAUTTER-BIHL, M.L.; SELDMAYER, F.; SOUCHON, R.; WENZ, F.; SAUER, R. DEGRO practical guidelines for radiotherapy of breast cancer VI: therapy of locoregional breast cancer recurrences. Strahlentheronkol, v.192, n.4, p.199-208, 2016.

HELYER, K.L.; VARNIC, M.; LE, L.W.; LEONG, W.; MCCREADRY, D. Obesity is a Risk Factor for Developing Postoperative Lymphedema in Breast Cancer Patients. The Breast Journal,v.16, n.1, p.48-54, 2010.

HENDERSON, C. Breast cancer: fundamentals of evidence-based disease management. Oxford Press: San Francisco, California. 2015.

HEYMSFIELD, S.B.; EBBELING, C.B.; ZHENG, J.; PIETROBELLI, A.; STRAUSS, B.J.; SILVA, A.M.; LUDWIG, D.S. Multi-Component Molecular-Level Body Composition Reference Methods: Evolving Concepts and Future Directions. Obesity Reveiws, v.16, n.4, p.282-294, 2015.

HEYMSFIELD, S.B.; SCHERZER, R.; PIETROBELLI, A.; LEWIS, C.E.; GRUNFELD, C. Body mass index as a phenotypic expression of adiposity: quantitative contribution of muscularity in a population-based sample. International Journal of Obesity, v.33, n.12, p.1363-1373, 2009. 
HEYMSFIELD, S.B.; SMITH, R.; AULET, M.; BENSEN, B.; LITCHMAN, S.; WANG, J.; JUNIOR PIERSON, R.N. Appendicular skeletal muscle mass: measurement by dual-photon absorptiometry. The American Journal of Clinical Nutrition, v.52, n.2, p.214-218, 1990.

HOJAN, K.; MOLIŃSKA-GLURA, M.; MILECKI, P. Physical activity and body composition, body physique, and quality of life in premenopausal breast cancer patients during endocrine therapy-a feasibility study. ActaOncologica, v. 52, n. 2, p. 319-326, 2013.

HONDA, K.; TAKESHITA, K.; MUROTANI, K.; MITSUMA, A.; HAYASHI, H.; TSUNODA, N.; KIKUMORI, T.; MUROHARA, T.; ANDO, Y.Assessment of left ventricular diastolic function during trastuzumab treatment in patients with HER2positivebreast cancer. Breast Cancer, 2016. [NO PRELO].

HOONING, M.J.; BOTMA, A.; ALEMAN, B.M.; BAAIJENS, M.H.; BARTELINK, H.; KLIJN, J.G.; TAYLOR, C.W.; VAN LEEUWEN, F.E. Decreased Risk of Stroke Among 10-Year Survivors of Breast Cancer. Journal of Clinical Oncology, v.24, n.34, p.5388-5394, 2006

IMAYAMA, I.; ALFANO, C.M.; NEUHOUSER, M.L.; GEORGE, S.M.; SMITH, W.A.; BAUMGARTNER, R.N.; BAUMGARTNER, K.B.; BERNSTEIN, L.; WANG, C.Y.; DUGGAN, C.; BALLARD-BARBASH, R.; MCTIERNAN, A. Weight, inflammation, cancer-related symptoms and heath related quality of life among breast cancer survivors. Breast Cancer Research and Treatment, v.140, n.1, p.159-176, 2013

INTERNACIONAL AGENCY FOR RESEARCH ON CANCER.GLOBOCAN 2012. Estimated cancer incidence, mortality and prevalence worldwide in 2012. Disponível em: <http://globocan.iarc.fr/Pages/fact_sheets_population.aspx, 2012> . Acessadoem $>$ 23/09/2015.

INTERNATIONAL ATOMIC ENERGY AGENCY.Radiation biology: a handbook for teachers and students. Viena, Áustria: IAEA, Press, 2010.

INWALD, E.C.; KOLLER, M.; KLINKHAMMER-SCHALKE, M.; ZEMAN, F.; HOFSTÄDTER, F.; LINDBERG, P.; GERSTENHAUER, M.; SCHÜLER, S.; TREECK, O.; ORTMANN, O. Adjuvant endocrine therapy in pre- versus postmenopausal patients with steroid hormone receptor-positive breast cancer: results from a large population-based cohort of a cancer registry. J Cancer Res ClinOnco, v.141, n.12, p.2229-2240, 2015.

IRALA, C.H. Qualidade de vida, resposta imune, consumo alimentar de pacientes com câncer de mama tratadas no Hospital Universitário de Brasília. 121 f., il. 2011. [Dissertação]. Mestrado em Nutrição Humana, Universidade de Brasília, Brasília, 2011. 
ISACCO, L.; DUCHE, P.; THIVEL, D.; MEDDAHI-PELLE, A.; LEMOINE-MOREL, S.; DUCLOS, M.; BOISSEAU, N. Fat mass localization alters fuel oxidation during exercise in normal weight women. MedSci Sports Exerc, v. 45, n. 10, p. 1887-1896, 2013. Acessado em 26/08/2015. doi: 10.1249/MSS.0b013e3182935fe3.

IWASE, T.; SANGAI, T.; NAGASHIMA, T.; SAKAKIBARA, J. HAYAMA, S.; ISHIGAMI, E.; MASUDA, T.; MIYAZAKI, M. Impact of body fat distribuition on neoadjuvant chemotherapy outcomes in advanced breast cancer patients. Cancer Medicine, v.5, n.1, p.41-48, 2016.

JEMAL, A.; WARD, E.; THUN, M. Declining death rates reflect progress against cancer. PLoS One, v. 5, n. 3, p. e9584, 2010.

JENKINS, P.; ELYAN, S.; FREEMAN, S. Obesity is not associated with increased myelosuppression in patients receiving chemotherapy for breast cancer. European Journal of Cancer, v.43, n.3, p.544-548, 2007.

JENNINGS, J.E. Dissection of the axilla in radical operations for cancer of the breast. Annals of Surgery, v.83, n.6, p.770-773, 1926.

KAMIŃSKA, M.; CISZEWSKI, T.; KUKIELKA-BUDNY, B.; KUBIATOWSKI, T.; BACZEWSKA, B.; MAKARA-STUDZIŃSKA, M.; STAROSLAWSKA, E.; BOJAR, I. Life quality of women with breast cancer after mastectomy or breast conserving therapy trated with adjuvant chemotherapy. Annals of Agricultural and Environmental Medicine, v.22, n.4, p.724-730, 2015.

KHAN, S.; SHUKLA, S.; SINHA, S.; MEERAN, S.M. Role of adipokines in obesityassociated breast cancer: therapeutic targets. Cytokine \&Gorwth Factor Reviews, v.24, n.6, p.503-513, 2013.

KIM, W.Y.; WOO, S. U.; SEO, J. H.; SON, G. S.; LEE, J. B.; BAE, J. W. Toxicities, dose reduction and delay of docetaxel and paclitaxel chemotherapy in breast cancer without distant metastases.Journal of Cancer Research and Therapeutics, v.7, n.4, p.412-415, 2011.

KIM, W.Y.; WOO, S.U.; SEO, J.H.; SON, G.S.; LEE, J.B.; BAE, J.W. Toxicities, dose reduction and delay of docetaxel and paclitaxel chemotherapy in breast cancer withoud distant metastases. Journal of Cancer Research and Therapeutics, v.7, n.4, p.412-415, 2011.

KIROVA, Y.M.; GAMBOTTI. L.; DE RYCKE, Y.; VILCOQ, JR.; ASSELAIN, B.; FOURQUET, A. Risk of second malignancies after adjuvant radiotherapy for breast 
cancer: a large-scale, single-institution review.International Journal of Radiation Oncology, Biology, Physics, v.68, n.2, p.359-363, 2007.

KLUTHCOVSKY, A.C.; URBANETZ, A.A. Qualidade de vida em pacientes sobreviventes de câncer de mama comparada à de mulheres saudáveis.

RevistaBrasileira de Ginecologia e Obstetrícia, v.34, n.10, p.453-458, 2012.

KRIJGSMAN, O.; ROEPMAN, P.; ZWART, W.; CARROLL, J.S.; TIAN, S.; SNOO, F.A.; BENDER, R.A.; BERNARDS, R.; GLAS, A.M. A diagnostic gene profile for molecular subtyping of breast cancer associated with treatment response. Breast Cancer Research and Treatment, v.133, n.1, p.133-137, 2012.

KROENKE, C.H.; KWAN, M.L.; NEUGUT, A.L.; ERGAS, I.J.; WRIGHT, J.D.; CAAN, B.J.; HERSHMAN, D.; KUSHI, L.H. Social networks, social support mechanisms, and quality of life breast cancer diagnosis. Breast Cancer Research and Treatment, v.139, n.2, p.515-527, 2013.

KRUMBHAAR, E. B.; KRUMBHAAR, H.D. The blood and bone marrow in yellow cross gas (mustard gas) poisoning: changes produced in the bone marrow of fatal cases. The Journal of Medical Research, v. 40, n. 3, p. 497, 1919.

KUERER, H.M.; NEWMAN, L.A.; SMITH, T.L.; AMES, F.C.; HUNT, K.K.; DHINGRA, K.; THERIAULT, R.L.; SINGH, G.; BINKLEY, S.M.; SNEIGE, N; BUCHHOLZ, T.A.; ROSS, M.I.; MCNEESE, M.D.; BUZDAR, A.U.; HORTOBAGYI, G.N.; SINGLETARY, S.E. Clinical Course of breast cancer patients with complete patologic primary tumor and axillary lymph node response to doxorubicin- based neoadjuvantchemoterapy. Journal of Clinical Oncology, v.17, n.2, p.460-469, 1999.

KUSHI, L.H.; DOYLE, C.; MCCULLOUGH, M.; ROCK, C.L.; DEMARKWAHNEFRIED, W.; BANDERA, E.V.; GAPSTUR, S.; PATEL, A.V.; ANDREWS, K.; GANSLER, T.The American Cancer Society 2010 Nutrition; Physical Activity Guidelines Advisory Committee. Reducing the Risk of Cancer With Healthy Food Choices and Physical Activity. CA Cancer J Clin, v.62, n.1, p.30-67, 2012.

KWAN, M.L.; CHEN, M.Y.; KROENKE, C.H.; WELTZIEN, E. K.; BEASLEY, J.M.; NECHUTA S.J.; POOLE, E.M.; LU, W.; HOLMES, M.D.; JUNIOR QUESENBERRY, C.P.; PIERCE, J.P.; SHU, X.O.; CAAN, B.J. Pre-diagnosis body mass index and survival after breast cancer in the After Breast Cancer Pooling Project. Breast Cancer Res Treat, v.132, n.2, p.729-739, 2012.

LEE, H.J.; PARK, I.A.; SONG, I.H.; KIM, S.B.; JUNG, K.H.; AHN, J.H.; AHN, S.H.; KIM, H.H.; GONG, G. Comparison of Pathologic Response Evaluation Systems after Anthracycline with/without Taxane-Based Neoadjuvant Chemotherapy among Different Subtypes of Breast Cancers. Plos one, v.10, n.9, p.e0137885. 2015. 
LEE, H.J.; SEO, A.N.; KIM, E.J.; JANG, M.H.; SUH, K.J.; RYU, H.S.; KIM, Y.J.; KIM, J.H.; IM, S.A.; GONG, G.; JUNG, K.H.; PARK, I.A.; PARK, S.Y. HER2 Heterogeneity Affects Trastuzumab Responses and Survival in Patients With HER2-Positive Metastatic Breast Cancer. American Journal of Clinical Pathology, v.142, n.6, p.755-766, 2014.

LEE, J.; AHN, M.H; JANG, Y.H.; LEE, E.J.; PARK, J.H.; RHO, J.; KIM, Z.;KIM, H.M.; HAN, S.W.; LIM, C.; LEE, M.H.; KIM, S.Y. Toxicity and quality of life of Korean breast cancer patients treated with docetaxel-containing chemotherapy without primary GCSF prophylaxis. Breast Cancer, v.21, n.6, p.670-676, 2014a.

LEE, K.H.; KEAM, B.; IM, S.A.; KIM; T.Y.; HAN, S.W.; OH, D.Y.; KIM, J.H.; LEE, S.H.; HAN, W.; KIM, D.W; KIM,T.Y.; PARK, I.A.; NOH, D.Y.;HEO, D.S.;BANG, Y.J. Body Mass Index Is Not Associated with Treatment Outcomes of Breast Cancer Patients Receiving Neoadjuvant Chemotherapy: Korean Data. Journal of Breast Cancer, v.15, n.4, p.427-433, 2012.

LEONG, A.; ZHUANG, Z.The Changing Role of Pathology in Breast Cancer Diagnosis and Treatment.Pathobiology, v.78, n.2, p.99-114, 2011.

LIEDTKE, C.; MAZOUNI, C.; HESS, K.R.; ANDRE, F.; TORDAI, A.; MEJIA, J.A.; SYMMANS, W.F.; GONZALEZ-ANGULO, A.M.; HENNESSY, B.; GREEN, M.; CRISTOFANILLI, M.; HORTOBAGYI, G.N.; PUSZTAI, L. Response to neoadjuvant therapy and long-term survival in patients with triple-negative breast cancer.Journal of Clinical Oncology, v.26, n.8, p.1275-1281, 2008.

LIN, N.U.; VANDERPLAS, A.; HUGHES, M.E.; THERIAULT, R.L.; EDGE, S.B.; WONG, Y.N.; BLAUNEY, D.W.; NILAND, J.C.; WINER, E.P.; WEEKS, J.C. Clinicopathologic Features, Patterns of Recurrence, and Survival Among Women With Triple-Negative Breast Cancer in the National Comprehensive Cancer Network. Cancer, v.118, n.22, p.5463-5472, 2012.

LITTON, J.K.; GONZALEZ-ANGULO, A.M.; WARNEKE, C.L.; BUZDAR, A.U.; KAU, S.W.; BONDY, M.; MAHABIR, S.; HORTOBAGYI, G.N.; BREWSTER, A.M. Relationship Between Obesity and Pathologic Response to Neoadjuvant Chemotherapy Among Women With Operable Breast Cancer. Journal of Clinical Oncololy, v.26, n.26, p.4072-4077, 2008.

LIU, L.N.; WEN, F.H.; MIASKOWSKI, C.; LIN, Y.C.; WANG, J.S.; JENG, C.; CHEN, M.L. Weight change trajectory in women with breast cancer receiving chemotherapy and the effect of different regimens. Journal of Clinical Nursing, v.23, n.19-20, p.2757-2768, 2014. 
LÔBO, S.A.; et al.Qualidade de vida em mulheres com neoplasias de mama em quimioterapia.Acta Paul Enferm, v.27, n.6, p.554-559, 2014.

LOCKER G.Y.; MANSEL, R.; CELLA, D.; DOBREZ, D.; SORENSEN, S.; GANDHI, S.S. Cost-effectiveness analysis of anastrozole versus tamoxifen as primary adjuvant therapy for postmenopausal women with early breast cancer: a US healthcare system perspective. The 5-year completed treatment analysis of the ATAC ('Arimidex', Tamoxifen Alone or in Combination) trial. Breast Cancer Research and Treatment, v. 106, n. 2, p. 229-238, 2007.

LOUE, S.; SAJATOVIC, M. Encyclopedia of aging and public health.Springer Science \& Business Media, Springer US, 2008.

MAAS, P.; BARRDAHL, M.; JOSHI, A.D.; AUER, PL.; GAUDET, M.M.; MILNE, R.L; SCHUMACHER, F.R.; ANDERSON, W.F.; CHECK, D.; CHATTOPADHYAY, S.; BAGLIETTO, L.; BERG, C.D.; CHANOCK, S.J.; COX, D.G.; FIGUEROA, J.D.; GAIL, M.H.; GRAUBARD, B.I.; HAIMAN, C.A.; HANKINSON, S.E.; HOOVER, R.N.; ISAACS, C.; KOLONEL, L.N.; LE MARCHAND, L.; LEE IM; LINDSTRÖM, S.; OVERVAD, K.; ROMIEU, I.; SANCHEZ, M.J.; SOUTHEY, M.C.; STRAM, D.O.; TUMINO, R.; VANDERWEELE, T.J.; WILLETT, W.C.; ZHANG, S.; BURING, J.E.; CANZIAN, F.; GAPSTUR, S.M.; HENDERSON, B.E.; HUNTER, D.J.; GILES, G.G.; PRENTICE, R.L.; ZIEGLER, R.G.; KRAFT, P.; GARCIA-CLOSAS, M.; CHATTERJEE, N. Breast Cancer Risk From Modifiable and Nonmodifiable Risk Factors Among White Women in the United States. JAMA Oncol.2016, [NO PRELO].

MACCIÒ, A.; MADEDDU, C. Obesity, Inflammation, and Postmenopausal Breast Cancer: Therapeutic Implications. The Scientific World Journal, v. 11, p. 20202036, 2011.Disponívelem: <http://www.ncbi.nlm.nih.gov/pmc/articles/PMC3217612/>. Acessadoem: 23/08/2015

MACCIÒ, A.; MADEDDU, C.; MANTOVANI, G. Adipose tissue as target organ in the treatment of hormone-dependent breast cancer: new therapeutic perspectives .Obesity Reviews, n.10, v.6, p.660-670. 2009.

MACGREGOR, A.B. The search for a chemical cure for cancer.Medical History, v. 10, n. 04, p. 374-385, 1966.

MACHIAVELLI, M.R.; ROMERO, A.O.; PÉREZ, J.E.; LACAVA, J.A.; DOMÍNGUEZ, M.E.; RODRIGUEZ, R.; BARBIERI, M.R.; ALCUÑA, R.L.A.; ALCUÑA. R.J.M.; LANGHI, M.J.; AMATO, S.; ORTIZ, E.H.; VALLEJO, C.T.; LEONE, B.A. Prognostic significance of pathological response of primary tumor and metastatic axillary lymph nodes after neoadjuvant chemotherapy for locally advanced breast carcinoma. The Cancer Journal from Scientific American, v. 4, n. 2, p. 125-131, 1997. 
MAHER, J.M.; MARKEY, J.C.; EBERT-MAY, D. The other half of the story: effect size analysis in quantitative research. CBE-Life Sciences Education, v. 12, n. 3, p. 345351, 2013.

MAKARI-JUDSON, G.; JUDSON, C.H.; MERTENS, W.C. Longitudinal Patterns of Weight Gain after Breast Cancer Diagnosis: Observations beyond the First Year. The Breast Journal, v.13, n.3, p.258-265, 2007.

MANDELBLATT, J.S.; et al. Associations of physical activity with quality of life and functional ability in breast cancer patients during active adjuvant treatment: the Pathways Study. Breast Cancer Research and Treatment, v. 129, n. 2, p. 521-529, 2011.

MANSEL, R.; LOCKER, G.; FALLOWFIELD, F.; BENEDICT, A.; JONES, D. Costeffectiveness analysis of anastrozolevstamoxifen in adjuvant therapy for early stage breast cancer in the United Kingdom: the 5-year completed treatment analysis of the ATAC ('Arimidex', Tamoxifen alone or in combination) trial. British Journal of Cancer, v. 97, n. 2, p.152-161, 2007.

MANTARRO, S.; ROSSI, M.; BONIFAZI, M.; D'AMICO, R.; BLANDIZZI, C.; LA VECCHIA, C.; NEGRI, E.; MOJA, L. Risk of severe cardiotoxicity following treatment with trastuzumab: a meta-analysis of randomized and cohort studies of 29,000 women with breast cancer. InternEmergMed, v.11, n. 1, p: 123-140, 2016. Acessado em: 12/01/2016, doi: 10.1007/s11739-015-1362-x.

MCLNNESS, J.A.; KNOBF, M.T.; Weight gain and quality of life in women treated with adjuvant chemotherapy for early-stage breast cancer. OncologyNursingForum, v.28, n.4, p.675-684, 2001.

MENDES, I.S.; TAKESHI, S.T.F.; CASTRO, G.S.; CESAR, M.R.R.; QUEIROZ, D.S.; PUPIO, F.S.L.; OLIVEIRA, A.A.; OLIVEIRA. M.L.; Correlação da dor e qualidade de vida de mulheres pós-tratamento cirúrgico de câncer de mama. $\mathbf{O}$ Mundo da Saúde. v.38, n.2, p.189-196, 2014.

MONTAGUE, E.D.; FLETCHER, G. H. Local regional effectiveness of surgery and radiation therapy in the treatment of breast cancer. Cancer, v. 55, n. S9, p. 2266$2272,1985$.

MORRISON, W. B. Cancer chemotherapy: an annotated history. Journal of Veterinary Internal Medicine, v. 24, n. 6, p. 1249-1262, 2010.

MOSCHER, C.E.; SLOANE, R.; MOREY, R.C.; SNYDER, D.C.; COHEN, H.J.; MILLER, P.E.; DEMARK-WAHNEFRIED, W. Associations between Lifestyle Factors and Quality of Life among Older, Long-term Breast, Prostate, and Colorectal Cancer 
Survivors.Cancer, v.115, n.17, p.4001-4009. 2009. Disponível em: <doi:10.1002/cncr.24436.> Acessado em: 12/01/2016

NATALI, P.G.; NICOTRA, M.R.; BIGOTTI, A.; VENTURO, I.; SLAMON, D.J.; FENDLY, B.M.; ULLRICH, A.; Expression of the p185 encoded by HER2 oncogene in normal and transformed human tissues. International Journal of Cancer, v. 45, n. 3, p. $457-461,1990$.

NATIONAL CENTER FOR BIOTECHNOLOGY INFORMATION.Homo sapiens erbb2 receptor tyrosine kinase 2 (ERBB2), RefSeqGene (LRG_724) on chromosome 17.2008. Disponível em:

<http://www.ncbi.nlm.nih.gov/nuccore/NG_007503.1>Acessado em 12122015.

NISSEN, M.K.; SHAPIRO, A.; SWENSON, K.K. Changes in weight and body composition in woman receiving chemotherapy for breast cancer.Clinical Breast Cancer, v.11, n.1, p.52-60, 2011.

NOMURA, Y.; YAMAGATA, J.; TAKENAKA, K.; TASHIRO, H. Steroid hormone receptors and clinical usefulness in human breast cancer.Cancer, v.15, n. 46, supl 12, p. 2880-2883, 1980.

ORDING, A.G.; BOFFETTA, P.; GARNE, J.P.; NYSTRÖM, P.M.W.; CRONINFENTON, D.; FROSLEV, T.; SILLIMAN, R.; SORENSEN, H.Y.; LASH. T.L.Relative mortality rates from incident chronic diseases among breast cancer survivors - A 14 year follow-up of five-year survivors diagnosed in Denmark between 1994 and 2007. European Journal of Cancer, v.51, n.6, p.767-775, 2015.

O'SULLIVAN, C.C.; SMITH, K.L. Therapeutic Considerations in Treating HER2Positive Metastatic Breast Cancer.Curr Breast Cancer Rep, v. 6, n. 3, p.169-182, 2014.

PACHARINSAK, C.; BEITZ, A. Animal models of cancer pain.Comparative Medicine, v. 58, n. 3, p. 220-233, 2008.

PACHIONI, F.S.M.; FREGONESI, C.E.P.T.; MANTOVANI, A.M.; O efeito da terapia morfoanalítica na qualidade de vida, estresse e flexibilidade de mulheres pós-cirurgia de câncer de mama. Manual Therapy, Posturology\& Rehabilitation Journal, v.12, p.95-114, 2014

PANIS, C.; PAVANELLI, W.R. Cytokines as Mediators of Pain-Related Process in Breast Cancer. Mediators of inflammation, v. 2015, 2015.doi:10.1155/2015/129034 
PAPAC, R.J. Origins of Cancer Therapy. Yale Journal of Biology and Medicine. v.74, n.6, p.391-398, 2001.

PAREKH, H. CHANDRAN, U. BANDERA, E.V. Obesity in cancer survival.Annual Review of Nutrition, v. 32, n.10, p.1-39, 2012.

PARISE, C.A.; BAUER, K.R.; BROWN, M.M.; CAGGIANO, V. Breast Cancer Subtypes as Defined by the Estrogen Receptor (ER), Progesterone Receptor (PR), and the Human Epidermal Growth Factor Receptor 2 (HER2) among Women with Invasive Breast Cancer in California, 1999-2004. Breast J, v.15, n.6, p. 593-602, 2009

PARISE, C.A.; CAGGIANO, V. Breast Cancer Survival Defined by the ER/PR/HER2 Subtypes and a Surrogate Classification according to Tumor Grade and Immunohistochemical Biomarkers. Journal of Cancer

Epidemiology,2014:469251.Acessado em 3/04/2015. doi: 10.1155/2014/469251.

PARKIN, D.M.; BRAY, F.; FERLAY, J.; PISANI, P. Global Cancer Statistic.A Cancer Journal for Clinicians,v. 55, n.2, p.74-108, 2012.

PARR, C.L.; BATTY, G.D.; LAM, T.H.; BARZI, F.; FANG, X.; HO, S.C.; JEE, S.H.; ANSARY-MOGHADDAM, A.; JAMROZIK, K.; UESHIMA, H.; WOODWARD, M.; HUXLEY, R.R.; Asia-Pacific Studies Collaboration. Body-mass index and cancer mortality in the Asia-Pacific Cohort Studies Collaboration: pooled analyses of 424, 519 participants. Lancet Oncol, v.11, n.8, p.741-52, 2010.

PATEY, D.H.; DYSON, W.H. The prognosis of carcinoma of the breast in relation to the type of operation performed. Br J Cancer, v.2, n.1, p: 7-13, 1948.

PAXTON, R.J.; PHILLIPS, K.L.; JONES, L.A.; CHANG, S.; TAYLOR, W.C.; COURNEYA, K.S.; PIERCE, J.P. Associations Among Physical Activity, Body Mass Index, and Health-Related Quality of Life by Race/Ethnicity in a Diverse Sample of Breast Cancer Survivors. Cancer, v.118, n.16, p. 4024-4031, 2012.

PEDERSEN, B.K.; FEBBRAIO, M.A. Muscles, exercise and obesity: skeletal muscle as a secretory organ. Nature Reviews Endocrinology, v.8, n.8, p.457-465, 2012.

PERDERSEN, B.K.; STEENSBERG, A.; KELLER, P.; KELLER, C.; FISCHER, C.; HISCOCK, N.; VAN HALL, G.; PLOMGAARD, P.; FEBBRAIO, M.A. Muscle-derived interleuking-6: lipotyc, anti-inflammatory and immune regulatory effects.

PflügersArchiv, v.446, n.1, p.9-16, 2003. 
PEREIRA, M.G. Epidemiologia: Teoria e Prática. Rio de Janeiro. Guanabara Koogan. 2005.

PEROU, C.M.; SERLIE, T.; EISEN, M.B.; RIJN, M.V.D.; JEFFREY, S.S.; REES, C.A.; POLLACK, J.R.; ROSS, D.T.; JOHNSEN, H.; AKSLEN, L.A.; FLUGE, O.; PERGAMENSCLICKOV.; WILLIAMS, C.; ZHU, S.X.; LENNING, P.E.; BORRESENDALE, A.; BROWN, P.O.; BOTSTEIN, D. Molecular PortraitsofHumanBreastTumours. Letters to Nature.v.406, n.6797, p.747-752, 2000.

PHIPPS, A.I.; MALONE, K.E.; PORTER, P.L.; DALING, J.R.; LI, C.I. Body size and risk of luminal, HER2-overexpressing, and triple negative breast cancer in postmenopausal women. Cancer epidemiol biomarkers prev, v.17, n.8, p.20782086, 2008.

PIERCE, L.J. Treatment guidelines and techniques in delivery of postmastectomy radiotherapy in management of operable breast cancer. Journal of the National Cancer Institute, Monographs, v. 30, p.117-124, 2001.

PLAYDON, M.C.; BRACKEN, M.B.; SANFT, T.B.; LIGIBEL, J.A.; HARRIGAN, M.; IRWIN, M.L. Weight Gain After Breast Cancer Diagnosis and All-Cause Mortality: Systematic Review and Meta-Analysis. J Natl Cancer Inst, v.107, n.12, p. 1-15, 2015.

PODBREGAR, M.; LAINSCAK, M.; PRELOVSEK, O.; MARS, T. Cytokine response of cultured skeletal muscle cells stimulated with proinflammatory factors depends on differentiation stage. The Scientific World Journal, v. 2013, 2013. Disponível em: http://www.ncbi.nlm.nih.gov/pmc/articles/PMC3590685/ .Acessado em: 2/08/2015.

POIKONNEM, P.; BLOMGVIST, C.; JOENSUU, H. Effect of obesity on the leukocyte nadir in women treated with adjuvant cyclophosphamide, methotrexate, and fluorouracil dosed according to body surface area.ActaOncologica, v. 40, n. 1, p. 6771, 2001.

POWELL, S. Radiotherapy for breast cancer in the 21st Century. The Breast Journal, v. 16, p.S34-S38, supl.1, 2010.

PRADO, M.M.C.; MAIA, L.M.; ORMSBEE, Y.; SAWYER, M.M.B.; BARACOS, B. $\mathrm{V}$. Assessment of nutritional status in cancer-the relationship between body composition and pharmacokinetics. Anti-Cancer Agents in Medicinal Chemistry (Formerly Current Medicinal Chemistry-Anti-Cancer Agents), v. 13, n. 8, p. 11971203, 2013.

PRADO, C.M.M.; LIMA, I.S.F.; BARACOS, V.E.; BIES, R.R.; MCCARGAR, L.J.; REINMAN, T.; MACKEY, J.R.; KUZMA, M.; DAMARAJU, V.L.; SAWYER, M.B. An 
exploratory study of body composition as a determinant of epirubicin pharmacokinetics and toxicity.Cancer ChemotherPharmacol, v.67, n.1, p.93-101. 2011.

PRADO, C.M.M.; BARACOS, V.E.; MACCARGAR, L.J.; REIMAN, T.; MOUTZAKIS, M.; TONKIN, K,; MACKEY, J.R.; KOSKI, S.; PITUSKIN, E.; SAWYER, M.B. Sarcopenia as a Determinant of Chemotherapy Toxicity and Time to Tumor Progression in Metastatic Breast Cancer Patients Receiving Capecitabine Treatment. Clin Cancer Res, v.15, n.8, p.2920-2926. 2009.

PRADO, C.M.M.; LIEFFERS, J.R.; MCCARGAR, L.J.; REIMAN, T.; SAWYER, M.B.; MARTIN, L.; BARRACOS, V.E. Prevalence and clinical implications of sarcopenic obesity in patients with solid tumors of the respiratory and gastrointestinal tracts: A population-based study. Lancet Oncol, v.9, n.7, p.629-635. 2008.

PRADO, C.M.M.; BARACOS, V.E.; MCCARGAR, L.J.; MOURTZAKIS, M.; MULDER, K.E.; REIMAN, T.; BUTTS, C.A.; SCARFE, A.G.; SAWYER, M.B. Body Composition as an Independent Determinant of 5-Fluorouracil- Based Chemotherapy Toxicity.

Clinical Cancer Research, v.13, n.11, p.3264-3268. 2007.

PROTANI, M.; COORY, M.; MARTIN, J.H. Effect of obesity on survival of women with breast cancer: systematic review and meta-analysis. Breast Cancer Research and Treatment, v.123, n.3, p.627-35, 2010.

PUTSZTAI L.; MAZOUNI C.; ANDERSON K.; WU Y.; SYMMANS W. F. Molecular Classification of Breast Cancer: Limitations and Potentials. The Oncologist, v.11, n.8, p.868-877, 2006

QUINTEL, C.; MARTINELLI, F.; COENS, C.; SPRANGERS, M.A.; RIGNASH, J.; GOTAY, C.; BJORDAL, K.; GREIMEL, E.; REEVE, B.B.; MARINGWA, J.; EDIEBAH, D.E.; ZIKOS, E.; KING, M.T.; OSOBA, D.; TAPHOORN, M.J.; FLECHTNER, H.; SCHUMACKER-VON KOCH, J. WEIS, J.; BOTTOMLEY, A. A global analysis of multitrial data investigating quality of life and symptoms as prognostic factors for survival in different tumor sites.Cancer, v.120, n.2, p.302-311, 2014.

RAKHA E.A.; ELLIS I.O. Modern Classification of Beast Cancer: Should we Stick With Morphology or Convert to Molecular Profile Characteristics. Advances in Anatomic Pathology, v.18, n.4, p. 255-267, 2011

RAYTER, Z.; MANSI, J. History of breast cancer therapy.Medical therapy of breast cancer, Ed. Rayter, 2003. Disponível em:

$<$ https://www.google.com.br/url?sa=t\&rct=i\&q=\&esrc=s\&source=web\&cd=1\&cad=rja\& uact $=8 \&$ ved=0ahUKEwjy2qeQ45zNAhWNnJAKHXPNBU0QFgghMAA\&url=http\%3A \%2F\%2Fcatdir.loc.gov\%2Fcatdir\%2Fsamples\%2Fcam033\%2F2001043947.pdf\&usg= 
AFQjCNFORGm8BNhVRZ8cS3gTRMnVyelrQ\&sig2=nJFzLQK6ygDJr6GFKR5YwA>. Acessadoem: 02/12/2015

REDDY, P.; CHOW, M.S. Safety and efficacy of antiestrogens for prevention of breast cancer.Am J Health Syst Pharm, v. 57, n. 14, p: 1315-1322, 2000.

REEVES, G.K.; PIRIE, K.; BERAL, V.; GREEN, J.; SPENCER, E.; BULL, D. Cancer incidence and mortality in relation to body mass index in the Million Women Study: cohort study. BMJ, v.335, n.7630, P; 1134, 2007

RIBEIRO, L.F.J. Estudo randomizado comparando drenagem versus não drenagem após linfadenectomia axilar por câncer de mama. 2010. 86 f., il. Tese (Doutorado em Ciências da Saúde)-Universidade de Brasília, Brasília, 2010.

ROBERTSON, J.F. Fulvestrant (Faslodex) -- how to make a good drug better.Oncologist, v.12, n. 7, p: 774-784, 2007.

ROCKENBACH, G.; DI PIETRO, P.F.; AMBROSI, C.; BOAVENTURA, B.C.; VIEIRA, F.G.; CRIPPA, C.G.; DA SILVA, E.L.; FAUSTO, M. A. Dietary intake and oxidative stress in breast cancer: before and after treatments. NutrHosp, v.26, n.4, p.737-44, 2011.

RODRÍGUEZ, M.J.; MARTÍNEZ, A.G.; BEGOÑA, M.K. Influencia del peso corporal enelpronóstico de lassupervivientes de cáncer de mama: abordaje nutricional trasel diagnóstico. NutriciónHospitalaria, v. 28, n. 6, p. 1829-1841, 2013.

ROSNER, G.L.; HARGIS, J.B.; HOLLIS, D.R.; WEISS, R.B.; HENDERSON, I.C.; SCHILSKY, R.L. Relationship between toxicity and obesity in women receiving adjuvant chemotherapy for breast cancer: results from cancer and leukemia group $B$ study 8541. Journal of Clinical Oncology, v.14, n.11, p.3000-3008, 1996.

SAKORAFAS, G.H. Breast Cancer Surgery- Historical Evolution, Current Status and Future Perspectives. Acta Oncologica. v.40, n.1, p.5-18, 2001.

SANTO, H.E.; DANIEL, F.B. Calcular e apresentar tamanhos do efeito em trabalhos científicos: As limitações do $p<0,05$ na análise de diferenças de médias de dois grupos. Revista Portuguesa de Investigação Comportamental e Social, v.1, n.1, p: 3-16. 2015.

SANTOS JÚNIOR, N.C. Depressão, ansiedade e qualidade de vida em mulheres em tratamento de câncer de mama. 2010. 70 f. Dissertação (Mestrado em Ciências da Saúde)-Universidade de Brasília, Brasília, 2010. 
SARRAZIN, D.; LÊ, M.G.; ARRIAGADA, R.; CONTESSO, G.; FONTAINE, F.; SPIELMANN, M.; ROCHARD, F.; CHEVALIER, T.L.; LACOUR, J. Ten-year results of a randomized trial comparing a conservative treatment to mastectomy in early breast cancer.Radiotherapy and Oncology, v.14, n.3, p.177-184. 1989.

SCHNITT, S.J. Classification and Prognosis of Invasive Breast Cancer: From Morphology to Molecular Taxonomy. Modern Pathology. v. 23, p: 560-564, supl.2. 2010.

SCHWENTNER, L.; HARBECK, N.; SINGER, S.; EICHLER, M.; RACK, B.; FORSTBAUER, H.; WISCHNIK, A.; SCHOLZ, C.; HUOBER, J.; FRIEDL, T.W.; WEISSENBACHER, T.; HÄRTL, K.; KIECHLE, M.; JANNI, W.; FINK, V. Short term quality of life with epirubicin-fluorouracil-cyclophosphamid (FEC) and sequential epirubicin/cyclophosphamid-docetaxel (EC-DOC) chemotherapy in patients with primary breast cancer - Results from the prospective multi-center randomized ADEBAR trial. Breast, v.27, p.69-77. 2016

SCOTT, A.M.; WOLCHOK, J.D.; OLD, L.J. Antibody therapy of cancer. Nature Reviews Cancer, v. 12, n. 4, p. 278-287, 2012.

SEDJO, R.L.; BYERS, T.; BARRERA JUNIOR, E.; COHEN, C.; FONTHAM, E.T.; NEWMAN, L.A.; RUNOWICZ, C.D.; THORSON, A.G.; THUN, M.J.; WARD, E.; WENDER, R.C.; EYRE, H.J.; ACS Cancer Incidence \& Mortality Ends Committee. A Midpoint Assessment of the American Cancer Society Challenge Goal to Decrease Cancer Incidence by 25\% Between 1992 and 2015. CA Cancer J Clin., v.57, n.6, p. 326-340, 2007.

SHILS, M.E.; SHIKE, M. Modern nutrition in health and disease.Lippincott Williams \& Wilkins, 2006.

SIEGEL, P.M.; DANKORT, D.L.; HARDY, W.R.; MULLER, W.J. Novel activating mutations in the neu proto-oncogene involved in induction of mammary tumors. Mol Cell Biol, v.14, n.11, p: 7068-7077, 1994.

SIEGEL, R.; NAISHADHAM, D.; JEMAL, A. Cancer Statistics 2012.CA. A cancer Journal for Clinicians, v.62, n.5, p.10-29. 2012

SIEGEL, R.L.; FEDEWA, S.A.; MILLER, K.D.; GODING-SAUER, A.; PINHEIRO, P.S.; MARTINEZ-TYSON, D.; JEMAL, A. Cancer statistics for Hispanics/Latinos, 2015. CA: A Cancer Journal for Clinicians, v. 65, n. 6, p. 457-480, 2015. 
SIMEÃO, S.F.A.P.; LANDRO, I.C.R.; CONTI, M.H.S.; GATTI, M.A.N.; DELGALLO, W.D.; VITTA, A.D. Qualidade de vida em grupos de mulheres acometidas de câncer de mama. Ciênc Saúde Coletiva, v.18, n.3, p.779-88, 2013.

SIMONE, V.; D'AVENIA, M.O.R.E.N.A.; ARGENTIERO, A.; FELICI, C.; RIZZO, F.; DE PERGOLA, G.; SILVESTRIS. Obesity and Breast Cancer: Molecular Interconnections and Potential Clinical Applications. Oncologist, v.21, n.4, P.404-417, 2016.

SIMPSON, E.R.; BROWN, K.A. Obesity and breast cancer: role of inflammation and aromatase. Journal of Molecular Endocrinology, v. 51, n. 3, p. T51-T59, 2013.

SKEEL, R.T.; KHLEIF, S. N. Handbook of cancer chemotherapy.Lippincott Williams \& Wilkins, 2011.

SLATTERY, M.L.; CURTIN, K.; SWEENEY, C.; WOLFF, R.K.; BAUMGARTNER, R.N.; BAUMGARTNER, K.B.; GIULIANO, A.R.; BYERS, T.Modifying Effects of IL-6 Polymorphisms on Body Size- Associated Breast Cancer Risk. Obesity (Silver Spring), v.16, n.2, p.339-347. 2008.

SLEDGE, G.W.; MAMOUNAS, E.P.; HORTOBAGYI, G.N.; BURSTEIN, H.J.; GOODWIN, P.J.; WOLFF, A.C. Past, present, and future challenges in breast cancer treatment. Journal of Clinical Oncology, v. 32, n. 19, p. 1979-1986, 2014.

SMITH, T.J. et al. Recommendations for the use of WBC growth factors: American Society of Clinical Oncology clinical practice guideline update. Journal of Clinical Oncology, v. 33, n. 28, p. 3199-3212, 2015.

SOBIN, L.H.; GOSPODAROWICZ, M.K.; WITTEKIND, C. TNM Classification of Malignant Tumours. 7a ed. West sussex: Willey-Blackwell. 2009.

SONG, M.; GIOVANNUCCI, E. Preventable Incidence and Mortality of Carcinoma Associated With Lifestyle Factors Among White Adults in the United States. JAMA Oncol. 2016, Acessado em: 22/05/2016, doi: 10.1001/jamaoncol.2016.0843. [NO PRELO]

SØRLIE, Thereseet al.Gene expression patterns of breast carcinomas distinguish tumor subclasses with clinical implications. Proceedings of the National Academy of Sciences, v. 98, n. 19, p. 10869-10874, 2001.

SOTIROU, C.; NEO, S.Y.; MCSHANE, L.M.; KORN, E.L.; LONG, P.M.; JAZAERI, A.; MARTIAT, P.; FOX, S.B.; HARRIS, A.L.; LIU, E.T. Breast cancer classification and prognosis based on gene expression profiles from a population-based study. Pnas, v.100, n.18, p.10393-10398, 2003. 
SOUSA, M.G.B.; PINHEIRO, M.M.; SZEJNFELD, V.L.; CASTRO, C.H.M. Body Composition Parameters in Healthy Brazilian Women Differ From White, Black, and Hispanic American Women Reference Range. Journal of clinical densitometry: assessment \& management of musculoskeletal, v.16, n.3, p.360-367, 2013.

SPARREBOOM, A.; WOLFF, A.C.; MATHIJSSEN, R.H.; CHATELUT, E.; ROWINSKY, E.K.; VERWEIJ, J.; BAKER, S.D. Evaluation of alternate size descriptors for dose calculation of anticancer drugs in the obese. Journal of Clinical Oncology, v. 25, n. 30, p. 4707-4713, 2007.

SUN, X.; NICHOLS, H.B.; ROBINSON, W.; SHERMAN, M.E.; OLSHAN, A.F.; TROESTER, M.A. Post-diagnosis adiposity and survival among breast cancer patients: influence of breast cancer subtype. Cances causes control, v.26, n.12, p.1803-1811, 2015.

THARIAT, J.; HANNOUN-LEVI, J.M.; MYINT, A.S.; VUONG, T.; GÉRARD, J.P. Past, present, and future of radiotherapy for the benefit of patients. Nat rev clinoncol, v.10, n.1, p. 52-60, 2013.

THIBAULT, R.; CANO, N.; PICHARD, C. Quantification of lean tissue losses during cancer and HIV infection/AIDS.CurrOpinClinNutrMetab Care, v.14, n.3, p.261-267, 2011.

THIBAUT, R.; GENTON, L.; PICHARD, C.Body composition: Why, when and for who? Clinical Nutrition, v.31, n.4, p.435-447, 2012.

THILL, M.; PISA, G.; ISBARY, G. Targets for Neoadjuvant Therapy-The Preferences of Patients with Early Breast Cancer. Geburtshilfe und Frauenheilkunde, v. 76, n. 05, p. 551-556, 2016.

THIVAT, E.; THÉRONDEL, S.; LAPIROT, O.; ABRIAL C.; GIMBERGUES P.; GADÉA E.; PLANCHAT E.; KWIATKOWSKI F.; MOURET-REYNIER M. A.; CHOLLET P.; DURANDO X. Weight change during chemotherapy changes the prognosis in nonmetastatic breast cancer for the worse. BMC Cancer, v.10, n.648, p.2-9, 2010.

THONG, M. S. Y.; MOLS F.; STEIN K. D.; SMITH T.; COEBERGH J. W; VAN DE POLL-FRANSE L.V. Population-Based Cancer Registries for Quality-of-Life Research: a work-in-progress resource for survivorship studies?. American Cancer Society, v.1, n.119, p. 2109-2123, 2013.

TOKALTI, F.; KAYA, M.; KOCAK, Z.; TURE, M.; MERT, S.; UNLU, E.; ALKAYA, F.; CAKIR, B. Sequential pulmonary effects of radiotherapy detected by functional and 
radiological end points in women with breast cancer. J. ClinOncol (R Coll Radiol).v.17, n.1, p. 39-46, 2005.

TOLENTINO, G.P. Análise da potência aeróbia e estados de humor em mulheres sobreviventes ao câncer de mama. 2007. 144 f. Dissertação (Mestrado) Universidade Católica de Brasília, Brasília, 2007.

TOLENTINO, G.P.; BATTAGLINI, C.L.; ARAUJO, S.S.; OTANO, A.S.; CONDE, D. M.; EVANS, E.S.; OLIVEIRA, R.J. Cardiorespiratory fitness andquality-oflifeanalysisposttreatment in breastcancersurvivors. Journal of psychosocial oncology, v. 28, n. 4, p. 381-398, 2010.

TORO, A.L.; COSTANTINO, N.S.; SHRIVER, C.D.; ELLSWORTH, D.L.; ELLSWORTH, R.E. Effect of obesity on molecular characteristics of invasive breast tumors: gene expression analysis in a large cohort of female patients. BMC Obes, v.3, n.22, 2016. Acessadoem: 29/10/2015. doi: 10.1186/s40608-016-0103-

7. eCollection, 2016.

UNDÉN, A.L.; ANDRÉASSON, A.; ELOFSSON, S.; BRISMAR, K.; MATHSSON, L.; RÖNNELID, J.; LEKANDER, M. Inflammatory cytokines, behaviour and age as determinants of self-rated health in women. ClinSci (Lond), v.112, n. 6, p. 363-373, 2007.

URBAN, J.A. Surgical excision of internal mammary nodes for breast cancer. $\mathbf{B r} \mathbf{J}$ Surg, v.51, p: 206-212, 1964.

VAN DE VIJER, M.J. Molecular tests as prognostic factors in breast cancer. Virchows Arch, v.464, n.3, p.283-291. 2014;

VAN DER KLOOT, W.A., UCHIDA, Y.; INOUE, K.; KOBAYASHI, K.; YAMAOKA, K.; NORTIER, H.W.; KAPTEIN, A.A. The effects of illness beliefs and chemotherapy impact on quality of life in Japanese and Dutch patients with breast or lung cancer. Chinese Clinical Oncology, v. 5, n. 1, p. 1-12, 2016.

VANA, J.; BEDWANI, R.; METTLIN, C.; MURPHY, G.P. Trends in diagnosis and management of breast cancer in the US: from the surveys of the American College of Surgeons. Cancer, v. 48, n. 4, p. 1043-1052, 1981.

VANCE, V.; MOURTZAKIS, M.; MCCARGAR, L.; HANNING, R. Weight gain in breast cancer survivors: prevalence, pattern and health consequences. Obesity Reviews, v. 12, n. 4, p. 282-294, 2011. 
VEIGA, D.F.; et al.Mastectomy versus conservative surgical treatment: the impact on the quality of life of women with breast cancer. RevistaBrasileira de

SaúdeMaternolnfantil, v. 10, n. 1, p. 51-57, 2010.

VELLOSO, F.S.B.; BARRA, A.A.; DIAS, R.C. Functional performance of upper limb and quality of life after sentinel lymph node biopsy of breast cancer.Brazilian Journal of Physical Therapy, v. 15, n. 2, p. 146-153, 2011.

VENTER, D.; KUMAR, S.; TUZI, N.; GULLICK, W. Overexpression of the c-erbB-2 oncoprotein in human breast carcinomas: immunohistological assessment correlates with gene amplification. The Lancet, v. 330, n. 8550, p. 69-72, 1987.

VERONESI, U. Quadrantectomy versus lumpectomy for small size breast cancer.European Journal of Cancer and Clinical Oncology, v. 26, n. 6, p. 671-673, 1990.

VIEIRA, C. A. Efeitos de diferentes intervalos de recuperação entre séries de contrações isocinéticas na recuperação da força de mulheres sobreviventes de câncer de mama. 2014. 77 f. Tese (Doutorado em Ciências da Saúde) -Universidade de Brasília, Brasília, 2014.

VINAY KUMAR. Robbins \&Cotran Patologia - Bases Patológicas das Doenças .6 ed. São Paulo:ElsevierBrasil, 2011.

VOSKUIL, D.W.; VAN NES, J.G.H.; JUNGGEBURT, J.M.C.; VAN DE VELDE, C.J.H.; VAN LEEUWEN, F.E.; HAES, J.C.J.M. Maintenance of physical activity and body weight in relation to subsequent quality of life in postmenopausal breast cancer patients. AnnalsofOncology, v.21, n.10,p.2094 - 2101, 2010.

WAITZBERG, D.L. Nutrição oral, enteral e parenteral na prática clínica. Atheneu, 2009.São Paulo; Atheneu; 2009.

WATERS, D.L.; BAUMGARTNER, Richard N. Sarcopenia and obesity.Clinics in geriatric medicine, v. 27, n. 3, p. 401-421, 2011.

WILLIAMS, J.E.; WELLS, J.C.; WILSON, C. M.; HAROUN, D.; LUCAS, A.; FEWTRELL, M. S.; et al. Evaluation of Lunar Prodigy dual-energy X-ray absorptiometry for assessing body composition in healthy persons and patients by comparison with the criterion 4-component model. The American journal of clinical nutrition, v. 83, n. 5, p. 1047-1054, 2006.

WINCHESTER, D.J.; MENCK, H.R.; WINCHESTER, D.P. The National Cancer Data Base Report on the Results of a Large Nonrandomized Comparison of Breast 
Preservation and Modified Radical Mastectomy. Commission on Cancer and the American Cancer Society. v.80, n.1, p:162-167, 1997.

WINGO, P. A.; CARDINEZ, C.J.; LANDIS, .SH.; GREENLEE, R.T.; RIES, L.A.; ANDERSON, R.N.; THUN, M.J. Long-term trends in cancer mortality in the United States, 1930-1998. Cancer, v. 97, n. S12, p. 3133-3275, 2003.

WOLIN, K.Y.; CARSON, K.; COLDITZ, G.A. Obesity and Cancer.Oncologist, v.15, n.6, p. 556-65, 2010.

WONDERGEM, J. Circulating atrial natriuretic peptide plasma levels as a marker for cardiac damage after radiotherapy. RadiotherOncol. v.58, n.3, p:295-301, 2001.

WONG, A. L. et al. Body fat composition impacts the hematologic toxicities and pharmacokinetics of doxorubicin in Asian breast cancer patients. Breast cancer research and treatment, v. 144, n. 1, p. 143-152, 2014.

WONG, M.; BALLEINE, R.L.; BLAIR, E.Y.; MCLACHLAN, A.J.; ACKLAND, S.P.; GARG, M.B.; EVANS, S.; FARLOW, D.; COLLINS, M.; RIVORY, L.P.; HOSKINS, J.M.; MANN, G.J.; CLARKE, C.L.; GURNEY, H.Predictors of vinorelbine pharmacokinetics and pharmacodynamics in patients with cancer. J ClinOncol, v.24, n.16, p. 2448-2455, 2006.

WOLRD HELATH ORGANIZATION (WHO). Obesity: preventing and managing the global epidemic.Report of a WHO Consultation. WHO Technical Report Series 894. Geneva: World Health Organization, 2000. 253 p. Disponível em:

<http://whqlibdoc.who.int/trs/WHO_TRS_894.pdf> Acessado em: 01/02/2007

WORLD HEALTH ORGANIZATION. Physical Status: The Use and Interpretation of Anthropometry. Geneva: World Health Organization, 1995. WHO Technical Report Series 854. Disponívelem: <

https://www.google.com.br/url?sa $=t \& r c t=j \& q=\& e s r c=s \&$ source $=$ web \&cd $=1 \& c a d=r j a \& u$ act=8\&ved=0ahUKEwjbkNv_ HNAhVCS5AKHTkWCp4QFggjMAA\&url=http\%3A\%2 F\%2Fwww.who.int\%2Fchildgrowth\%2Fpublications\%2Fphysical_status\%2Fen\%2F\&u sg=AFQjCNG-7AS-rUBGLIQVpQPj59f308_PpQ\&sig2=Sukzqu7xBbwdz6MN2nilag >. Acessadoem: 23/04/2010

WORLD HEALTH ORGANIZATION.WHO Working Group.Use and Interpretation of Anthropometric Indicators of Nutritional Status. Bulletin of the World Health Organization, v. 64, n.6, p. 929-941, 1986.

YARDEN, Y. Biology of HER2 and its importance in breast cancer.Oncology, v. 61, supl.2, p. 1-13, 200. 
YAW, Y.H.; SHARIFF, Z.M.; KANDIAH, M.; MUN, C.Y.; YUSOF, R.M.; OTHMAN, Z.; SAIBUL, N.; WEAY, Y.H.; HASHIM, Z. Weight changes and lifestyle behaviors in women after breast cancer diagnosis: a cross-sectional study. BMC Public Health, v.11, n.309, p.1-10, 2011.

YUEN, D.Y.C.; et al. Interleukin-6 attenuates insulin-mediated increases in endothelial cell signaling but augments skeletal muscle insulin action via differential effects on tumor necrosis factor-a expression. Diabetes, v. 58, n. 5, p. 086-1095, 2009.

ZAMAN, K.; BODMER, A.; PRALONG, F.; CASTIGLIONE-GERTSCH, M. Cancer du seinetobésité, une liaison dangereuse. RevueMédicaleSuisse, v. 8, n. 342, p. 11011104, 2012.

APÊNDICE A - Perfil socioeconômico e cultural

Nome:

1) Data de nascimento:

2) Naturalidade:

3) Qual sue estado civil ?

( ) solteiro ( ) união estável ( ) casado ( ) viúvo ( ) divorciado ( ) outro

4) Qual seu nível de escolaridade?

( ) não-alfabetizado;

( ) Concluiu até a 4ํㅗㄹie;

( ) Ensino fundamental completo

( ) Ensino superior incompleto

( ) Pós graduação lato-sensu

( ) alfabetizado;

( ) Ensino fundamental incompleto

( ) Ensino médio incompleto

( ) Ensino superior completo

( ) Pós graduação stricto-sensu 
5) Quantos dependentes você possui?
( ) Nenhum
( ) 4 dependentes
( ) 1 dependente
( ) 2 dependentes ( ) 3 dependentes dependentes
( ) 8 dependentes
( ) 5 dependentes
( ) 6 dependentes ( ) 7
( ) 9 dependentes
( ) acima de 10

6) Você possui alguma religião ou crença? ( ) Não ( ) Sim.

Se a resposta for SIM, pro favor assinale uma das opções abaixo:
( ) Católica
( ) Evangélica
( ) Induísmo
( ) Judaísmo
( ) Outra.
( ) Espiritismo
( ) Budismo
Qual?

7) Você praticava alguma atividade física regular, no mínimo 3 vezes por semana, com duração mínima de 30 minutos por sessão antes do Diagnóstico de Câncer de Mama?
( ) Não
( ) Sim

Caso a respostas seja SIM, por favor escreva qual era essa atividade e qual era a duração dessa prática.

8) Você FAZ uso regular de algum outro medicamento além daqueles prescritos para tratamento do câncer de mama? ( ) Não ( ) Sim.

Caso a resposta seja SIM, por favor, escreva o nome do(s) medicamento(s) utilizado(s)

9) Por favor, assinale qual o estágio reprodutivo você se encontra.

( ) pré-menopausa ( ) pós-menopausa

\begin{tabular}{|l|l|l|}
\hline 28) Você tem o hábito de fumar? & ( ) SIM & ( ) NÃO \\
\hline $\begin{array}{l}\text { Você tinha o hábito de fumar antes do diagnóstico de câncer } \\
\text { de mama? }\end{array}$ & ( ) SIM & ( ) NÂO \\
\hline 29) Você tem o hábito de consumir bebidas alcoólicas? & ( ) SIM & ( ) NÃO \\
\hline $\begin{array}{l}\text { Você consumia bebidas alcoólicas antes do diagnóstico de } \\
\text { câncer de mama? }\end{array}$ & ( ) SIM & ( ) NẪO \\
\hline
\end{tabular}

\begin{tabular}{|l|l|l|l|}
\hline 30) Você tem plano de saúde? & $\begin{array}{l}\text { ( ) } \\
\text { SIM }\end{array}$ & ( ) NÃO & Qual: \\
\hline $\begin{array}{l}\text { 31) O médico Ihe informou que } \\
\text { você possui alguma outra } \\
\text { doença? }\end{array}$ & SIM & ( ) NÃO & Qual: \\
\hline $\begin{array}{l}\text { 32) Você faz uso diário de } \\
\text { algum remédio indicado pelo } \\
\text { médico? }\end{array}$ & $\begin{array}{l}\text { ( ) } \\
\text { SIM }\end{array}$ & ( ) NÃO & Qual: \\
\hline
\end{tabular}




\section{APËNDICE B - TERMO DE CONSENTIMENTO LIVRE E ESCLARECIDO Termo de Consentimento Livre e Esclarecido - TCLE}

A Senhora está sendo convidada a participar do projeto: Alterações da composição corporal e qualidade de vida em mulheres diagnosticadas com câncer de mama e submetidas ao tratamento quimioterápico no Distrito Federal. Que tem como objetivo comparar a composição corporal em mulheres diagnosticadas com câncer de mama nos períodos pré e pós quimioterapia. Com a intenção de avaliar como o peso e gordura corporal irão variar após este tratamento, e de que forma esta variação pode influenciar o curso do tratamento do câncer. 
A senhora receberá todos os esclarecimentos necessários antes e no decorrer da pesquisa e lhe asseguramos que seu nome não aparecerá sendo mantido o mais rigoroso sigilo através da omissão total de quaisquer informações que permitam identificá-la.

A sua participação limitar-se-á a responder 0 inquérito do perfil socioeconômico e cultural, o questionário de atividade física habitual de Baecke, o questionário genérico de qualidade de vida relacionada à saúde Medical OutcomesStudy 36 - Item Short-Form Health Survey (SF-36), que levarão um tempo médio de 30 (trinta) minutos para serem aplicados. A Sra também realizará medidas da massa corporal (peso) e estatura, além do exame de densitometria óssea, que acontecerão antes e após as sessões de quimiterapia, no Laboratório de Imagem da faculdade de Educação Física da UnB (endereço: av L4 Norte, campus da UnB), na data combinada com um tempo estimado 30 (trinta) minutos. Não existindo, obrigatoriamente, um tempo pré-determinado, para responder os questionários ou realizar os exames. Será respeitado o tempo de cada um. Informamos que a Senhora pode se recusar a prestar qualquer informação ou não realizar qualquer procedimento que lhe traga constrangimento, podendo desistir de participar da pesquisa em qualquer momento sem nenhum prejuízo para a senhora.

Também faz-se necessário que a Sraconsita o acesso ao seu prontuário médico a pesquisadora Grassyara Pinho Tolentino, junto à Instituição médica no qual a Sra. realiza o seu tratamento. O seu prontuário são um conjunto de documentos médicos, e que lhe pertencem e por sua autorização, a referida pesquisadora pode ter acesso a ele. Em momento algum seu prontuário será retirado do Hospital nem reproduzido ou alterado. Interessando a esta pesquisa apenas informações sobre seu estado de saúde e o tratamento oncológico ao qual a Sra. foi submetida.

Os resultados da pesquisa serão divulgados no Hospital de Base de Brasília podendo ser publicados posteriormente. Os dados e materiais utilizados na pesquisa ficarão sob a guarda do pesquisador.

Se a Senhora tiver qualquer dúvida em relação à pesquisa, por favor telefone para: Grassyara Tolentino, na Faculdade de Educação Física da Universidade de Brasilia, o telefone: (61) 3107-2512 ou (61) 8258 - 6424 no horário: das 08:00 às 12:00. Ou para o seu Orientador o Prof. Dr. Ricardo Jacó de Oliveira, na Faculdade de Educação Física da Universidade de Brasilia, o telefone: (61) 3107-2512 ou (61) 81308007 , no horário: das 08:00 às 12:00. 
Este projeto foi Aprovado pelo Comitê de Ética em Pesquisa da SES/DF. As dúvidas com relação à assinatura do TCLE ou os direitos do sujeito da pesquisa podem ser obtidos através do telefone: (61) 3325-4955.

Este documento foi elaborado em duas vias, uma ficará com o pesquisador responsável e a outra com o sujeito da pesquisa. É necessário que tanto o pesquisado quanto o voluntário rubriquem todas as páginas deste documento.

Nome / assinatura

\section{Pesquisador Responsável}

Nome e assinatura

Brasília, de de

\section{ANEXO- AMedical Outcomes Study 36 - Item Short-Form Health Survey (SF-36) Versão Brasileira do Questionário de Qualidade de Vida -SF-36}

Instruções: Esta pesquisa questiona você sobre sua saúde. Estas informações nos manterão informados de como você se sente e quão bem você é capaz de fazer suas atividades de vida diária. Responda toda questão marcando a resposta como indicado. Caso você esteja inseguro ou em dúvida em como responder, por favor, tente responder o melhor que puder.

1- Em geral você diria que sua saúde é: (Circule uma)

\begin{tabular}{|c|c|c|c|c|}
\hline Excelente & Muito Boa & Boa & Ruim & Muito Ruim \\
\hline $\mathbf{1}$ & $\mathbf{2}$ & $\mathbf{3}$ & $\mathbf{4}$ & $\mathbf{5}$ \\
\hline
\end{tabular}

2- Comparada a um ano atrás, como você classificaria sua saúde em geral, agora? (Circule uma)

\begin{tabular}{|l|c|c|c|c|}
\hline Muito Melhor & Um Pouco & Quase a Mesma & Um Pouco Pior & Muito Pior \\
\hline
\end{tabular}




\begin{tabular}{|l|c|l|l|l|}
\hline & Melhor & & & \\
\hline $\mathbf{1}$ & $\mathbf{2}$ & $\mathbf{3}$ & $\mathbf{4}$ & $\mathbf{5}$ \\
\hline
\end{tabular}

3- Os seguintes itens são sobre atividades que você poderia fazer atualmente durante um dia comum. Devido à sua saúde, você teria dificuldade para fazer estas atividades? Neste caso, quando? (Circule um número em cada linha)

\begin{tabular}{|l|c|c|c|}
\hline Atividades & $\begin{array}{c}\text { Sim, dificulta } \\
\text { muito }\end{array}$ & $\begin{array}{c}\text { Sim, dificulta } \\
\text { um pouco }\end{array}$ & $\begin{array}{c}\text { Não, não dificulta } \\
\text { de modo algum }\end{array}$ \\
\hline $\begin{array}{l}\text { a) Atividades Rigorosas, que exigem } \\
\text { muito esforço, tais como correr, } \\
\text { levantar objetos pesados, participar em } \\
\text { esportes árduos. }\end{array}$ & $\mathbf{2}$ & $\mathbf{2}$ & \\
\hline $\begin{array}{l}\text { b) Atividades moderadas, tais como } \\
\text { mover uma mesa, passar aspirador de } \\
\text { pó, jogar bola, varrer a casa }\end{array}$ & 1 & 2 & 3 \\
\hline c) Levantar ou carregar mantimentos & 1 & 2 & 3 \\
\hline d) Subir vários lances de escada & 1 & 2 & 3 \\
\hline -e) Subir um lance de escada & 1 & 2 & 3 \\
\hline f)Curvar-se, ajoelhar-se ou dobrar-se & 1 & 2 & 3 \\
\hline g) Andar mais de 1 quilometro & 1 & 2 & 3 \\
\hline h) Andar vários quarteirões & 1 & 2 & 3 \\
\hline i) Andar um quarteirão & 1 & 2 & 3 \\
\hline j) tomar banho ou vestir-se & 1 & 2 & 3 \\
\hline
\end{tabular}

4- Durante as últimas 4 semanas, você teve algum dos seguintes problemas com seu trabalho ou com alguma atividade regular, como conseqüência de sua saúde física? (circule uma em cada linha)

\begin{tabular}{|l|c|c|}
\hline & Sim & Não \\
\hline $\begin{array}{l}\text { a) Você diminuiu a quantidade de tempo que dedicava-se ao seu } \\
\text { trabalho ou a outras atividades? }\end{array}$ & $\mathbf{1}$ & $\mathbf{2}$ \\
\hline b) Realizou menos tarefas do que você gostaria? & 1 & 2 \\
\hline c) Esteve limitado no seu tipo de trabalho ou a outras atividades & 1 & 2 \\
\hline $\begin{array}{l}\text { d) Teve dificuldade de fazer seu trabalho ou outras atividades(p. } \\
\text { ex. necessitou de um esforço extra) }\end{array}$ & 1 & 2 \\
\hline
\end{tabular}

5- Durante as últimas 4 semanas, você teve algum dos seguintes problemas com seu trabalho ou outra atividade regular diária, como conseqüência de algum problema emocional ( como sentir-se deprimido ou ansioso)? (Circule uma em cada linha)

\begin{tabular}{|l|c|c|}
\hline $\begin{array}{l}\text { a) Você diminuiu a quantidade de tempo que dedicava-se ao seu } \\
\text { trabalho ou a outras atividades? }\end{array}$ & $\mathbf{1}$ & $\mathbf{2}$ \\
\hline b) Realizou menos tarefas do que você gostaria? & $\mathbf{1}$ & $\mathbf{2}$ \\
\hline $\begin{array}{l}\text { c) Não realizou ou fez qualquer das atividades com tanto cuidado } \\
\text { como geralmente faz }\end{array}$ & $\mathbf{1}$ & $\mathbf{2}$ \\
\hline
\end{tabular}


6- Durante as últimas 4 semanas, de que maneira sua saúde física ou problemas emocionais interferiram nas suas atividades sociais normais, em relação à família, amigos ou em grupo? (Circule uma)

\begin{tabular}{|c|c|c|c|c|}
\hline $\begin{array}{c}\text { De forma } \\
\text { nenhuma }\end{array}$ & Ligeiramente & Moderadamente & Bastante & Extremamente \\
\hline $\mathbf{1}$ & $\mathbf{2}$ & $\mathbf{3}$ & $\mathbf{4}$ & $\mathbf{5}$ \\
\hline
\end{tabular}

7- Quanta dor no corpo você teve durante as últimas 4 semanas? (Circule uma)

\begin{tabular}{|c|c|c|c|c|c|}
\hline Nenhuma & Muito Leve & Leve & Moderada & Grave & Muito Grave \\
\hline $\mathbf{1}$ & $\mathbf{2}$ & $\mathbf{3}$ & $\mathbf{4}$ & $\mathbf{5}$ & $\mathbf{6}$ \\
\hline
\end{tabular}

8- Durante as últimas 4 semanas, quanto a dor interferiu com seu trabalho normal (incluindo o trabalho dentro de casa)? (Circule uma)

\begin{tabular}{|c|c|c|c|c|}
\hline $\begin{array}{c}\text { De maneira } \\
\text { alguma }\end{array}$ & Um pouco & Moderadamente & Bastante & Extremamente \\
\hline $\mathbf{1}$ & $\mathbf{2}$ & $\mathbf{3}$ & $\mathbf{4}$ & $\mathbf{5}$ \\
\hline
\end{tabular}

9- Estas questões são sobre como você se sente e como tudo tem acontecido com você durante as últimas 4 semanas. Para cada questão, por favor dê uma resposta que mais se aproxime da maneira como você se sente, em relação às últimas 4 semanas. (Circule um número para cada linha)

\begin{tabular}{|l|c|c|c|c|c|c|}
\hline & $\begin{array}{l}\text { Todo } \\
\text { Tempo }\end{array}$ & $\begin{array}{l}\text { A } \\
\text { maior } \\
\text { parte } \\
\text { do } \\
\text { tempo }\end{array}$ & $\begin{array}{l}\text { Uma } \\
\text { boa } \\
\text { parte } \\
\text { do } \\
\text { tempo }\end{array}$ & $\begin{array}{l}\text { Alguma } \\
\text { parte } \\
\text { do } \\
\text { tempo }\end{array}$ & $\begin{array}{l}\text { Uma } \\
\text { pequena } \\
\text { parte do } \\
\text { tempo }\end{array}$ & Nunca \\
\hline $\begin{array}{l}\text { a) Quanto tempo } \\
\text { você tem se sentido } \\
\text { cheio de vigor, de } \\
\text { vontade, de força.? }\end{array}$ & 1 & 2 & 3 & 4 & 5 & 6 \\
\hline $\begin{array}{l}\text { b) Quanto tempo } \\
\text { você tem se sentido } \\
\text { uma pessoa muito } \\
\text { nervosa? }\end{array}$ & 1 & 2 & 3 & 4 & 5 & 6 \\
\hline $\begin{array}{l}\text { c) Quanto tempo } \\
\text { você tem se sentido } \\
\text { tão deprimido que } \\
\text { nada pode animá- } \\
\text { lo. }\end{array}$ & 1 & 2 & 3 & 4 & 5 & 6 \\
\hline $\begin{array}{l}\text { d) Quanto tempo } \\
\text { você tem se sentido } \\
\text { calmo ou tranqüilo? }\end{array}$ & 1 & 2 & 3 & 4 & 5 & 6 \\
\hline $\begin{array}{l}\text { e) Quanto tempo } \\
\text { você tem se sentido } \\
\text { com muita energia? }\end{array}$ & 1 & 2 & 3 & 4 & 5 & 6 \\
\hline $\begin{array}{l}\text { f) Quanto tempo } \\
\text { você tem se sentido } \\
\text { desanimado ou } \\
\text { abatido? }\end{array}$ & 1 & 2 & 3 & 4 & 5 & 6 \\
\hline
\end{tabular}




\begin{tabular}{|l|c|c|c|c|c|c|}
\hline $\begin{array}{l}\text { g) Quanto tempo } \\
\text { você tem se sentido } \\
\text { esgotado? }\end{array}$ & 1 & 2 & 3 & 4 & 5 & 6 \\
\hline $\begin{array}{l}\text { h) Quanto tempo } \\
\text { você tem se sentido } \\
\text { uma pessoa feliz? }\end{array}$ & 1 & 2 & 3 & 4 & 5 & 6 \\
\hline $\begin{array}{l}\text { i) Quanto tempo } \\
\text { você tem se sentido } \\
\text { cansado? }\end{array}$ & 1 & 2 & 3 & 4 & 5 & 6 \\
\hline
\end{tabular}

10- Durante as últimas 4 semanas, quanto do seu tempo a sua saúde física ou problemas emocionais interferiram com as suas atividades sociais ( como visitar amigos, parentes etc.) (Circule uma)

\begin{tabular}{|c|c|c|c|c|}
\hline Todo tempo & $\begin{array}{l}\text { A maior parte } \\
\text { do tempo }\end{array}$ & $\begin{array}{l}\text { Alguma parte } \\
\text { do tempo }\end{array}$ & $\begin{array}{l}\text { Uma pequena } \\
\text { parte do } \\
\text { tempo }\end{array}$ & $\begin{array}{l}\text { Nenhuma } \\
\text { parte do } \\
\text { tempo }\end{array}$ \\
\hline $\mathbf{1}$ & $\mathbf{2}$ & $\mathbf{3}$ & $\mathbf{4}$ & $\mathbf{5}$ \\
\hline
\end{tabular}

11- O quanto verdadeiro ou falso é cada uma das afirmações para você? (Circule uma em cada linha)

\begin{tabular}{|l|c|c|c|c|c|}
\hline & $\begin{array}{c}\text { Definitivament } \\
\text { e Verdadeiro }\end{array}$ & $\begin{array}{c}\text { A maioria } \\
\text { das vezes } \\
\text { verdadeir } \\
0\end{array}$ & $\begin{array}{c}\text { Nã } \\
\text { Sei }\end{array}$ & $\begin{array}{c}\text { A } \\
\text { maiori } \\
\text { a das } \\
\text { vezes } \\
\text { falso }\end{array}$ & Definitivamentefals \\
\hline $\begin{array}{l}\text { a) Eu } \\
\text { costumo } \\
\text { adoecer } \\
\text { um pouco } \\
\text { mais } \\
\text { facilment } \\
\text { e que as } \\
\text { outras } \\
\text { pessoas }\end{array}$ & 1 & 2 & 3 & 4 & 5 \\
\hline $\begin{array}{l}\text { b) Eu sou } \\
\text { tão } \\
\text { saudável } \\
\text { quanto } \\
\text { qualquer } \\
\text { pessoa } \\
\text { que eu } \\
\text { conheço }\end{array}$ & 1 & 2 & 3 & 4 & 5 \\
\hline $\begin{array}{l}\text { c) Eu } \\
\text { acho que } \\
\text { a minha } \\
\text { saúde vai } \\
\text { piorar. }\end{array}$ & 1 & 2 & 3 & 4 & 5 \\
\hline $\begin{array}{l}\text { d) Minha } \\
\text { saúde é } \\
\text { excelente }\end{array}$ & 1 & & 3 & 5 & \\
\hline
\end{tabular}




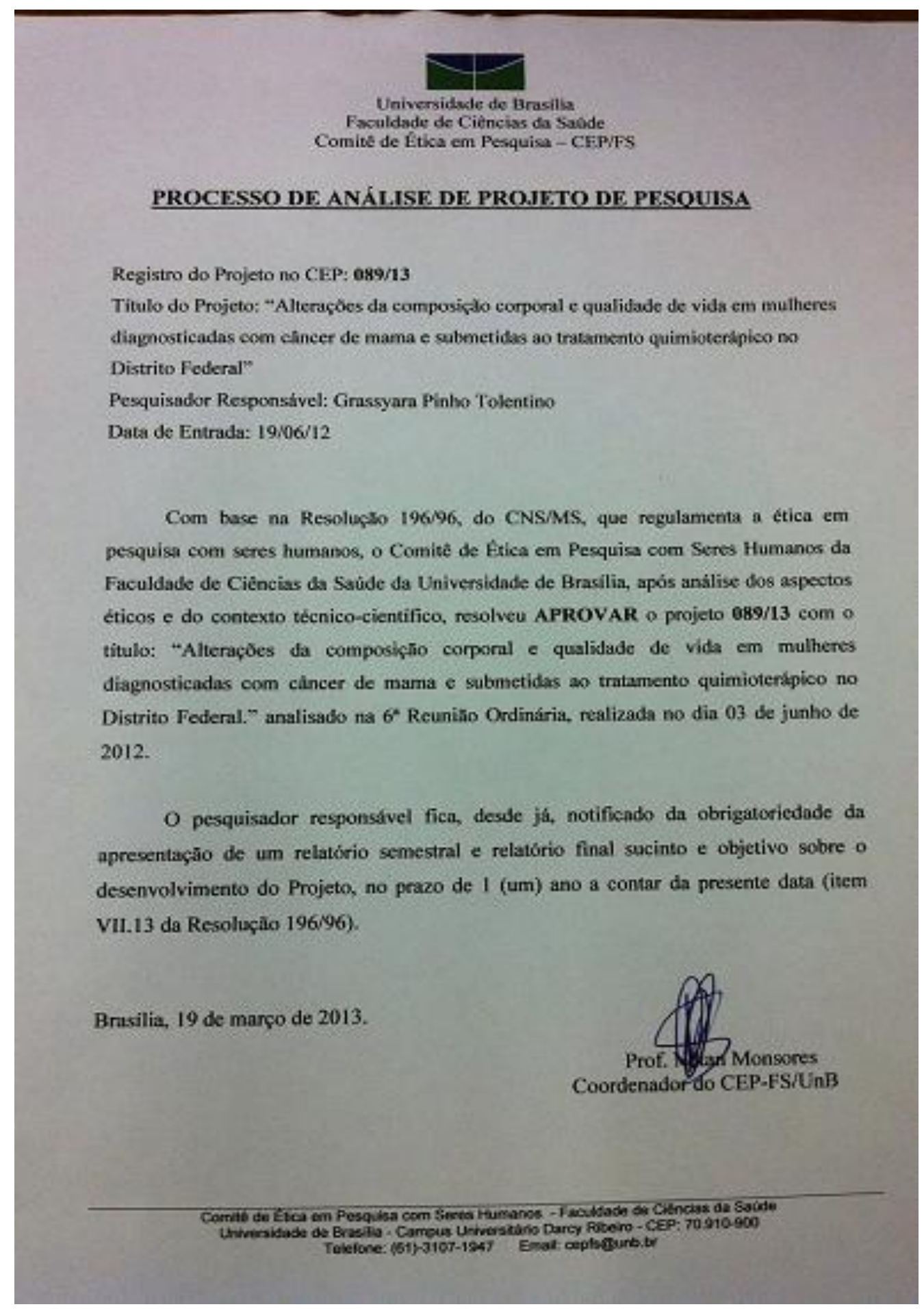




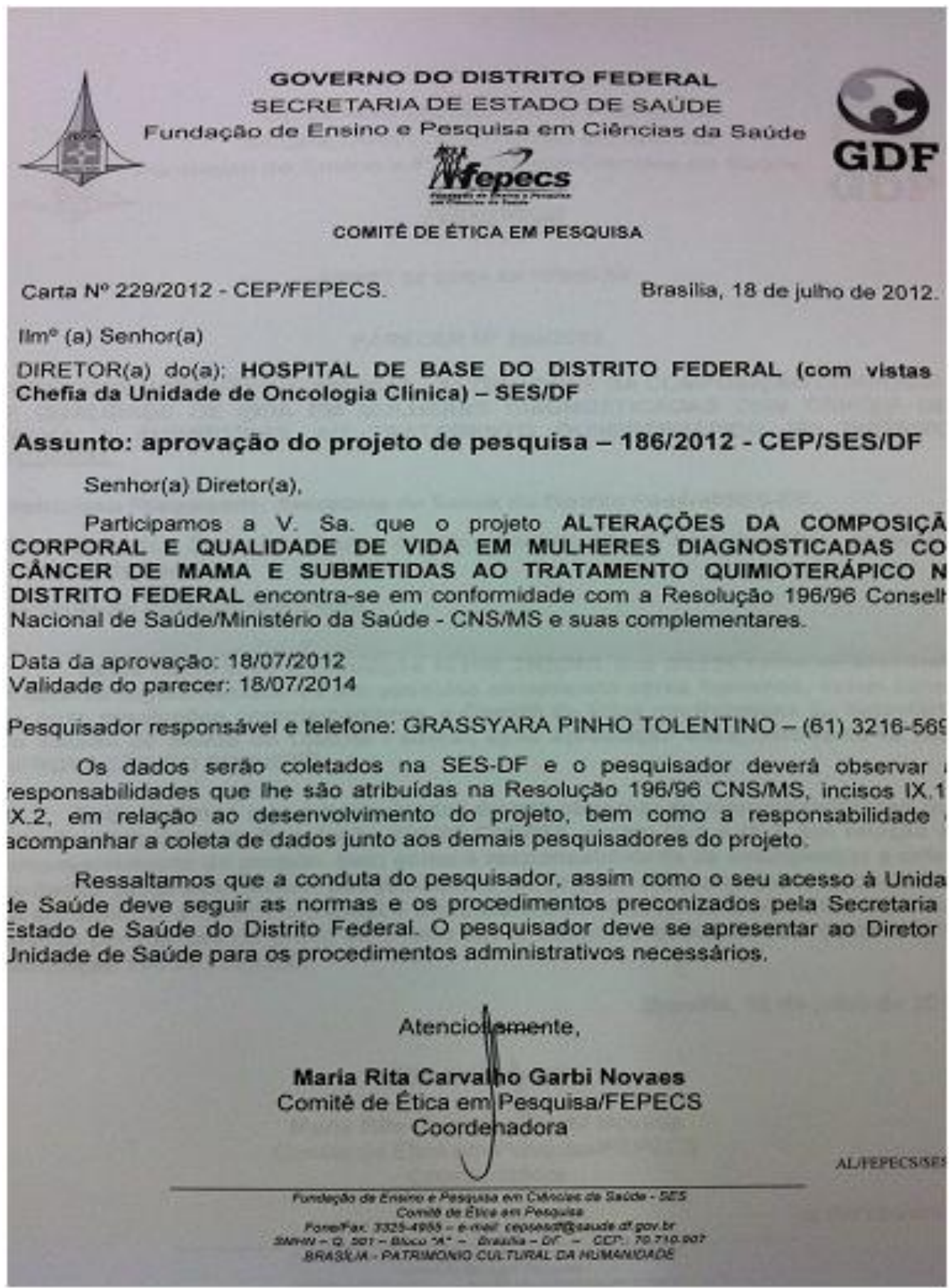

